\title{
U.S. Green Building Conference-1994
}

A. H. Fanney, K. M. Whitter, A. E. Traugott, and L. N. Simon, Editors 
he National Institute of Standards and Technology was established in 1988 by Congress to "assist industry in the development of technology . . needed to improve product quality, to modernize manufacturing processes, to ensure product reliability . . . and to facilitate rapid commercialization . . . of products based on new scientific discoveries."

NIST, originally founded as the National Bureau of Standards in 1901, works to strengthen U.S. industry's competitiveness; advance science and engineering; and improve public health, safety, and the environment. One of the agency's basic functions is to develop, maintain, and retain custody of the national standards of measurement, and provide the means and methods for comparing standards used in science, engineering, manufacturing, commerce, industry, and education with the standards adopted or recognized by the Federal Government.

As an agency of the U.S. Commerce Department's Technology Administration, NIST conducts basic and applied research in the physical sciences and engineering and performs related services. The Institute does generic and precompetitive work on new and advanced technologies. NIST's research facilities are located at Gaithersburg, MD 20899, and at Boulder, CO 80303. Major technical operating units and their principal activities are listed below. For more information contact the Public Inquiries Desk, 301-975-3058.

Technology Services

- Manufacturing Technology Centers Program

- Standards Services

- Technology Commercialization

- Measurement Services

- Technology Evaluation and Assessment

- Information Services

Electronics and Electrical Engineering Laboratory

- Microelectronics

- Law Enforcement Standards

- Electricity

- Semiconductor Electronics

- Electromagnetic Fields ${ }^{1}$

- Electromagnetic Technology ${ }^{1}$

Chemical Science and Technology

Laboratory

- Biotechnology

- Chemical Engineering ${ }^{1}$

- Chemical Kinetics and Thermodynamics

- Inorganic Analytical Research

- Organic Analytical Research

- Process Measurements

- Surface and Microanalysis Science

- Thermophysics ${ }^{2}$

Physics Laboratory

- Electron and Optical Physics

- Atomic Physics

- Molecular Physics

- Radiometric Physics

- Quantum Metrology

- Ionizing Radiation

- Time and Frequency ${ }^{1}$

- Quantum Physics ${ }^{1}$
Manufacturing Engineering Laboratory

- Precision Engineering

- Automated Production Technology

- Robot Systems

- Factory Automation

- Fabrication Technology

Materials Science and Engineering

Laboratory

- Intelligent Processing of Materials

- Ceramics

- Materials Reliability ${ }^{1}$

- Polymers

- Metallurgy

- Reactor Radiation

Building and Fire Research Laboratory

- Structures

- Building Materials

- Building Environment

- Fire Science and Engineering

- Fire Measurement and Research

Computer Systems Laboratory

- Information Systems Engineering

- Systems and Software Technology

- Computer Security

- Systems and Network Architecture

- Advanced Systems

Computing and Applied Mathematics Laboratory

- Applied and Computational Mathematics

- Statistical Engineering ${ }^{2}$

- Scientific Computing Environments ${ }^{2}$

- Computer Services ${ }^{2}$

- Computer Systems and Communications ${ }^{2}$

- Information Systems

'At Boulder, CO 80303.

${ }^{2}$ Some elements at Boulder, CO 80303. 


\section{NIST Special Publication 863}

\section{U.S. Green Building Conference-1994}

A. H. Fanney and K. M. Whitter, Editors

Building and Fire Research Laboratory

National Institute of Standards and Technology

Gaithersburg, MD 20899-0001

A. E. Traugott and L. N. Simon, Editors

U.S. Green Building Council

Washington, DC 20036

June 1994

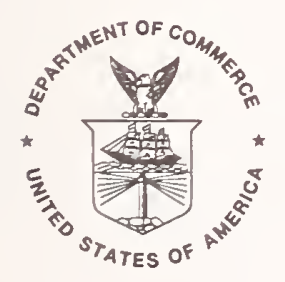

U.S. Department of Commerce

Ronald H. Brown, Secretary

Technology Administration

Mary L. Good, Under Secretary for Technology

National Institute of Standards and Technology

Arati Prabhakar, Director 
National Institute of Standards and Technology

Special Publication 863

Natl. Inst. Stand. Technol.

Spec. Publ. 863

150 pages (June 1994)

CODEN: NSPUE2
U.S. Government Printing Office Washington: 1994

For sale by the Superintendent of Documents

U.S. Government Printing Office Washington, DC 20402 


\section{PREFACE}

This report constitutes the proceedings of the Green Building Conference held in Gaithersburg, Maryland, February 16-17, 1994. The conference was co-sponsored by the National Institute of Standards and Technology (NIST) and the U.S. Green Building Council (USGBC). Over 450 individuals attended the conference representing building product manufacturers, building owners and managers, environmental groups, utilities, contractors, builders, architects, engineers, and the local, state, and the federal governments. The conference provided an opportunity to acquire practical, useful information on green buildings, resources, and guidelines.

The conference commenced with welcoming remarks from David Gottfried, USGBC President and Samuel Kramer, Associate Director of NIST. Cathy Zoi from the White House Office of Environmental Policy gave the keynote address entitled "Green Buildings - The White House Perspective." The remainder of the conference focused on the following topics:

* International Activities - A presentation of assessment methodologies and performance criteria for green buildings in Canada, the United Kingdom, and the United States.

* U.S. Activities - An overview of the leading national non-profit organizations and government agencies involved in the development of green building programs, standards, and educational resources.

* Exemplary Green Buildings - A presentation of green building case studies, including residential, commercial, and institutional structures.

* Current and Future Technology Needs - A discussion of current and promising new technologies in the areas of building materials, lighting, and indoor air quality.

On the evening of February 16, visionaries Bill McDonough, AIA, and Author Paul Hawken spoke on the "Future and Making of Things." Their presentation focused on a new approach to design, industry, public policy, and commercial activity which would lead to a restorative and prosperous future. The final conference event was a tour of the NIST Building and Fire Research Laboratories involved in research related to green buildings.

This proceedings includes papers from the majority of the speakers. Five of the 24 speakers failed to submit written text to the editors. 



\section{TABLE OF CONTENTS}

\section{PAPERS}

NIST Welcome

Samuel Kramer ......................................... 1

Assessing the Environmental Impact of Buildings in the UK

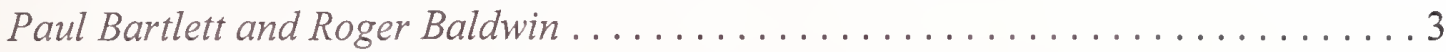

Building Environmental Performance Assessment Criteria, BEPAC

Raymond J. Cole ....................................... 14

The City of Austin Green Builder Program

W. Laurence Doxsey . . . . . . . . . . . . . . . . . . . . . . . . . . . . . 21

Canada's Advanced Houses Program

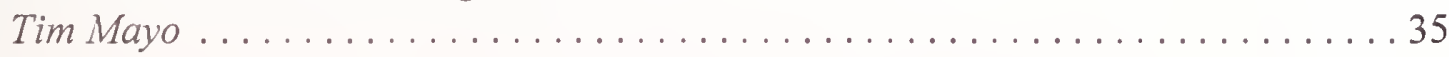

The NIST Green Building Program

James E. Hill ........................................442

The American Institute of Architects Committee on The Environment

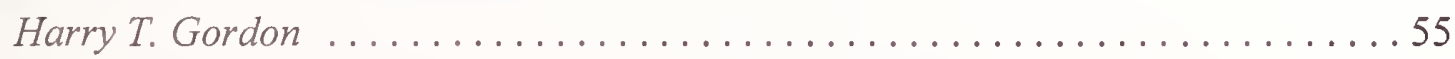

The U.S. Green Building Council's Initiatives to Improve the Energy and

Environmental Efficiency of the "Whole Building Environment"

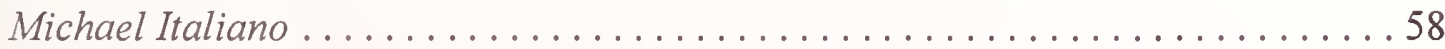

Life Cycle Assessment

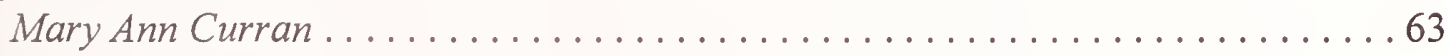

Greening the White House

William D. Browning and Dianna Lopez Barnett .................. 68

Our Future and the Making of Things

William McDonough .................................. 76

Audubon House

Jan Beyea .......................................... 83 
Design and Implementation of a Sustainable University Student Living Laboratory Sharon R. Stine ...................................... 90

Sustainable Design Options for the U.S. Fish \& Wildlife Prairie Learning Center Susan Reilly ......................................... 101

Architecture, Ethics \& The Environment, An Exploration of Nature \& The Human Spirit

John A. Clark, Neal I. Payton and David Tice ................... 108

The Resource Conservation Research House

Liza K. Bowles .................................... 117

Performance of Building Envelopes, New Materials and Research Findings J.D. Ned Nisson . . . . . . . . . . . . . . . . . . . . . . . . . . . . . 121

Environmental Building Materials: What are they? Where are they? Paul Bierman-Lytle ....................................... 127

Green Buildings: DOE's Historical Role and New Directions John P. Millhone 


\section{NIST WELCOME}

\section{Samuel Kramer, Associate Director National Institute of Standards and Technology Gaithersburg, Maryland}

With Dave's (David Gottfried, President of U.S. Green Building Council) profound challenge and insight on this conference and the introduction, I ought to say thank you and sit down. I would be better off at that point, but I want to thank the Council for co-sponsoring this meeting with us, and I also wanted to take a moment to acknowledge the work of Hunter Fanney and Jim Hill, who have leadership roles in green building technology programs here at NIST, for their efforts in organizing the Conference.

Green buildings are not new to NIST or as it was known before 1988 as NBS. As you know, the term "Green Buildings" means buildings which are designed, constructed, operated, and eventually demolished to have minimum impact on our global and internal environment. NIST has had a long interest in this field. Going back before the oil embargo of 1973, NIST was involved in developing the algorithms for calculation of energy usage and energy conservation in buildings, and these techniques are used today in almost all major energy calculation programs, including the Department of Energy's DOE2 computer program. After the oil embargo, NBS at that time, developed the very first draft of the energy conservation design standards for buildings. It was the predecessor of the ASHRAE Standard 90, which is now incoporated within virtually all building regulations in the United States. NIST has many programs in many diversified areas, and presently we have many programs related to green buildings such as waste minimization; energy conservation; air, soil, water quality; indoor air quality; ozone depletion; global warming; and green building designs.

Jim Hill, who is Chief of our Building Environment Division, will be discussing the NIST laboratory and green building programs. We have significant activities under way in our laboratories, and as Dave said, I hope you take the opportunity to visit our labs and to see the programs, and to see who we are working with. NIST is directly involved in working with manufacturers and the design profession, with the people outside who are actually creating the buildings, the people who are designing them, and the people who are operating them. NIST is charged with working with industry. We are the lead agency of the federal government that has a specific mandate of working with industry and the private sector, and we look forward to working with industry and interacting with them and the many professionals and intermediary organizations as we move forward and make the transition to green technology. I think that Dave did a very good job in describing the overall impact of green technology, and the need to further the development of green technologies.

As Dave noted, I am personally involved in a major design and construction program at NIST. It is a $\$ 540$ million program to develop the advanced technology laboratories that will enable us to pursue modern technology programs in measurement that are needed by industry in this country. 
In doing this, we have under design major facilities, both here in Gaithersburg, Maryland and in Boulder, Colorado for advanced technology laboratories. These laboratories will provide an environment for the NIST researchers that will be world class. They will be able to do work which cannot be done anywhere in the United States and will attain the ability to compete with the European and Japanese labs that in many cases are today much more advanced than ours. The new advanced technology laboratories will allow us to address the technology needs of today as well as 20 years from now. In addition, we will be undertaking major rehabilitation of our existing laboratories. The designers, the architects and engineers who are working on this project, some of whom are here in the audience today, have been charged from the very beginning with incorporating to the maximum extent possible green technology and to recognize the impact of facilities on the environment. And so, in all of our design reviews we are raising questions related to green technology, and it covers a very, very wide spectrum. I might add, anecdotal, that in addition, these major construction programs of new and rehabilitated facilities will be entirely metric. Those of you in the design profession who are here, and I notice scanning the list of attendees that there are many here, may want to watch this project because it will be a major project, and it will be done entirely in metric. It will not be soft metric. It will be hard metric, and there will be no equivalency dimensioning in the plans and specs.

We are delighted to host this conference with the U.S. Green Building Council, and although the Council is less than a year old, I think the Council holds a promise to be a major voice for the building industry. I think with Dave's insight, the Council will be a major voice for the community because you have to have a wide vision necessary to recognize what is the impact of your work on the environment and the people around you. We look forward to working with the Council. We look forward to working with industry, with ASTM and the other federal agencies, and others as we pursue further developments in the adoption of green technology.

I want to note one more thing. The importance of recognizing the environment is great, and it is continuously being reinforced by those of us in government and the senior policy decision makers in government. On February 11, just a few days ago, President Clinton signed Executive Order 12898, which is entitled "Federal Actions to Address Environmental Justice in Minority Populations and Low Income Populations." This is another action which is evidence of the continual reinforcement and reaffirmation of the importance of consideration of the environment. All of our actions, no matter what we do in this world, unless we are living in some isolated shell, our behavior, what you do, affects others. That's what we are talking about in green buildings. All of our actions make a difference. 


\title{
Assessing the Environmental Impact of Buildings in the UK
}

\author{
Paul Bartlett and Roger Baldwin \\ Building Research Establishment \\ Garston, Watford, WD2 7JR, UK
}

- Crown Copyright 1994 - Building Research Establishment

\begin{abstract}
The protection of the environment is one of today's key issues demanding international action. In the UK, the government has issued a 'green' White Paper ${ }^{(1)}$ and two updating reviews, setting out its Agenda; businesses are also responding by developing environmental policy statements as part of their business strategy; general public concern is evident through changes in purchasing practices and an increasing interest in recycling waste such as paper, cans, and bottles. In Europe, initiatives are being taken to develop ecolabelling schemes specifically for assessing consumer products. Environmental management systems are being developed through BSI and internationally.

Underlying these concerns is a perception that industrialised economies have significantly and irreversibly changed (or perhaps about to change) the planet's climate, atmosphere and ecosystems. This perception is fuelled by reports in the media of rising pollution, poor air quality, threats to ecosystems such as historic hedgerows, and even graffiti and litter.

What is not generally realised is that buildings, in their construction, use and demolition account for a large share of environmental impacts. People spend about $90 \%$ of their time indoors, at least in Northern Europe and probably much more time in the urban environment. More importantly, buildings have an impact on the global environment through energy use and the use of chemicals such as CFCs for cooling. In the UK and other Western European countries, buildings account for about $50 \%$ of primary energy use (and hence $\mathrm{CO}_{2}$ output), far outweighing the contribution of either transport or industry sectors.
\end{abstract}

This paper describes action taken by the BRE to set standards for environmentally friendlier buildings which uses market forces to bring about environmental sensitivity in the industry. BREEAM is an environmental assessment method, embodied in an accreditation scheme, which is enjoying considerable success in the UK. The paper describes its development and underlying philosophy and provides details of its content and operation.

\section{Introduction}

The protection of the environment is one of today's key issues demanding international action. In the UK, the government has issued a 'green' White $\mathrm{Paper}^{(1)}$ and two updating reviews, setting out its Agenda; businesses are also responding by developing environmental policy statements as part of their business strategy. General public concern is evident through changes in purchasing practices and an increasing interest in recycling waste such as paper, 
cans, and bottles. In Europe, initiatives are being taken to develop ecolabelling schemes specifically for assessing consumer products. Environmental management systems are also being developed in Europe and elsewhere.

Underlying these concerns is a perception that industrialised economies have significantly and irreversibly changed (or are perhaps about to change) the planet's climate, atmosphere and ecosystems. This perception is fuelled by reports in the media of rising pollution, poor air quality, threats to ecosystems and even graffiti and litter.

What is not generally realised is that buildings, in their construction, use and demolition account for a large share of environmental impacts. People spend about $90 \%$ of their time indoors, at least in Northern Europe. More importantly, buildings have an impact on the global environment through energy use and the use of chemicals such as CFCs for cooling. In the UK and other Western European countries, buildings account for about $50 \%$ of primary energy use (and hence $\mathrm{CO}_{2}$ output), far outweighing the contribution of either transport or industry sectors.

This paper describes action taken by the BRE to set standards for environmentally friendlier buildings which uses market forces to bring about environmental sensitivity in the industry. BREEAM is an environmental assessment method, embodied in an accreditation scheme, which is enjoying considerable success in the UK. The paper describes its development and underlying philosophy and provides details of its content and operation.

\section{The BREEAM Scheme}

The Building Research Establishment Environmental Assessment Method (BREEAM) is a scheme for environmental labelling of buildings developed by BRE with a number of private sector sponsors. The basis of the scheme is a Certificate awarded to individual buildings stating clearly, and in a way that can be made visible to Clients, the performance of the building against a set of defined environmental criteria. This Certificate can be displayed in the building, or in the promotional portfolio, and may form part of the developer and occupier's overall environmental policy statement and management system. It thus rewards positive actions by the client or the designer to improve the environmental performance of the building, and provides a credible way of differentiating greener buildings from other designs, and assists in marketing to an environmentally selective clientele. Developers can thus present environmental performance as an aspect of overall quality and gain a commercial advantage from doing so.

The scheme is voluntary and self-financing. Assessments are carried out by independent assessors licensed by BRE. BRE, as owner, underpins the UK scheme, with its reputation for authority and independence, and provides technical support for the various criteria and algorithms used. BRE also provides quality control, guidance to assessors on complex technical issues and updates the scheme. 
The first version, launched in 1991 was for new office buildings, assessed at the design stage, and was recently been updated ${ }^{(2)}$ last year, to reflect developing knowledge and experience gained in the operation of the scheme. It has proved very popular with around 200 buildings assessed so far, about $25 \%$ of eligible new office designs developed in this period. It also forms part of standard specifications for designs for major property owners and managers, such as Property Holdings, the UK government estate managers.

Other schemes have been launched for new homes ${ }^{(4)}$, and supermarkets ${ }^{(3)}$, and light industrial buildings $^{(5)}$ and others are being planned. A significant new development, however, is a new scheme for existing offices ${ }^{(6)}$, launched by the Secretary of State for the Environment in April 1993, which for the first time provides guidelines on the operation and management of the building as well as its fabric and services. The Certificate is in two parts one dealing with the fabric and services, the other with operation and management, allowing different groups to use the scheme, and accommodating the various opportunities for assessment during the life of the building.

\section{Development of the Scheme}

The scheme has been developed with sponsorship from major developers in the UK.

Table 1 Sponsors of BREEAM

Stanhope Properties Plc

Greycoat Plc

J Sainsbury Plc

Olympia and York

National Westminster Bank Plc

Property Holdings

Prudential Plc

Slough Estates

The Commission for the New Towns

Municipal Mutual Insurance

\author{
Safeway PLC \\ Budgens \\ $\mathrm{BBC}$ \\ Lloyds Bank Plc \\ Barclays Bank Plc \\ Davis Langdon \& Everest \\ Cable and Wireless Plc \\ English Estates \\ Trafford Park Plc \\ AMEC
}

Table 1 lists the sponsors of the BREEAM portfolio to date. They have made substantial intellectual contributions to the underlying philosophy, the market orientation of the scheme, and the practicality of the criteria and assessment procedures. This pattern has been followed in subsequent versions.

The first problem in developing the scheme is the vast range of environmental issues which potentially could be included. Another problem is that there is already a wide range of legal obligations relating to the environment. Of a more practical nature, there is a financial limit to the effort that can be put into any assessment, governed by the client's willingness to pay. One technical problem is the need to specify not only environmental criteria, but also a practical way of assessing whether the building complies with the criteria. 
It was decided to group the issues in a simple way under three main headings:

- global issues and use of resources

- local issues

- indoor issues

As an example, the issues covered for existing offices are summarised in Table 2.

It was decided not to reward designers for complying with their legal obligations, so criteria were set going beyond these obligations, setting higher environmental standards. Issues were only included if a real environmental matter was involved; if sensible criteria could be set; and importantly if there was some means of assessing compliance. This eliminated a large number of issues, many of some importance (eg energy content of materials). However, BRE took the view that in spite of these gaps, enough was known to make significant steps in defining and assessing 'greener' buildings. Issues omitted will be included at a later stage, as knowledge develops. The published reports describing the scheme list these missing issues. On assessing compliance, it is worth noting that assessing energy performance is the most technically demanding: most energy models make substantial and costly demands for data input, and our problem was to find a 'simple' energy model of sufficient accuracy. These appear to be in short supply, representing an urgent research need.

Finally, the Certificate was designed so that issues received individual, discrete 'credits', as shown in Table 2. A credit signifies the design satisfies the criteria for that issue. It is tempting to add up the credits to given an overall score for the building. However, assessing the relative important of disparate issues is a considerable and currently intractable problem, so this was not attempted. In later schemes, to aid communication we have included a summary of performance expressed as a single rating of FAIR, GOOD, VERY GOOD or EXCELLENT, based on a minimum level of credits in each of the three Sections (Global/Resources, Local and Indoor). A rating of EXCELLENT indicates a high standard of performance across the range of impacts, although there may still be scope for further refinement.

\section{Technical Contents of BREEAM for New Offices}

The following sections describes some of the technical issues covered in the New Offices Version in more depth. 
TABLE 2: Examples of credits covered in BREEAM 4/93 (Existing Offices)

Part 1: Fabric and services

\section{Global issues and use of resources Carbon dioxide emissions}

* 1 credit for less than 120 points

* 2 credits " 110

* "

* "

*9 credits " " 40 "

*1 credit for individual check meters for each tenant

*1 credit for adequate sub-metering for each tenant

\section{Ozone depletion}

*1 credit for refrigerant ODP of less than 0.06 or no air conditioning

*1 credit for refrigerant ODP of zero or no air conditioning

*1 credit for a refrigerant leak detection system or no air conditioning

*1 credit for on site refrigerant recovery or no air conditioning

*1 credit for avoiding halon-based fire protection

\section{Local Issues}

Water conservation

*1 credit for building with two of the following:

- water meter

- WCs with maximum 6-litre flush

- water economy devices on urinals

Legionnaires' disease

*1 credit for no evaporating cooling towers or condensers

\section{Indoor issues}

Lighting

*1 credit for high-frequency ballasts fitted to luminaires

Air quality

*1 credit for adjustable openable windows in each room or for mechanical ventilation where there is no visible free-standing water in the ductwork

*1 credit for no humidification or for steam humidification

*1 credit for an effective filtration system capable of removing pollen particles
Part 2: Operation and management

\section{Environmental Policy}

*1 credit for having an established and openly available overall company policy on the environment

*1 credit for a company purchasing policy which excludes the use of timber from unsustainable sources

*1 credit for a company purchasing policy which excludes the use of other environmentally damaging materials

\section{Global issues and use of resources}

\section{Carbon dioxide emissions}

* 1 credit for having an energy policy endorsed by the board of directors, with a suitably trained member of staff to implement it

$* 1$ credit for energy audit of the building

*1 credit for monitoring and targeting system

* 1 credit for an energy efficiency improvement investment budget in relation to refurbishment

* 1 credit for an operating manual for services

$* 1$ credit for regular dissemination of information on energy use and means of saving energy to services systems operators and occupants

*1 credit for a regular system maintenance schedule

\section{Ozone depletion}

*1 credit for regular inspection for refrigerant leaks or where no air conditioning is provided

*1 credit for minimising unnecessary emission of halon or where no halon-based fire protection is in use

\section{Local Issues}

Legionnaires' disease

*1 credit for a management system which identifies and ensures regular maintenance and treatment of the building's cooling tower(s)

\section{Indoor Issues}

Lighting

*1 credit for a planned programme of luminaire cleaning and lamp replacement

\section{Air Quality}

*1 credit for a policy at avoiding health hazards arising from passive smoking

*1 credit for a maintenance policy which ensures regular filter replacenient

*1 credit for measured carbon dioxide levels of less than 800 parts per million in selected spaces

\section{Healthy-building indicators}

*1 credit for 30 points or more

$* 2$ credits for 45 points or more

*3 credits for 60 points or more 


\subsection{Global Issues}

\section{Carbon Dioxide Production due to Energy Consumption}

Since BREEAM focuses on the environment, it is appropriate to concentrate on the reduction of $\mathrm{CO}_{2}$ production rather than the consumption of delivered energy.

Generally offices receiving the highest credit for $\mathrm{CO}_{2}$ production will have all of the features listed below,

- improved insulation

- no air conditioning

- good use of daylighting

- energy efficient artificial light with effective controls

- efficient appliances and gas as the predominant fuel.

With all of these features in mind, it is possible to consider a quantitative scale for carbon dioxide emissions resulting from energy use. The annual energy consumption for a particular building is predicted using a program developed by the Electricity Association, ESICHECK.

\section{Ozone Depletion due to CFCs, HCFCs and Halons}

Building services can have a profound impact on the amount of damage done to the ozone layer from CFCs, HCFCs and Halons. As other uses of CFCs are eliminated (for example aerosols) the relative importance of buildings as a potential threat to the ozone layer increases. Chlorofluorocarbons (CFCs), Hydrochlorofluorocarbons (HCFCs) and Halons are chemical compounds which cause damage to the earths stratospheric ozone layer. The ozone depletion potential (ODP) for a given substance is a measure of the contribution of that substance to ozone depletion relative to that of CFC 11. Thus CFC 11 has an ODP of 1, and is the most damaging of the CFCs.

From both the energy and ozone depletion point of view, the best thing would be to design buildings so that they did not need air conditioning. However, if air conditioning systems must be used, they should be designed to operate on refrigerants that either pose no threat to the environment or who at least use refrigerants which have a lower ozone depletion potential than CFC 11. So against this background there are a total of five credits available for the design of air conditioning. But all of these five credits are available to schemes which have no air conditioning at all. In addition to air conditioning, the avoidance of the use of halons is also considered. The elimination of ozone depleting substances from thermal insulation is also credited. 


\subsection{Local Issues}

\section{Legionnaire's Disease Arising from Wet Cooling Towers}

The purpose of this credit is to eliminate the risk of Legionnaire's disease arising from wet cooling towers associated with air conditioning systems. Once again this credit is available to buildings which have no air conditioning or have air conditioning without wet cooling towers. However, some buildings do have wet cooling towers and in order to achieve this credit, they would have to conform to the specification described in CIBSE TM13( ${ }^{(7)}$.

\section{Noise}

Unwanted sound from equipment on office buildings can cause serious noise pollution and consequent problems for surrounding residents. The acceptability of the noise source in a residential area can be assessed using the rating system described in the British Standard BS4142 $1990^{(8)}$. Minimal noise pollution can be achieved by ensuring that noise from fans and other plants associated with the building, near a residential building is not less that $5 \mathrm{db}$ below the background levels during any period of the day or evening, and does not exceed the background level during any period of the night.

\section{Overshadowing of Other Buildings}

Large buildings can cause substantial overshadowing of neighbouring properties; both sunlight and light from the sky can be effected. The impact of a new building on all nearby buildings where daylight is of value should be checked; this would include homes, hospitals, hotels, schools and most offices and workshops. In general any overshadowing should be minimised. The BRE Report Site layout Planning for Daylight and Sunlight: A Guide to Good Practice ${ }^{(9)}$, contains a means of checking the degree of overshadowing.

Large buildings will also block sunshine, this is especially important for adjacent homes and gardens. The British Standard on daylight BS8206 part $2^{(10)}$, recommends that the interiors of homes should receive over a quarter of yearly probable sunshine hours, with at least $5 \%$ of yearly probable sunshine hours being received in the 6 months September to March. The BREEAM scheme therefore gives a credit for buildings which do not cause substantial overshadowing of neighbouring properties or which do not cause an existing situation to deteriorate.

\section{Water Economy}

Water is increasingly becoming a scarce resource with an associated increase in the degree of financial and environmental cost. A credit is available for providing WC's which have a maximum flushing capacity of 6 litres or less. 


\subsection{Indoor Issues}

\section{Ventilation, Passive Smoking and Humidity}

The purpose of each of the credits in this section is to improve the level of indoor air quality, whilst maintaining energy efficiency. Buildings which rely on natural ventilation and which have openable windows are a highly effective way of meeting this objective. However, in deep plan buildings where natural ventilation would be inadequate, the CIBSE recommendations on ventilation rates need to be followed with particular attention to the potential presence of smoking. Therefore in the BREEAM scheme a credit is available for the provision of openable windows and also for buildings with air conditioning or mechanical ventilation who are able to provide a ventilation rate appropriate to the level of smoking likely to occur in the building.

Following along the theme of smoking, a credit is also available for providing a separately ventilated area for smokers. This area needs to be fully partitioned and allow the polluted air to escape outside without mixing with the air for the rest of the building. An alternative, which is difficult to achieve in speculative developments, is to specify a no smoking policy for the whole building.

The final section on air quality relates to humidity. In the HSE Specialist Inspectors Report No $11^{(11)}$, the control of workplace humidity is acknowledged as an important dimension of air quality. To counter this effect, it is common practice to use a humidifier to boost the amount of humidity in the air particularly in cold weather. If the humidifier is allowed to become contaminated with micro-organisms, it may in itself become a health hazard. Inhalation of contaminated water from the humidifiers can cause various illnesses, one of these is humidifier fever. In general, steam humidification has not been associated with humidifier fever, and there is also some evidence that the sick building syndrome symptoms are sometimes reduced when steam rather than spray humidification is used.

It is acknowledged that there is a contradictory element to recommending the use of steam humidifiers because they increase the amount of energy consumption. However, it is still important to eliminate potential sources of illness generated by buildings. This particular issue illustrates how the BREEAM scheme is able to cope with two environmental issues which are important, yet might be ignored because of their complex inter-relationship.

\section{Lighting}

Again the BRE Report Site Planning for Daylight and Sunlight - A Guide to Good Practice ${ }^{(9)}$, is used as the criterion for establishing whether or not a design maximises the effective use of daylight. Most people prefer natural light to artificial light, and it has the added bonus of reducing electricity consumption for lighting. 
Turning to artificial lighting, a credit is available for the use of high frequency ballasts in place of conventional ballasts. In offices, headaches and eyestrain have successfully been reduced when high frequency ballasts have been substituted for conventional ballasts used in fluorescent lighting.

The final lighting credit aims to ensure occupant comfort by encouraging designers to follow the recommendations contained in the CIBSE Code for Interior Lighting ${ }^{(12)}$. The energy impacts of lighting are taken into account in the $\mathrm{CO}_{2}$ calculation.

\section{Thermal Comfort and Overheating}

With the strong emnhasis on reducing $\mathrm{CO}_{2}$ emissions, it is possible to forget that there is a risk of discomfort due to both overheating and underheating in buildings. For this reason the scheme gives a credit for demonstrating that the building design has been subject to an assessment consistent with the CIBSE Guide Volume A on thermal comfort ${ }^{(13)}$. BRE believes that increasing awareness of this issue is an important first step.

\section{The Role of BREEAM and the Benefits it Provides.}

The benefits to the different participants in the scheme can be identified in a number of ways.

\subsection{Benefits of Recognition.}

When the scheme was launched, it was apparent that there was a demand for environmentally friendlier buildings. Some designers and developers were trying to respond to this demand. However, clients had no common set of standards to make an assessment of how extensively environmental issues had been considered. Without these standards it was impossible to have an objective and credible way of differentiating green buildings from all the rest. BREEAM provides a way of achieving this.

\subsection{Marketing Benefits.}

By differentiating greener buildings from other designs, BREEAM is able to provide the construction industry with a product to sell to environmentally conscientious clients.

BREEAM rewards a developer's positive actions towards the environment by providing market advantage denied to those designing outside the scheme. One of the intentions of BREEAM is to bring to the construction industry commercial benefits from addressing environmental issues. It stimulates a market for environmentally friendlier products.

\subsection{Environmental Benefits.}

Whatever the designers/developers motives, the existence of BREEAM has encouraged designers to become more environmentally sensitive. Buildings have a long life, so any improvements in their initial design will significantly reduce their future environmental impact. As the scheme is voluntary, it allows important environmental issues to be addressed 
sooner than if they were covered by legislation. BREEAM could be thought of as bringing consensus to complicated and contradictory environmental issues. This work draws from existing research programs being undertaken by BRE, on behalf of the Department of the Environment, and also by widespread consultation with the construction industry and professionals.

\subsection{Benefits to everyone who use buildings.}

Finally, BREEAM can be seen as a way of recognising that the indoor environment of greener buildings protects the health and well-being of the buildings occupants. It draws attention to the need to ensure the quality of the internal environment is not compromised.

\section{Conclusion}

BREEAM is believed to be the first scheme in the world specifically to provide recognition of buildings where due attention has been paid to reducing environmental impacts. It has proved popular in the UK, and a range of building types is now included in the scheme. Similar schemes are now under development in other European countries, using BREEAM as a model. This scheme demonstrates a means whereby voluntary, market led actions can lead to environmental improvement.

\section{References}

1. This Common Inheritance: Britain's environmental strategy. London: HMSO.

2. J J Prior. BREEAM 1/93 - an environmental assessment for new office designs. Building Research Establishment. Report No. BR234, 1993.

3. V H C Crisp; J V Doggart; M P Attenborough. BREEAM 2/91 - an environmental assessment for new superstores and supermarkets. Building Research Establishment. Report No. BR207. Garston, 1991.

4. J J Prior; G J Raw; J L Charlesworth. BREEAM 3/91 - an environmental assessment for new homes. Building Research Establishment. Report No. BR208. Garston, 1992.

5. C R T Lindsay; P B Bartlett; A Baggett; M P Attenborough; J V Doggart; BREEAM $5 / 93$ - An environmental assessment for new industrial, warehousing and non-food retail units. Building Research Establishment. Report No. 252, Garston, 1993.

6. S J Leach; M P Attenborough; J V Doggart; R Baldwin; P B Bartlett. BREEAM 4/93 - an environmental assessment for existing offices. Building Research Establishment. Report No. 240, 1993.

7. The Chartered Institution of Building Services Engineers 'Minimising the Risk of Legionnellas Disease' CIBSE Technical Memorandum TM 13. London 1991 
8. British Standards Institute, 'Method for rating industrial noise affecting mixed residential and industrial areas' British Standards BS 4142: 1990 London, BSI, 1990

9. P J Littlefair, 'Site Layout planning for Daylighting and Sunlight: a guide to good Practice' Building Research Establishment Report. Garston, BRE, 1991.

10. British Standards Institute,'Lighting for Buildings Part 2. Code of Practice for lighting' British Standard BS8206: Part 2:1992, London, BSI, 1992.

11. J Sykes, 'Precautions Against Illness Associated with Humidifiers', Health and Safety Executive Specialists Report No 11. Bootle, HSE, 1988.

12. The Chartered Institute of Building Services Engineers, 'Code for Interior Lighting'. London, CIBSE, 1993.

13. The Chartered Institute of Building Services Engineers, 'CIBSE Guide, Volume A,: Design Data' London, CIBSE, 1988. 
BUIIDING ENVIRONMENTAL PERFORMANCE ASSESSMENT CRITERIA, BEPAC

Raymond J. Cole

School of Architecture, University of British Columbia

6333 Memorial Road

Vancouver V6T 122, Canada

\begin{abstract}
Building Environmental Performance Assessment Criteria (BEPAC) is the first comprehensive method in Canada for evaluating the environmental performance of both new and existing office buildings. BEPAC is comprised of a comprehensive set of environmental criteria, structured in five major topics: Ozone Layer Protection, Environmental Impacts of Energy Use, Indoor Environmental Quality, Resource Conservation and Site and Transportation. The credited criteria of BEPAC are organized within four modules. These modules are designed differently for the Base Building and Tenancies. Design and Management are addressed at both levels. Each module addresses the five topic areas. BEPAC criteria begin where average practice and codes leave off. The standards set in BEPAC are those which are consistent with "best practice" today and will lead industry towards more environmentally responsive practice in the future.
\end{abstract}

\title{
Introduction
}

Current patterns of human activity, settlement and development create regional and global environmental degradation at a scale which poses a serious threat to continued human existence. The acknowledged severity of global warming, ozone layer depletion, resource depletion and degradation of the planet's ecosystems, together with greater understanding of the effects buildings have on occupant health and well-being, has precipitated a growing awareness of the need to take action to preserve and protect our environment.

As the twenty first century approaches, we can anticipate a maturing and strengthening of the public's concern and knowledge on environmental issues, and an expectation for greater environmental responsibility. This will prompt a search for environmental criteria to guide policy and decision-making in all sectors of society; the building industry is no exception. The building industry will be increasingly scrutinized for its environmental responsibilities and will be required to develop approaches and practices which adhere to the principles of sustainability.

\section{The Building Environmental Performance Assessment Criteria (BEPAC)}

The Building Environmental Performance Assessment Criteria (BEPAC) program is a comprehensive method of evaluating buildings with respect to a declared set of criteria spanning global, local and indoor environments and was inspired by the U.K. BREEAM program. 
BEPAC is voluntary in its application and, when applied, offers a certificate of design and management performance for office buildings and their tenancies. The primary goal of BEPAC is to guide and encourage the market to take major steps in introducing more environmentally responsive practices and higher performance standards. The initial version applies to new and existing office buildings in British Columbia. The program will eventually be extended to cover a broad range of building types and accommodate regional differences across Canada.

The basis for evaluations in all cases will be the performance expected by "best practice approaches," given the current and emerging knowledge base in these fields and the available standards which guide design and operation. BEPAC will be applied in the field by trained assessors who have demonstrated knowledge of all the criteria covered in the program. Two complementary assessments of office buildings are provided within the BEPAC program: one for the base building and the other for the tenancy. Each assessment results in a separate certificate. However, an assessment of a tenancy cannot be made without the base building having been previously assessed.

A BEPAC assessment offers many advantages to building owners:

$\square$ BEPAC as an Assessment TOOI: BEPAC provides a comon and verifiable set of criteria and targets so that building owners striving for higher environmental standards will have a means of demonstrating that effort.

- BEPAC as a Management TOol: A BEPAC assessment gathers and organizes detailed information on the building which itself can be used by building management to lower operating, financing and insurance costs, lower vacancy rates and increased marketability.

$\square$ BEPAC as a Strategic Planning Tool: BEPAC can be used by building owners to identify priorities for future administration measures, building retrofits, etc., which will keep a property current within a changing marketplace.

$\square$ BEPAC as a Design Tool: In a rapidly expanding field of knowledge, it will become increasingly important to have a means of structuring environmental information for new building designs and major renovations. BEPAC offers this and provides a reference by which building owners and design teams can formulate effective environmental design strategies.

- BEPAC as a Communication Tool: Building owners can use the BEPAC assessment to comunicate to prospective tenants the inherent environmental qualities of the building they are leasing.

$\square$ BEPAC as a Public Education TOol: BEPAC, as a framework for buildingrelated environmental issues, is a valuable tool for improving public awareness of these important matters.

\section{BEPAC Modules}

The environmental performance of building results from the interaction of the base building and its major systems with the interiors and sub-systems introduced by the building's tenants on the one hand, and the manner in which the building and its various tenancies are subsequently managed on the other. 
As such, the structure of BEPAC distinguishes between design and management criteria for both the base building and the tenancies. The credited criteria of BEPAC are covered within four modules: base building design, base building management, tenancy design and tenancy management.

Each module contains topic areas covering a comprehensive range of environmental issues. Criteria are defined and credited for each of the topic areas and formulated appropriately for either designers or managers.

\section{BEPAC TOPics}

Each BEPAC module offers a comprehensive set of environmental criteria covering issues related to interior, local and global scales. These are structured in five major topics areas:

O Ozone Layer Protection

[ Environmental Impact of Energy Use

I Indoor Environmental Quality

- Resource Conservation

G Site and Transportation

Each topic area contains a series of criteria and, where appropriate, these are further divided into more detailed sub-criteria. The criteria incorporate objective performance standards using numeric evaluations where possible. Environmental issues will clearly change over time, these categories are sufficiently broad to embrace any potential consideration. Moreover, although no hierarchy of importance is implied, ozone layer protection and the environmental impacts of energy use considerations have profound implications and currently being framed within national and international statutes of limitation.

\section{Ozone Layer Protection}

With the discovery of ozone layer thinning in the Arctic and the midlatitudes, evidence of the damage caused by chlorofluorocarbons (CFCs) continues to grow, leading to scientific consensus that an eighty-five percent reduction in controlled Ozone layer Depleting Substances (ODSs) emissions is required to stop future depletion of the layer. Ozone layer protection will remain a priority environmental issue until ODSs are completely eliminated.

The challenges that building owners, designers, contractors and manufacturers face in reducing ODS emissions will be both difficult and expensive, but inevitable. The BEPAC ozone layer protection criteria are credited on the basis of reducing the amount of ozone depletion substances used in buildings and the management and elimination of those which remain.

Under building design, points are awarded for:

- Making a full inventory of ODSs.

$\square$ Paying care and attention to equipment selection and installation to minimize the release of refrigerants or fire suppressants. 
Making provision for future retrofit to non-ozone layer depleting substances.

Under building management, points are awarded for:

$\square$ Assessing annual emissions of ODSs from a building.

$\square$ Comitment to a goal of zero ODS use by formulating and implementing an ODS elimination schedule.

Ensuring that building operators are trained in maintenance practices which minimize the release of ODSs.

\section{Enviromental Inpacts of Energy Use}

Energy use is central to addressing the environmental agenda. However, rather than being solely concerned with energy use reduction per se, BEPAC assesses the environmental impacts of using different fuels. The energy related criteria are premised on:

- Reducing the emissions from combustion which are known to contribute to global warming and which contribute to urban and regional air pollution and acid rain.

$\square$ Offsetting the demand for new power facilities. Electricity is treated separately in this version of BEPAC because 96\% of British Columbia's electrical capacity resides in existing hydro dams. Credits are therefore awarded for both electricity conservation and for peak demand reductions.

Under building design, points are awarded for:

$\square$ Reducing the total amount of annual emissions of greenhouse gases (carbon monoxide, methane and nitrogen oxides) from the building.

$\square$ Reducing the total amount of annual emissions of regional pollutants (sulphur oxides, nitrogen oxides and carbon monoxide) from the building.

- Reducing the total annual amount of electricity used in the building.

- Reducing the peak electrical energy demand in the building.

$\square$ Meeting or exceeding the envelope and systems design criteria in ASHRAE/IES Standard 90.1-1989.

Under building management, points are awarded for:

$\square$ Conducting an annual review of the building's energy performance.

$\square$ Designating an Energy Conservation Manager and training staff in energy conserving operations.

$\square$ Being proactive in making building occupants aware of opportunities for reducing energy use in their own businesses and tenant spaces.

$\square$ Undertaking preventative maintenance programs of the building's mechanical and electrical systems and documenting such practices.

\section{Indoor Enviromental Quality}

The qualities of the indoor environment which are evaluated in BEPAC are indoor air quality; lighting quality and acoustic control. 
Indoor Air Quality

Clean indoor air is a fundamental necessity for health and productivity in the workplace. BEPAC air quality criteria are organized on the basis that control of indoor pollution at source is the primary strategy for maintaining indoor air quality and that dilution by ventilation is a necessary, but secondary strategy .

Under building design, points are awarded for:

$\square$ Reducing the potential sources of pollution in the building through effective moisture control, minimizing fiber release and specifying materials with low toxic emissions.

Isolating potential sources of pollution by specifying effective filtration systems, isolating cooling towers to prevent the release of contaminants and separately zoning sources of contamination generated indoors.

$\square$ Providing a mechanical system which can provide and maintain required ventilation rate.

Locating and designing the air intakes for the ventilation system to ensure the best possible quality air supply.

$\square$ Designing effective system controls and commissioning the system.

Under building management, points are awarded for:

$\square$ Designating an Indoor Air Quality manager and arranging for his/her ongoing training.

$\square$ Ensuring regular systems checks and maintenance and providing the operator with operation and maintenance schedules.

$\square$ Maintaining a no smoking policy and providing clear signage to that effect.

$\square$ Undertaking regular, environmentally sound building maintenance practices.

Lighting Quality

Quality illumination is a fundamental necessity for comfort and productivity in the workplace. BEPAC lighting quality criteria are organized on the basis that:

Daylight and visual access to the exterior is a fundamental part of quality illumination.

- Well designed and controlled electric lighting is necessary for achieving effective daylighting integration and a glare free environment for VDT work.

$\square$ Appropriate task lighting which allows individual adjustment is essential within an overall lighting design strategy.

Under building design, points are awarded for:

$\square$ Providing naturally lit interiors and unencumbered views to the exterior.

$\square$ Providing high quality electric lighting and specifying high frequency electronic ballasts.

Under building management, points are awarded for commitment to regular window cleaning and lamp maintenance programs. 
Acoustic Control

There are two important premises to the BEPAC acoustic quality criteria:

Protection from excessive exterior and interior noise is a fundamental necessity for comfort and productivity in the workplace.

Appropriate conditions for conversational privacy are best provided by adequate acoustic partitioning and moderate background sound from

activities and equipment and by acoustic design of workstations.

Only building design issues are assessed under acoustic quality at the base building level for specifying and designing low system and equipment room noise and reduced sound transmission.

\section{Resource Conservation}

Reducing the environmental cost of material use in offices is an important complement to reducing the operating energy and ozone depletion impacts. This typically entails programs to reduce consumption, to reuse and recycle and to purchase products with lower initial "environmental cost" such as those with recycled content.

The fundamental position taken in the resource conservation section is that reduction is the primary method of conservation:

Under building design, points are awarded for:

The retention of existing building elements and landscape, salvaging or reuse of building materials and construction waste reduction.

- Specifying materials having lower environmental impacts, e.g., durable materials with recycled content.

$\square$ Conservation of tropical and domestic wood by efficient wood use and specifying products from sustainably managed forests.

$\square$ The efficient control and use of site water through the retention of storm water, water conserving landscape and use of efficient irrigation and water recycling systems.

$\square$ Facilitating water conservation within the building by specifying low flow fixtures and elimination of chillers which use potable water.

Providing dedicated recyclables storage and consumer recycling facilities.

Under building management, points are awarded for:

Designating a Building Recycling Coordinator and instituting an environmentally responsible purchasing policy.

$\square$ Requiring efficient construction and demolition waste management practices and instituting and promoting in-house office paper conservation and cafeteria waste programs.

\section{Site and Transportation}

The major premise of the site and transportation section is that automobile commuting is the most important environmental impact of office building location and that strong management incentives are necessary to alter the commuting habits of people. 
Given the fundamental differences between the topic areas, it is neither meaningful nor possible to apply weightings between them.

\section{Extraordinary Performance}

The BEPAC Certificate keeps the credits for the individual criteria within topic areas distinct and thereby presents a comprehensive profile of building performance. This deters the reduction of the assessment to a simple, misleading aggregating of points. In anticipation of unique and thoughtful solutions, BEPAC provides for recognition of extraordinary performance at both a design and management level. Though there is no direct points credit given for extraordinary performance, there will be a citation appearing on the BEPAC Certificate noting the special reason for merit. The intent is to reward the use of innovative and productive design approaches and management practices, and to spread awareness of such strategies to other building owners, designers and the public.

\section{Acknowledgments}

BEPAC is sponsored by a unique collaboration of all sectors of British Columbia's building industry: Architectural Institute of B.C.; Association of Professional Engineers and Geoscientists of B.C.; Building Owners and Manager's Association, B.C.; B.C. Buildings Corporation; The B.C. Energy Management Task Force; Edgecombe Group Inc.; Real Estate Foundation of B.C.; Environment Canada's Environmental Partners Fund Power Smart, B.C. Hydro; ASHRAE B.C. 


\section{THE CITY OF AUSTIN GREEN BUILDER PROGRAM}

W. Laurence Doxsey, Coordinator

City of Austin Environmental and Conservation Services Department Green Builder Program

206 E. 9th St., Suite 17.102

Austin, TX 78701

Abstract. Home energy rating systems (HERS) are relatively well known and offered in North America as a mechanism for encouraging energy resourceful building construction. The City of Austin Green Builder Program was modeled after the market based incentives inherent in home energy rating systems but applied toward the more holistic perspective involved with constructing "sustainable" buildings. The Program was originally designed to address new residential construction. It now is offering guidelines for commercial building as well as all City funded projects.

The Program enrolis building professionals who agree to offer their customers a range of options and building approaches that are presented in the Program's Green Building Guide and Green Commercial Guidelines according to the interests of their customers and other practical considerations. The first version of the Green Building Guide presents an environmental rating system where building options are valued numerically allowing a score (rating) to be developed for individual projects.

Program participants receive recognition through a general marketing campaign by the city. The marketing campaign is aimed at educating the general public to the values and advantages of green building. The Program additionally provides technical assistance and guidance to building professionals, City departments, and other citizens wishing to incorporate environmentally responsible building practices.

\subsection{BACKGROUND}

"Sustainability," or meeting present needs without compromising the needs of future generations to meet their needs, implies an holistic approach to developing the built environment. Yet, while the relationships between human activity and the natural environment are studied, mainstream development continues with minimal recognition of sustainable building practices. While sustainability is as much common sense as an ideal concept, building impacts have rarely been approached from this holistic point of view. The building industry represents a significant user of resources, both in the building process and in the finished products. Through proper consideration and response to its impacts, it presents an important opportunity for creating more sustainable communities. 
The traditional means for causing change in building practices is the adoption of codes and ordinances which force compliance with a given standard. This method meets with reasonable success relative to the ability of an entity such as a municipality to enforce the regulations, but it frequently creates political clashes of varying degrees between the governing body and the regulated party. These clashes often delay and compromise enactment of environmental initiatives. An alternative approach is to design a program that sells itself to the public without mandatory or financial incentives. The Austin Green Builder Program is designed around this marketing approach.

The City of Austin implemented a home energy rating program called Austin Energy Star in 1985. It was designed to give marketing assistance to builders who produced energy efficient homes that exceeded the minimum requirements of the newly adopted City Energy Code. More than 4,000 homes have been rated under this program, and most of the active builders in the Austin area are

participating at this time. Because of the improvements in energy efficiency of building stock seen over the past seven years, it was proposed that this approach be used to promote the broader scope of residential building issues associated with developing sustainable communities.

The Green Builder Program was initiated through a grant awarded in 1990 from the Urban Consortium Energy Task Force to develop a "Sustainable Systems Rating Program." Early development assistance was received from the Center for Maximum Potential Building systems of Austin, Texas. Two subsequent grant awards were received in 1991 and 1992 to further develop and enhance the program. Technical and logistical information related to green building was compiled and developed during this time as well as the initiation of multiple demonstration projects. The City of Austin now funds the entire operation of the Program.

Due to increased interest from the local commercial sector, the Program currently has additional assistance from commercial energy program staff to expand the scope of the Program to develop commercial guidelines. Inter-departmental cooperation and City Council support has recently led to initiatives to revise and develop guidelines and specifications for City low-income housing, City municipal facilities (libraries, fire stations, etc.), and the new municipal airport.

\subsection{Program Purpose}

The purpose of the project at its inception as proposed to Urban Consortium Energy Task Force was to develop a Sustainability Rating System that can be used as a marketing tool to encourage high levels of resource conservation, appropriate resource usage, and positive economic development in new residential homebuilding. Rating systems such as Austin's Energy Star Rating Program for new 
homes have become recognized as effective methods to bring about energy conservation; in the Green Builder Program, the rating system is used to lead homebuyers to look at and demand new homes that conserve all natural resources, minimize pollution, and impact positively on the local economy. The rating system, as part of a comprehensive marketing program, was presented as offering a transferable strategy to shift homebuyer and homebuilder consciousness such that housing is generally improved and the local economy is strengthened without compromising the quality of the local and planetary environment.

\subsection{Program Development}

The Green Builder Program employs an holistic analytical model based on the concept of life cycle assessment and incorporates it into a marketing program aimed at fostering sustainable (earthfriendly) construction practices for new homes. Development of this program entailed several specific tasks before a rating system could be established:

* Identify the key resource issues encompassed by new residential building.

* Determine the evaluative criteria for consideration of environmentally friendly options.

* Develop a model to measure impacts of options.

* Translate the model into a simplified presentation and rating for general public use.

The conceptual development effort identified four major resource issues for home construction: water, energy, materials, and waste. A systems flow model was then designed to track the resource issues through interactive matrices in the areas of sourcing, processing, using, and disposing or recycling. This model served as the basis for the rating system that results in a comparative basis for considering building options and approaches.

Energy, Water, Solid Waste, and Building Material issues form the core of the Program's current appraisal of a home's resource

impact. This purposely limits the evaluation to the building itself. It was decided that consideration of additional issues such as scale, location (infrastructure and transportation issues), zoning, and others, although of major importance, would delay and complicate the development of a single model that could be used, as an initial step to rate just a building proper. The four resource areas are presented and discussed in the initial Green Builder Program document, the City of Austin Green Building Guide. This Guide includes background information on the four resource issues and a rating section which allows users to assess the relative "sustainability" of a subject home. Intended for the general public and the building community, the Green Building Guide has been the central marketing product of this project. 
The Guide lists building options that were selected as being generally understood to be positive additions to a building in the Austin location. A decentralized bioregional perspective was accepted as an essential tenet of a sustainability-based approach. Any transferable considerations of individual building options listed in the Green Building Guide must take this into account.

Each of the four resource areas and some associated options are listed below (This is not a complete list. More options are shown in the Green Building Guide):

WATER

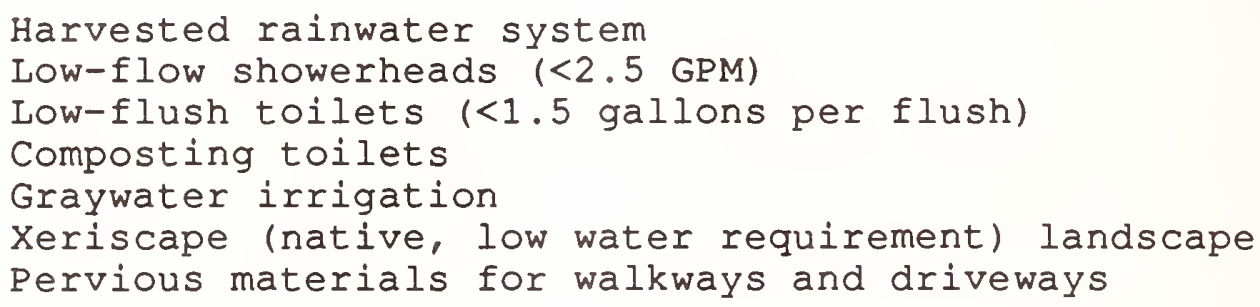

ENERGY

Rating from the Energy Star Home Rating Program

Passive heating and cooling design

Continuous ridge and soffit venting

Thermal chimney

Solar water heating

Proper tree planting for shade

Efficient lighting

Daylighting

Photovoltaic system

MATERIALS

Wood from "certified" sustainably managed forests

Flyash concrete

Indigenous stone and brick

Non-toxic termite protection

Gypsum/cellulose wallboard (recycled material)

Natural paints and sealers

Recycled doors

Cotton insulation

WASTE

Compost system

Built-in kitchen recycling center

Hazardous material safety storage system

Builder recycles construction waste 


\section{1 Sustainability Rating}

An initial effort into identifying existing or developing methodologies for determining environmental merit in 1991 identified few helpful precedents. Accepted standardized scientific life-cycle assessments were not developed and there appeared to be no programs for what we wanted to accomplish. As a result, due to our limited funding for research and development, we had to develop an approach that would be able to have subjective assumptions sufficiently clarified. It is made clear to the users that the current rating is employing the best knowledge presently available and is for comparison only; it does not attempt to recommend specific products.

Criteria were developed to quantify the relative "sustainability value" of listed options, and encompassed the following general guidelines or themes:

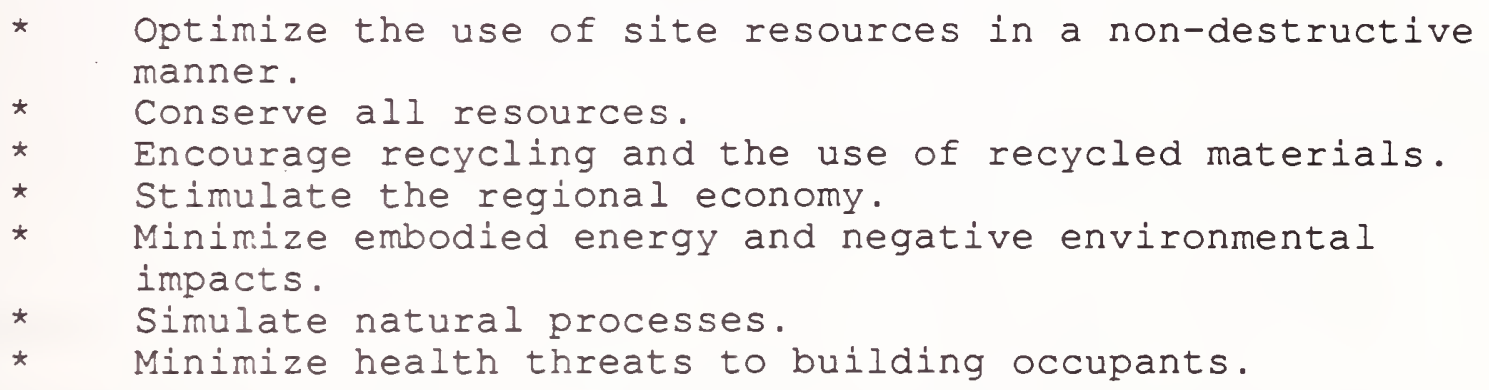

The following is a brief presentation of seven evaluation categories used in the "life-cycle " model, their respective subdivisions, scoring information, and pertinent discussion. Each option that was selected to be rated was subjected to an evaluation with each applicable characteristic being worth one (1) point (except when noted differently).

\section{Source eoints:}

* Site- The resource is inherent to the site. (i.e. rain, sun, wind, earth at the site)

* Recycled- The resource consists of over $25 \%$ recycled content (i.e. recycled plastic lumber, cellulose insulation). distinction was not made between post-consumer and post-industrial recycled-content materials.)

*Renewable- Relatively fast natural processes bring this resource into being. (i.e. wood, rain, sun, wind, not coal, clay, other earth materials, etc.)

*Regional-A regional resource is considered to have a positive economic impact and a lowered embodied energy in transportation factors. (i.e. earth materials, brick, stone as well as site resources such as sun, rain, wind, earth at site) 
* State- A resource is considered to have a positive economic impact if from within the state.

(note-A "regional" point gains a "state" point automatically. This reflects the additional value imparted by local economic activities.)

\section{Process points:}

* Embodied Energy- The process uses energy frugally to transform the resource (if transformed at all). Transportation distances are considered. Note that statistical data for embodied energy is not available for all items (materials) and standardized methods for computing embodied energy are needed for true equal comparisons. Only a process that was well known to have low embodied energy in its comparative family was valued in the rating.

* Environmental Impact- In many cases, the environmental impact and embodied energy of a process can be considered to parallel each other - the greater the embodied energy, the greater the environmental impact. However, this is also an area that requires extensive primary research since the effects will extend beyond energy-related effects (externalities). This was beyond the capacity of this project and, as a result, needed to be handled similarly to embodied energy.

*Regional- The process takes place regionally giving positive economic impact.

* State- The process takes place in-state giving positive economic impact. purposes.)

(note- if "regional" applies, so does "state" for scoring

\section{Use goints:}

*Quantity- Point(s) are scored if the use is highly conserving of resources. Certain building methods, systems, and materials are more conserving than others on a relative scale. For example, a solar water heater that provides over $50 \%$ of a home's hot water needs should be more highly valued than a solar hot water heater that provides $20 \%$ of the home's requirement. To account for these differences, the assigned point values in the rating system is as follows: [1] point- if the system or device saves up to 33\%; [2] points- if the amount saved is up to 67\%; [3] points- the amount conserved exceeds $67 \%$.

* Health- The use of the material or system is specifically non-deleterious to occupants in the short or long term. "Healthy" home issues are legitimate concerns and certain methods and materials are marketed to counter known health impairing materials. Although many other materials selected for the rating list could be classified as non-deleterious to health, only those 
that are acknowledged and recommended in current material health advisements were valued for a health "point".

*Durable- The material or method is long lived and low maintenance in its functional class (i.e. a 30-50 year life roof is durable compared to 20 year roofing; in proper installation a material such as wood lasts indefinitely in a dry location; brick siding is durable and low maintenance compared to wood siding.)

\section{Rost-use [lifel points:}

* Easy to Recycle- The material can be used again with processing through established systems or reused. The relative levels of recyclability resulted in a three point category valuing direct reuse as [3] points, processed recyclability as [2] points, and potential but not currently done processed recyclability as [1] point.

*Proper Disposal- The material can be handled appropriately to be non-polluting and/or is readily compostable.

(This category addresses the resource issues of Materials and Waste and was not considered an aspect of Water and Energy. The Integration category addresses "recycling" aspects of Energy and Water.)

\section{Integration:}

The ability of the system/resource to achieve several functions. (i.e. a brick wall on the interior of a house serves as a structural support or divider and as thermal mass supporting a thermal flywheel effect in the house; a greywater/irrigation system removes water from the wastewater system and irrigates the landscape.)

More than one point could be scored if multiple integration take place.

\section{Difficulty:}

Many good options from an environmental standpoint are difficult to implement due to poor availability and other factors. This category gives value to the extra effort that a building professional incurs in implementing the more difficult options for the following reasons.

- Extra cost

- The need for extraordinary special skills. (Consider the amount of need and availability in the following areas.)

*design

*engineering

*installation 
- Regulatory demands

- Material availability

- Value perception (This implies that the builder and/or homebuyer has acted upon knowledge of a building option, not commonly understood by the general public, as resource-conserving and essentially has taken a risk. Examples are composting toilets, straw bale construction. This would also apply to options selected that have long paybacks in the conventional economic sense.)

(This category was scored from an estimating point of view although a quantifying formula can be established.)

A total of 1 point is available from this category.

\section{Use Factor:}

A building option may be applicable to more than one use category. For example, a passive solar design that impacts the heating and cooling of a home has affected two areas - heating and cooling. If harvested rainwater is used for all indoor water classifications used in the analysis (in this case, potable needs, washing, toilet flushing), a use factor of 3 occurs. The Use Factor is multiplied by the total of the other categories. This is a slightly different perspective than "Integration" described previously based on intent.

Ratings for each of the listed options were determined through this evaluation. The final point rating, which compiles the "sustainability score" of the listed options, is reduced to a category of One Star (translate "fair"), Two Stars (translate "good"), Three Stars (translate "excellent"), Four Stars (translate "superior"). This element was provided to be the "bottom line" for those not interested in the complex details of sustainability, and to simplify the rating for marketing. (It was, however, similarly intended that as much educational benefit as possible could be derived from the process of rating a home.) A rating of One Star is determined by measures which go beyond standard practice, yet are readily available and not cost prohibitive. Ratings in the Two Star to Four star categories will result from options that, while not always more costly or difficult, will require increasing levels of commitment to less conventional building practices.

The range of points for each category allows the builder or customer to evaluate the home for each primary category, and then reduces the four category ratings to one final "Sustainability Rating." For example, a home may have a Three star "energy" rating, a One Star rating each for "water" and "materials", and a Two star rating in "solid waste." The resulting overall "Sustainability Rating" for the house would be Two Star 
scoring chart is provided in the rating section of the Guide that permits this calculation.) This approach allows the builder or customer to accurately identify weak and strong areas in the home's resource efficiency as well as have an overall rating for the house.

\section{1 .1 Does It Work?}

There are several factors that come into play in answering this question when we consider the ultimate goal of trying to change conventional building practices to sustainable building practices. on one level, the rating values for a project seem to consistently reflect what one would intuitively expect. Nevertheless, the mechanism itself has not been easy to use in a self-rating manner. Very few builders want to, or accurately, apply the rating system to their projects. Program staff are having to do the ratings which was not the intention at the outset. The goal was to make it simple by listing options with numerical values in place that could be just checked off. However, interest and influence in regards to green building seems high.

A questionable aspect of the rating system results in trying to simplify building options to a single value that may or not hold true under different circumstances. For example, the value of radiant barrier in an attic may not exist if higher attic insulation levels had been used.

Additionally, it is not clear that a very simple home with a few green material choices (but covering all the building components and systems) will score well versus a home that has many different green materials. This was attempted to be sorted out in reaching the point totals that give the one, two, three, and four star scores by adding point totals for different homebuilding scenarios. However, there have not been many simple homes to test this aspect.

Finally, the fact that there are more considerations in issues of sustainable development (scale, infrastructural development, etc.) misses some important concerns and should be addressed. For example, the 1993 Parade of Homes featured all "Green Builder" homes. Most of the homes were One Star but one home was a Three Star and another achieved Two Stars. The Parade occurred in an urban sprawl associated location. All the homes were on one acre or more lots (xeriscaped) and were greater than 4,000 square feet. We appreciated the highlighting of the Program elements in terms of building options but we had to acknowledge that major elements and understanding of sustainable development were missing.

\subsubsection{What Is Next For the Rating system?}

Currently, an evaluation of an informational focused evaluation system is being done. In this system, building options are listed 
as before but, instead of numerical values, a brief description of what is important about the option and some of the relevant circumstances involving appropriate application are noted. A list of options used in the building can be ascertained but the value for them can be assigned by the person reviewing the list (who is knowledgeable about them from the option descriptions).

It is possible that more salient influence on building practices can occur in this manner. For example, if a person inquires if a home was painted with low VOC paints, he or she would know that high VOC paints are harmful to the workers, the environment, and potentially to the future homeowner. It is difficult to respond to such an inquiry with an answer such as, "it was cheaper."

Although much of this information can be obtained in the glossary of the first Green Building Guide, it is not as accessible and as potentially influential as it would be in this format. It should be decided by April, 1994 if this approach can be made nonburdensome and attractive and then incorporated into the next printing of the Green Building Guide.

It is still being discussed if and how the current rating system results will serve as part of a label awarded to a builder's house. We feel a comparative relationship should still be able to be determined. An examination of baseline/threshold requirements is currently being conducted. The baseline/thresholds determinations could still take advantage of the rating format.

\subsection{The Sustainable Building sourcebook}

After listing "green" building options in the Green Building Guide, we recognized that the next step would be practical guidance and information in how to implement the options. This is done through regular technical seminars and conferences sponsored by the Program and through a manual designed for building professionals - the Sustainable Building Sourcebook.

(Concurrently, ongoing educational efforts through media articles and speaking engagements are used to reinforce the program's viability to impact building practices to the general public.)

The Sourcebook is designed to reflect upon the organizational presentation of the Guide but is capable of being a stand-alone work. It groups options from the Guide that go together into topics (such as separate elements of passive solar design singled out in the Guide) and presents information for each topic in three general categories - Overview, Guidelines, and Resources.

The overview contains an executive summary plus a matrix presentation of the commercial status and implementation issues of the topic. The Guidelines category presents pertinent implementation guidance. In the Resources category, there are three subsections listing logistical information - Professional Assistance, Materials/Components/Systems, and General Assistance. 
There are 43 topics divided among the Water, Energy, Building Materials, and Solid Waste sections of the Sourcebook. The 400 pages of information in the sourcebook is designed to fit into a three ring binder for updating.

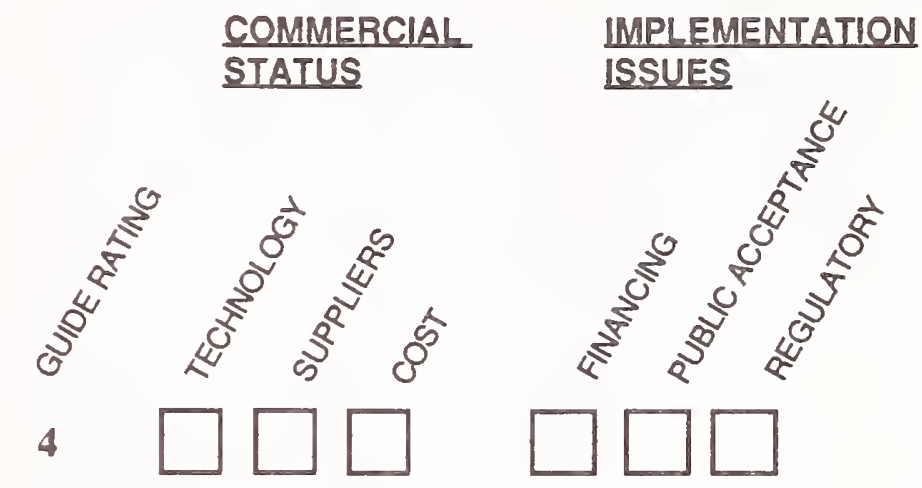

\section{LEGEND}

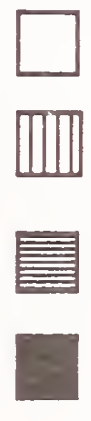

SATISFACTORY

SATISFACTORY IN MOST CONDITIONS

SATISFACTORY IN LIMITED

CONDITIONS

NOT SATISFACTORY OR DIFFICULT

Matrix used in Sourcebook

\subsection{Current Activities}

\subsubsection{Demonstration Projects}

The Program is currently working with an alternative learning center, the American Institute for Learning (AIL), and Austin Habitat for Humanity to construct three low cost green houses for low income residents. The AIL program, Casa Verde Builders, is doing an exemplary job of using at-risk youth in an educational and training format to construct the houses. The first house is recently completed and is documented through a video generated by the AIL students. A separate report is soon to be completed on this successful combination of social and environmental causes.

The homes are promoted during construction as green demonstrations and considerable media and public support has resulted. The success of this project has resulted in the AIL, the Green Builder Program and other City programs teaming up to propose additional work of this type in association with US HUD's YouthBuild Program. 
The City has pledged support for twelve more green low income houses to be constructed in this manner.

\subsubsection{Greening City Construction Guidelines}

All City low income housing construction guidelines are being revised to favor green building approaches. It was necessary to develop green guidelines that have no harmful upfront cost impacts to the future owners. These guidelines have been developed and implementation details are being completed. This will impact over 50 homes per year.

City commercial facilities guidelines are presently being developed for the Public Works Department. These guidelines will affect libraries, fire and EMS stations, waste transfer facilities, etc. Staff from the Commercial Energy Programs are helping develop these guidelines which also need to address renovation issues. The guidelines developed for the City facilities will then be developed for dissemination to all commercial development projects.

Green guidelines are also being developed for a new municipal airport. The development of the airport guidelines will overlap into the material being developed for the Public Works Department.

All these activities in the municipal arena reflect the increased interest the concept of sustainability has received from elected officials and other City personnel. The overall response from the citizenry is similarly positive.

\subsubsection{Educational Outreach and Economic Development}

Despite the seeming success of the Green Builder Program, construction activities and public awareness are still not as strongly affected as need to be. Receiving an international award for the Program at the 1992 United Nations Conference on the Environment and Development, a national award from the American Public Power Association, and numerous local awards have helped lend credibility and promotion to our efforts and have resulted in a fairly high national profile. Nevertheless, a boom economy currently occurring in Austin has created a frenetic pace of construction activities that is hard for the Program to significantly address.

With the help of monthly seminars of a local organization that spun off from the Program called the Sustainable Building Coalition and our own ongoing seminars, green building is being discussed in our City on a regular basis. Free media attention has also resulted from our efforts assisting in some outstanding examples of residential, multi-family, and commercial green projects. 
Our third annual Green Building Conference in March, 1994 will draw over 300 persons as it has in previous years. However, this conference will be carefully studied this year for possible development into an even larger event next year. All indications are that the marketplace is receptive to green building if it can be economically feasible and strong guidance is available.

The economic feasibility of green building will depend on our efforts to help steer economic development activities into regional business startups such as waste to material processing. Fortunately, seemingly due to the presence of the Green Builder Program, we are attracting interest regarding technology transfer in areas we feel offer positive environmental offerings to our community. We have already seen successful business startups in the service sector with rainwater harvesting and alternative wastewater services.

\subsection{Green Builder Program Description}

The Green Builder Program presently enrolls building professionals in two categories - Builders and Associates.

Builders are enrolled in the Green Builder Program by attending a half-day training which cover the fundamentals of sustainability and how it relates to the specific environment of the residential home. The primary obligation of the builder as a participating member of the Green Builder Program is to serve as a resource for interested buyers, promoting and distributing program information, and avoiding misrepresentation of the program. The builders agree to rate their homes and make the ratings available to prospective buyers. Builders are then supported by technical and marketing assistance from the City of Austin Environmental and Conservation Services Department through general advertising and information campaigns, periodic technical seminars, and technical news bulletins in the Austin Green Builder Newsletter.

As the Green Builder Program becomes an integral part of the local building industry, homes embracing the ideas presented in the Green Building Guide will be highlighted in advertising and award programs. The local home builders association has supported the Green Builder Program, primarily because the approach allows builders to participate in a positive, education-oriented program and make voluntary improvements in response to buyer demand instead of through mandatory regulations. They have been helpful allies in getting builders to enroll in the Program.

Associate members include architects, engineers, tradespersons, material suppliers, consultants. Like the Builders, they must attend an orientation and technical seminar and renew their membership annually by attending an additional technical seminar. Both membership groups receive written materials such as the Green Building Guide and the Sustainable Building Sourcebook at no cost. There is also no cost to be a member of the Program. 


\subsection{Program Incentives}

To help attract more participation in the Program, particularly in regards to the fact that a boom economy generates little incentive to try new building approaches, we are offering financial incentives to be members. These incentives are linked to the DSM strategies that our Department has developed. The benefit to the Green Builders is that DSM pilet incentives (rebates) are only available to Program members. Lumped together with existing DSM and water conservation rebates, the pilot incentives add up to a strong incentive, particularly since we are presenting them as "one stop shopping" rather than as separate opportunities. We anticipate more interest from volume builders as a result of this approach.

\section{0 Concluding Remarks}

The Austin Green Builder Program was developed based upon the success of marketing energy efficiency through the Energy Star Rating Program for new homes. The fundamental strategy is to inform buyers of the more "earth-friendly" options available to them when building a new home, while educating builders and using the building industry as the mechanism for distributing information on sustainable building. This positive, marketoriented approach brings interested buyers and informed builders together, stimulating voluntary improvements and maintaining a working relationship between the building industry and municipal government, while increasing the overall understanding of the public on the issues of sustainable community development.

It is encouraging to see the increasing interest in sustainability through our many contacts with others. We hope that our locallyfocused initiative and success will continue to assist similar efforts worldwide and help move us all closer to a sustainable relationship with our natural and human environment. 


\title{
CANADA'S ADVANCED HOUSES PROGRAM
}

\author{
Tim Mayo, Program Manager \\ Advanced Houses Program \\ CANMET \\ Department of Natural Resources \\ Ottawa, Canada K1A 0E4
}

\section{Abstract}

Canada's Advanced House Program is co-sponsoring the construction of ten Advanced Houses across the country. These Advanced Houses are field trials of new technologies to reduce the energy consumption in Canadian homes by 50 percent, improve their indoor air quality, and reduce their impact on the environment. Each house represents a unique solution to the detailed Technical Requirements. The ten Advanced Houses, all built by teams representing a broad spectrum of the industry, were constructed during 1992-93. The Advanced Houses are now open to the public for a one-year period before being sold and monitored. A number of clear trends for greener houses are emerging.

\section{Background}

The process of making Canadian homes more energy efficient had its beginnings in the steep oil price increases of the 1970s. At that time, the majority of Canadian homes were leaky, naturally ventilated, and heated by oil. In 1973 it was estimated that onefifth of the nation's energy was consumed by the residential sector and three-quarters of that was used for space heating. New houses in that period typically consumed $200-250 \mathrm{kWh} / \mathrm{m}^{2}$ of floor area, including the basement.

Today, Canadian homes are far more energy efficient than their earlier counterparts. Some provincial building codes, for example, specify more than double the insulation levels for new basements than was required less than 10 years ago. Similar increases have occurred in the requirements for air barriers, vapour retarders, and mechanical ventilation systems.

This dramatic change occurred in less than two decades through a combination of public and private research initiatives, grants, public education programs, and regulatory changes. Rather than forcing change with stringent, innovation-stifling regulations, the government stimulates change by creating a healthy research environment, co-funding demonstration projects with industry, and facilitating the transfer of information to the building industry and the general public. The Canadian government has a clearly focussed, three-pronged strategy for technological improvement to the housing sector: 
- R\&D initiatives to develop new technologies,

- programs to encourage the adoption of market-ready costeffective techniques, and

- regulatory minimum performance levels.

\section{The Housing and Regulatory Environment in Canada}

The significance of the Advanced Houses Program is underlined by certain unique characteristics of the housing and regulatory environment in Canada. Both the housing regulatory agencies and the home building industry in Canada are coordinated by strong, national bodies. As a result, instituting changes in regulations and building practice means dealing with a few appropriate agencies rather than a variety of fragmented groups.

Although housing is a provincial responsibility in Canada, the federal government influences change through funding research projects and setting national standards. Chief among the standards in the housing sector is the National Building Code (NBC) of Canada. The NBC establishes minimum building.standards related to safety and health in buildings, although not energy efficiency, and stands as the model for all provincial and territorial building codes. A national committee of building scientists, industry representatives, and both federal and provincial regulators evaluate the code and revise it on a fiveyear cycle. For the first time, a new Building Energy code will be issued in 1995 in conjunction with the 1995 NBC.

On the industry side, the Canadian Home Builders' Association (CHBA) represents 85 per cent of the home builders across the country. Through its network of provincial and local builder associations, the CHBA provides an avenue for information transfer and the promotion of energy-efficient house construction. In consultation with other industry and government agencies, the CHBA maintains technical resource committees that act as a clearing house for manufacturers, industry and government agencies and inform builders of new products, technologies and programs. With this direct access to the housing industry, programs brought forward at the federal level can quickly effect change across the housing sector. The powerful combination of industry and government coordination at the national level has spawned a number of successful cooperative projects which have brought the canadian housing industry to the point where it is today.

Canadian Milestones

Five milestone projects have played a major role in the development of energy-efficient housing in Canada.

The Saskatchewan Conservation House was the first super-insulated demonstration house built in Canada. Conceived as a research project by the National Research council, the house was built to 
test the theories of super insulation, air tightness, mechanical ventilation with heat recovery, and passive solar. Built in 1978, the house had an air tightness of less than 1 air change per hour at 50 Pascals $\left(\mathrm{ACH}_{50}\right)$ when the air tightness of conventional houses was typically 5-7 $\mathrm{ACH}_{50}$. In its first heating season, it used less than 20 per cent of the energy required by the typical saskatchewan house for heating.

In 1980 the Energy Showcase of Homes in Saskatoon demonstrated that conventional builders could be trained to use the construction techniques developed for the saskatchewan conservation House. Thirteen builders in saskatoon designed and built houses with the same level of performance as the Saskatchewan Conservation House.

In 1982, the federal department of Energy, Mines and Resources (now Natural Resources Canada) established the R-2000 Program to "mainstream" the building of safe, comfortable, super energyefficient housing. The R-2000 Program is based on five key features: builder training, independent plans evaluation, independent construction inspection, independent air-tightness testing, and house certification. The solid technical basis of the program was established through on-going basic research and the establishment of test procedures and monitoring protocols, product development, and quality assurance measures including standards, training, and certification procedures for ventilation system installers. The R-2000 Program continues today, spearheading the marketing of energy-efficient, comfortable houses. Over 6500 R-2000 houses have been certified, and the trickle-down effect has been immense.

Awareness of the need to reduce energy loads beyond space heating and to minimize the environmental impact of housing resulted in the Brampton Advanced House. Built in 1989, the house reduce all energy loads by half by demonstrating a prototypical integrated mechanical system and incorporating energy efficient appliances and lighting, plus featuring various water-conserving appliances and environmentally responsive products. The monitored annual energy consumption of the house was $49 \mathrm{kWh} / \mathrm{m}^{2}$ compared to the $\mathrm{R}-2000$ average of $104 \mathrm{kWh} / \mathrm{m}^{2}$. This success -- and the interest it aroused in leading-edge $\mathrm{R}-2000$ builders -- lead to the creation of the Advanced Houses Program.

\section{Objectives of the Advanced Houses Program}

The Advanced Houses Program is an important next step in the process of reducing the energy consumption of Canadian houses and in going beyond efficiency into issues such as indoor air quality, humidity control, water and waste reduction, recycling, eliminating CFCs, and the use of environmentally appropriate materials. 
The identification of energy efficiency as an environmental benefit in itself, particularly as a means of reducing $\mathrm{CO}_{2}$ production and global warming, as identified in the Montreal Protocol, is a key feature for both the program and the industry. Broader issues of urban planning, resource depletion, embodied energy, and transportation were not addressed.

The objectives of the Advanced Houses Program were three-fold:

- to encourage designers, builders, and manufacturers to fasttrack the development of green technologies,

- to lever financial support from other sources for research and development by providing seed funding, technical guidance, and monitoring activities

- to encourage canadian leadership in addressing global housing challenges.

A secondary objective was to field test the industry's ability to meet a set of energy and environmental performance requirements so as to be able to feed back into the $\mathrm{R}-2000$ program and, ultimately, the National Building Code. The Advanced Houses Program also addresses Canada's commitments to the International Energy Agency (IEA) and other bodies.

\section{Launching the Advanced Houses Program}

The Program was launched in 1991, in partnership with the Canadian Home Builders' Association, as a challenge to industry -- could they build Advanced Houses that were twice and energy efficient and twice as green as the best currently on the market? Thirtyone teams entered the competition; ten winners were chosen, based on five criteria:

- ability to meet the Technical Requirements

- technical innovation

- team expertise and project sponsorship

- monitoring and technology assessment

- technology transfer and marketing plans

The teams include designers, architects, engineers, builders, renovators, manufacturers, suppliers, utilities, and provincial and municipal officials. In addition, each project has an extensive list of manufacturers, suppliers, trades, consultants, professionals, gas and electric utilities, municipalities, and government agencies who have provided cash, services, labour, and goods. Private sector support ranges from small local firms to large multi-national corporations.

Technical Requirements for Advanced Houses

The technical Requirements for the Advanced Houses use the same 
performance-based approach used with the R-2000 Program, but expanded beyond space and water heating to cover both energy and environmental requirements -- total purchased energy, indoor comfort and health, and environmental features.

The total purchased energy requirement is set at exactly 50 percent less than that used by an equivalent R-2000 houses or 52 $\mathrm{kWh} / \mathrm{m}^{2}$-- about one-third of a conventional new house. Individual targets were established for space heating, cooling, hot water, lights, and appliances including motors for fans and pumps. Because the houses were field demonstrations, all lighting and appliances had to be supplied.

Designs were required to meet the sum of these individual targets, with trade-offs permitted between categories. Because only "purchased" energy was specified, the teams were able to explore "free" energy in the form of renewables and heat recovery.

Indoor environmental requirements include room-by-room ventilation, compliance with exposure guidelines for pollutants, noise limits from mechanical equipment, and humidity control.

Environmental requirements include a 50 percent reduction in water consumption, the use of federally approved "EcoLogo" products, recycled materials, indoor recycling facilities, and a construction waste management plan. Except for refrigerators, no CFCs were allowed.

\section{Current Status of Advanced Houses}

Ten winners were chosen in early 1992, and all were under construction later that year. By early 1993, nine of the ten were completed and opened to the public for a mandatory one-year demonstration period; most were also open to industry tours during construction.

Each of the ten Advanced Houses is unique, with its own impressive array of new ideas, new products, and developmental prototypes. Each Advanced House is pushing the limits of building technology to meet the Technical Requirements. This high-profile innovation has been used to gain considerable media attention and public interest in the issues surrounding environmentally responsible technologies. All ten have been the subject of local, national, and even international media coverage. Approximately 200,000 visitors have toured the houses, including a number of foreign trade delegations. Consumer awareness of and demand for green buildings has been greatly increased.

By the end of 1993, three Advanced Houses had been sold, again a mandatory requirement. Once occupied, they will be monitored for one year to evaluate their performance. The results of the performance data will be used as a basis for upgrading the requirements for $\mathrm{R}-2000$ houses. Commercialization strategies will 
be developed for those technologies determined to be winners.

\section{Emerging Trends}

The major trend in the Advanced Houses is an integrated design approach, the "house as a system." Because energy loads have been so drastically reduced, the old rules of thumb no longer apply.

The first step towards reducing loads was to upgrade the building envelope. Insulation levels are above conventional practice, but not excessive, typically R30-R45 walls and R50-R60 ceilings. Most use recycled cellulose insulation. Thicker walls are provided by trusses or manufactured studs. All used high-performance windows, usually triple-glazed, low-E coated, argon-filled units with nonconducting spacers; the result is that all attained a passive solar contribution of greater than 35 percent and four reached 50 percent or better.

With mechanical systems, the trend is toward integration of heating, cooling, hot water, and ventilation systems, with the ventilation system becoming the prime design consideration. With the significant reduction in heating and cooling loads, and a 50 percent reduction in internal gains from lights and appliances, a standard furnace is no longer the base around which the mechanical system is designed. Because loads are so low, completely new and different approaches to heating/cooling/ventilation supply and distribution can be explored.

Eight Advanced Houses used home automation systems to control their mechanical system. All but one used a water-based system, transferring the heating/cooling through fan coils into the ventilation ductwork. Several also used radiant-heated floors. Three houses experimented with earth cooling systems by burying cooling pipes around the foundation and under the floor slab during construction.

Selecting materials to comply with the indoor air quality requirements was a major problem for the builders. Exposed particleboard in cabinets and vanities was the major problem, following by flooring, paints, and adhesives. Solutions ranged from using solid wood cabinets to sealing all exposed particleboard with approved sealers to prevent out-gassing of formaldehydes. Floor finishes tended to prefinished hardwoods, ceramic tiles, and natural fibre carpeting. All houses used approved water-based paints and other finishes; none used recycled paint due to uncertainty as to the chemicals it might contain. Several houses used air filtering systems and one experimented with indoor plants as air purifiers. The effect of building materials on indoor air quality is a complex one and requires major additional work.

However, the benefit of eliminating indoor polluting materials is that ventilation becomes occupant-based rather than house-based. 
Seven of the houses use occupancy sensors -- motion detectors or $\mathrm{CO}_{2}$ sensors -- to control ventilation and thus provide an additional benefit of reducing fan energy consumption.

The environmental requirements drew an exciting range of responses. Water consumption is reduced indoors with low-wateruse fixtures and appliances, and reduced outdoors with droughtresistant landscaping and underground watering systems; one even used an old-fashioned rain barrel. Four houses used cisterns buried beneath a garage floor. Construction waste management plans made a significant reduction in the 2.5 tonnes of waste that a typical new house sends to landfill. One house reported no construction waste -- it was all recycled or re-used. Another house reported that while it sent 2,500 pounds to the dump, it managed to use over 20,000 pounds of recycled materials, including enough recycled newsprint to create a stack of newspapers six storeys high! Products with recycled content include rubber pavers, recycled gypsum wallboard, shingles and siding from cellulose, roofing from recycled steel, a crushed glass/gravel mix for foundation drainage, carpets made from plastic pop bottles, and many more.

\section{Conclusion}

Canada's Advanced Houses Program has successfully challenged the innovative spirit of the residential construction industry. By encouraging the formation of broad-based teams working with partners throughout with industry, the program has been able to obtain a 5:1 leverage on it federal funding dollars. Many new prototypes came out of their laboratories for field trials, and the commercialization of numerous products has been accelerated. All ten Advanced Houses are predicted to meet or exceed their energy targets. More technical information is needed on the effect of specific building materials on indoor air quality.

Finally, industry awareness and acceptance of the benefits of innovative green technologies is strong, and public response has been high. Several builders of Advanced Houses have added environmental features to all their houses or are offering environmental upgrade packages. Already the technical requirements for the R-2000 Program have been upgraded to reflect both the energy efficiency and environmental lessons learned in Advanced Houses. 


\title{
THE NIST GREEN BUILDING PROGRAM
}

\author{
James E. Hill \\ Chief, Building Environment Division \\ National Institute of Standards and Technology (NIST) \\ Gaithersburg, MD 20899
}

\begin{abstract}
For over 2 decades, NIST has been involved in energy conservation programs. NIST's current programs broadly span the areas from waste minimization to air, soil, water, indoor air quality, ozone depletion, and global warming. The latest endeavor NIST is undertaking is the "Green Building Program" in which NIST is at the forefront of designing buildings using environmentally safe materials. NIST's program has two components. The laboratorybased activities involve NIST staff working directly with manufacturers and designers to develop technologies conducive to energy efficiency. The second component, demonstration buildings, includes environmentally safe buildings which are monuments to green technologies. These buildings not only demonstrate cost effectiveness and evaluate green technologies, they also identify new technologies needed to develop an effective green building.
\end{abstract}

\section{Introduction}

Green buildings are ones designed, constructed, operated, and demolished to have a minimum impact on the global, neighborhood, and internal environments. Green buildings have long been an interest at NIST and its predecessor organization, the National Bureau of Standards (NBS). Even before the Oil Embargo of 1973, NIST had developed the basic algorithms or calculation techniques for predicting energy transfer in buildings [1]. These techniques are used today in all major energy simulation programs such as DOE-II for designing energy conserving buildings.

After the oil embargo, NIST developed the very first draft of an energy conservation design standard for buildings that was the predecessor of ASHRAE Standard 90, now used in all building regulations across the United States [2].

NIST currently has an extensive group of programs in a wide variety of environmental technologies:

$\begin{array}{ll}- & \text { waste minimization } \\ - & \text { energy conservation } \\ \text { - } & \text { air, soil, and water quality } \\ \text { - } & \text { indoor air quality } \\ \text { - } & \quad \text { ozone depletion and global warming } \\ \text { - } & \text { green building design }\end{array}$


Advances in technology, key to stimulating the nation's economic growth, are critical to solving the nation's environmental issues. According to President William Clinton and Vice President Albert Gore in Technology for America's Economic Growth, A New Direction to Build Economic Strength [3],

"Our most important measure of success will be our ability to make a difference in the lives of American people, to harness technology so that it improves the quality of their lives and the economic strength of our nation. We are moving in a new direction that recognizes the critical role technology must play in stimulating and sustaining the long-term economic growth that creates high-quality jobs and protects the environment."

As the only federal laboratory with the primary mission of helping U.S. industry strengthen its international competitiveness and as the nation's premier measurement laboratory, NIST is ideally poised to help U.S. industry to make the transition to "green" technologies.

\section{Laboratory-Based Activities}

The NIST Green Building Program has two main components: laboratory-based activities and a recently-begun demonstration phase. The laboratory-based activities have been designed to work directly with manufacturers and building designers to help develop technology for enhanced energy efficiency, improved indoor air quality, and replacements for chlorine-based refrigerants.

\section{Improved Energy Efficiency - Thermal Insulation}

NIST research on heat transfer through thermal insulation began in 1910 and in 1912 led to development of the first Guarded Hot Plate apparatus for precise measurement of heat transmission. This device and its successors have provided the basis for calibration of the measurement devices used by industry and regulatory authorities for determining the thermal resistance of insulation. Twenty-five millimeter thick calibration transfer standards were routinely supplied to industrial laboratories for calibration purposes prior to the 1970's. Concerns for energy efficiency after the 1973 Oil Embargo led to routine use of 150 to 450$\mathrm{mm}$ low density insulation in U.S. buildings. In 1978-79, the Federal Trade Commission proposed requiring manufacturers to label their products for thermal resistance at a thickness representative of typical installation. Industry representatives, concerned for the accuracy of labeling, requested that the rule be deferred until their measurement devices could be calibrated with full thickness, low-density insulation calibration transfer standards.

In the late 1960's NIST staff formulated a radical new approach for accurately measuring heat transmission through thermal insulation, a circular line-source Guarded Hot Plate. At industry's and the Federal Trade Commission's request, NIST built a 1-m diameter version of the Guarded Hot Plate capable of full thickness measurements up to $380 \mathrm{~mm}$ to within 1 percent uncertainty and made calibration transfer standards available to industry. 
In 1981, NIST completed the 1-m circular line-source Guarded Hot Plate that met design specifications. NIST subsequently developed two standard reference materials (SRM): a fibrous-glass blanket (SRM-1451) in 1985 and a fumed silica board (SRM-1449, 1459) in 1990. To date, approximately 60 SRMs have been sold and an additional 70 special calibrations have been completed for U.S. industry to support the accurate testing, production, and labeling of thermal insulation.

Advanced insulation products are now being developed and introduced into the U.S. market [4]. Examples of these products are aerogels, powder filled panels, and evacuated panels. These products offer extremely high insulating capabilities. For example, theoretical calculations reveal that an R-value approaching 100 may be achieved in a $25.4 \mathrm{~mm}$ thick evacuated panel.

Unfortunately, current test procedures for measuring thermal conductivity are only applicable to materials which are homogenous, have planar surfaces, and have relatively poor insulating capabilities compared to advanced insulation products. NIST is now developing appropriate measurement techniques to allow an accurate determination of the overall thermal conductance of advanced insulation systems.

A facility for the calorimetric testing of advanced insulation panels has been designed and fabricated. A Cooperative Research and Development Agreement (CRADA) is in place with a compact vacuum insulation manufacturer (Aladdin Industries). The new calorimeter will be tested using different insulation samples of known thermal conductivity. Each insulation sample will be evaluated over a range of mean temperatures and compared to measurements made on the NIST 1-m Guarded Hot Plate. These comparisons will be made to document the accuracy of the calorimeter when used to test homogenous materials. Once complete, the apparatus will be ready to determine the thermal conductivity of the evacuation insulation panels. Other measurement techniques, such as the use of infrared thermography, are also being investigated to determine the thermal conductivity of the evacuated insulation panels.

\section{Large Building Automation Systems}

Over the last 15 years, automatic control systems in buildings have changed from predominately pneumatic control systems to supervisory Energy Management and Control Systems (EMCS) to distributed direct digital control or DDC systems. Recently, the development of local area networks has now made it possible to distribute "intelligence" throughout a building with more of it being placed at both the highest and lowest levels. Centrifugal chillers and package air handling systems are now being manufactured with their own digital controls. In the future, integrated building services which combine EMCS, fire detection, security, data processing, and communications are likely to be increasingly in demand. 
This decade and a half of progress in building controls has been made in spite of the fact that the previous and present generation of EMCS and DDC systems all tend to employ proprietary communication protocols which prevent systems supplied by different manufacturers from communicating with each other. This has resulted in "captive customers" who, upon buying a control system, are unable to upgrade or expand it without going back to the same manufacturer. This lack of communication capability between control systems made by different manufacturers also prevents the building owner from obtaining the most capable building service. It does not allow building owners to choose, regardless of the manufacturer, the best EMCS system, the best digital controllers, the best security system, the best fire detection system, or the best telecommunications system. To do so today would result in incompatible, parallel systems, with redundant wiring and equipment, conflicting control functions, excessive costs, and a nightmare of different maintenance and operating procedures. The solution to the problems lies in the development of standard communication protocols for EMCS and DDC building control.

For the past 7 years, NIST has worked cooperatively with the American Society of Heating, Refrigerating, and Air-Conditioning Engineers (ASHRAE) to develop BACnet, a

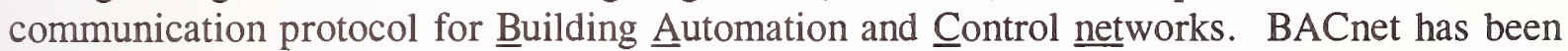
published as a draft ASHRAE standard and has completed its first public review. Several changes have been made to the draft standard as a result of the public review. A revised version of the standard was released in January, 1994 for additional public review. If this second review proceeds smoothly, it is expected that BACnet could be published as an ASHRAE standard in 1994.

The ASHRAE committee developing BACnet is known as the Standards Project Committee (SPC) 135P. The membership of SPC 135P represents a balance of interests between vendors, users, and general interest groups. The current membership of SPC 135P is shown in Table 1. 


\begin{tabular}{||l|c||}
\hline \multicolumn{1}{|c|}{ Voting Members } & Interest Category \\
Andover Controls, Inc. & Producer \\
Cornell University & User \\
Engineering Economics & User \\
Gresham, Smith \& Partners & User \\
Honeywell, Inc. & Producer \\
Johnson Controls, Inc. & Producer \\
The Kling Lindquist Partnership & General Interest \\
Landis \& Gyr Powers, Inc. & Producer \\
National Institute of & General Interest \\
Standards \& Technology & \\
PolarSoft & General Interest \\
Public Works of Canada & User \\
Siebe Environmental Systems & Producer \\
The Trane Company & Producer \\
& \\
\multicolumn{1}{|c||}{ Non-Voting Members } & Interest Category \\
& \\
Delta Controls, Inc. & Producer \\
Energyline Corporation & Producer \\
IBM & User \\
RRH Associates & General Interest \\
Staefa Control Systems, Inc. & Producer \\
\hline
\end{tabular}

A ground swell of pressure from the user community motivated ASHRAE to form a committee to develop the BACnet standard. The pressure from the user community has increased since that time as expectations have been raised by publication of the draft standard. The largest landlord in the world, the United States Government, is also beginning to participate. The General Services Administration is planning to make conformance to BACnet a requirement for control systems purchased by civilian federal government agencies. The Department of Defense is also considering a requirement to use BACnet in military facilities. This kind of consumer interest has been a strong influence on manufacturers of building control systems.

The three largest control system manufacturers in the United States, Honeywell, Johnson Controls, and Landis \& Gyr Powers have all publicly announced their intention to support BACnet in their products. At least 17 other manufacturers have also announced similar plans [5]. The Trane Company has announced that it will sell products which implement an early version of BACnet and provide a free upgrade to the final version of the standard. 
NIST has just organized a consortium to conduct interoperability tests on BACnet implementations. All manufacturers who want to develop a BACnet implementation have been invited to join the consortium and test their implementations. So far, 13 companies have joined NIST consortium: American Auto-Matrix, Andover Controls, Delta Controls, Johnson Controls, Inc., Landis \& Gyr Powers, PolarSoft, Siebe Environmental Controls, Snyder General, Staefa Control System, Inc., the Trane Company, Cornell University, Teletrol Systems, and Orion Analysis Corporation.

There is also international interest in the BACnet protocol. The European Community has formed a standards committee to adopt a standard protocol for Europe. BACnet is one of the leading candidates for adoption as a European standard.

The final answer on the success or failure of BACnet will not be known for some time but, for all of the above reasons, there are grounds for optimism.

\section{Building Envelope Design Methods}

NIST pioneered the development of a wide variety of diagnostic techniques for determining the integrity of building envelopes. They have covered tracer gas techniques for determining the air leakage into and out of buildings and the use of thermographic techniques for measuring the integrity of building envelopes [6-8]. Many have been incorporated into national and international standards.

NIST just completed a design guide for thermal integrity and airtightness of office building walls that incorporates a wide variety of recommendations developed as a result of using the diagnostic techniques in government office buildings [9]. Most recently, NIST has pioneered the development of analysis techniques for moisture migration and accumulation in building walls that destroy their thermal integrity. This has been implemented in the computer program MOIST [10]. MOIST predicts the combined transfer of heat and moisture in building envelopes. The program inputs hourly outdoor weather data and predicts the moisture content and temperature of the construction layers as a function of time of year. The algorithms of the program include moisture transfer by diffusion, convection, and capillary flows. The moisture transfer resistance offered by vapor retarders and paint layers are readily included in simulations $[11,12]$.

NIST is currently experimentally verifying MOIST by comparing a series of laboratory experiments. Twelve $1.2 \mathrm{~m} \mathrm{x} 1.2 \mathrm{~m}$ test walls were installed in the NIST calibrated hot box. Each of the test walls was instrumented to measure the heat transfer rate at the inside surface and the surface moisture content of the construction layers. The exterior surfaces of the test walls were subsequently exposed to simulate steady and time-dependent winter outdoor conditions. The heat transfer rate and the moisture content of the construction layers were measured as a function of time and compared to corresponding values predicted by MOIST. The preliminary agreement between the measurements and computer predictions is good. 
A MOIST user can investigate the effect of various parameters on moisture movement and accumulation within the building envelope. These parameters include climate, building materials, the use and placement of vapor retarders, and the relative placement of building materials. MOIST's capability to predict the moisture accumulation within each building material as a function of time allows the user to select the most appropriate building materials and construction for a given climate. This will insure that buildings do not exhibit moisture-related material degradation, thereby lengthening the service life of the materials.

\section{Improved Indoor Air Quality}

NIST has a major research program on building indoor air quality. Its goal is to develop measurement and testing procedures, technical data, and comprehensive computer models to assist building designers and operators to improve indoor air quality in buildings.

The program has two major elements. First, ventilation and building assessment protocols are being developed as tools for use by building operators and indoor air quality investigators. A large part of laboratory and field work has dealt with how air moves into and within large commercial buildings [13-19]. A unique feature of the work in two of the government buildings was the design and implementation of a "diagnostic center," centrally located instrumented facility in the building with the capability of automatically sampling air throughout the building [20].

The second major element of the program is development and application of multi-zone indoor air quality models that predict pollutant levels from sources introduced into buildings from outdoor air, and those generated inside from sources such as indoor combustion processes and furnishings. The modeling of contaminant dispersal has been accomplished by idealizing any building as a collection of well-mixed zones connected together by discrete flow paths. Element assembly techniques have been used where equations describing the discrete elements of the model are assembled into a set of equations approximating the behavior of the system as a whole. The modeling approach has been implemented into a computer program, CONTAM [21].

The CONTAM computer program has been applied to several test cases for the validation purposes. Comparisons between computed results and exact solutions for special cases of single and two-zone buildings and numerical solutions computed by other contaminants dispersal programs have shown excellent agreement. Comparisons between computed results and measured data have also been good. However, the amount of good measured data is limited. 


\section{Alternative Refrigerants}

Chlorofluorocarbons (CFCs) and hydrochlorofluorocarbons (HCFCs) are used as the working fluids in virtually all small and large-scale refrigeration and air-conditioning equipment. But, their chlorine is destroying the earth's stratospheric ozone layer. As a result, U.S. industry is replacing these chemicals as quickly as possible in response to national and international laws and agreements. Two independent, well-coordinated divisions within NIST, the Thermophysics and the Building Environment Divisions, have been focusing on the CFC problem since 1981.

NIST is providing the thermophysical properties and engineering data needed to identify promising alternatives, to retrofit existing equipment, and to design and optimize new equipment for the replacement fluids. The most promising replacements at this time are partially-fluorinated methane and ethane molecules with no chlorine and mixtures of such compounds. Fluorinated propanes, butanes, and ethers are also being investigated.

For the past 10 years, NIST has been involved in measuring selected thermophysical properties of the alternatives including vapor pressure, equation of state, heat capacity, speed of sound, thermal conductivity, and viscosity. NIST has developed models to predict the properties of pure fluids and mixtures, even when little or no data exist. Industrial cycle simulation codes and equipment design programs require such models in machine-readable form. Thus, NIST is providing computer packages for the CFC and HCFC alternatives and their mixtures. The most widely-distributed NIST-produced microcomputer-based predictive package to date is REFPROP [22], which can calculate the thermophysical properties of 38 pure refrigerants and all possible combinations of up to five component mixtures of these refrigerants.

For over 15 years, NIST has been developing the generic engineering data needed to assist refrigeration system designers in the selection of system configurations and hardware components. Many of the new refrigerants have a more complex molecular structure and higher molecular weight than the refrigerants being replaced. To assist the manufacturers, in general, NIST has incorporated the REFPROP data source into its machinery simulation codes and conducted thermodynamic cycle analyses to evaluate various alternative refrigerants and mixtures for the traditional refrigeration cycle with and without specific machinery modifications. The results of these analyses are then verified in a laboratory breadboard system.

In addition to the above generic studies, NIST is currently conducting about six proprietary laboratory studies with various manufacturers of refrigerants and equipment. The focus of these studies is on the specific adaptation of the most promising refrigerant alternatives and the determination of what hardware changes are necessary for energy performance optimization. 


\section{Demonstration Buildings}

Beginning in 1993, Congress directed NIST to begin a national demonstration of green building technologies. Four building projects were selected in 1993 and an additional one was added in 1994. The purpose of these projects is to:

1. demonstrate the environmentally-safe technologies that are currently available and cost-effective to use in specific building applications,

2. evaluate the effectiveness of the technology once in place, and

3. in the course of designing the buildings or building additions, identify the technologies that need development to make an effective green building.

The buildings and their status will be described briefly.

\section{Fish and Wildlife Refuge in Walnut Creek, Iowa}

This green building will be the Visitor's Center to be built on this new 2800 hectare refuge. The design is currently $50 \%$ complete, and construction is scheduled to begin in August, 1994 with occupancy in April, 1996. Enermodal Engineering has done the assessment of green technologies to be incorporated into this building. Technologies include daylighting of large parts of exhibit area, the use of biofuels for space heating, the use of sustainable building materials, the integration of mechanical system with fire protection, water storage, and the generation of electricity from methane at the solid waste landfill. Susan Reilly of Enermodal Engineering has described the results of this predesign study in a separate paper in the conference proceedings.

\section{New England Aquarium Expansion}

The New England Aquarium in the Boston Harbor is being expanded with an $11,000 \mathrm{~m}^{2}$ addition that will more than double the current facility. The project is currently in the preschematic design phase. An architecture engineering consulting firm has just been selected. Attention to date has been given to the nature of the expanded exhibits and exhibit areas prior to the design of the facility. It may be up to five years from today before the facility is completed. 


\section{NIST Advanced Technology Laboratories}

NIST has just embarked on a major 10-year renovation program for the NIST campuses in Gaithersburg, MD and Boulder, CO. As part of that program, NIST will be designing and constructing new Advanced Technology Laboratories on both campuses. The architecture and engineering firm under contract to NIST is now developing the program documents and has been charged with developing a section of Green Buildings criteria to be used in guiding this project.

The Advanced Technology Laboratories are currently in the early schematic design phase. The laboratory building in Gaithersburg is planned to have a floor area of approximately $30,000 \mathrm{~m}^{2}$. The one in Boulder, CO will be approximately half that size. The NIST green building staff is working closely with the architectual/engineering firm of Henningson, Durham, and Richardson, Inc. on these laboratory projects. The major challenge in a facility such as this will be to minimize the energy consumption with mechanical and electrical sysiems that must be designed first and foremost to provide exacting interior environmental conditions conducive for research work at molecular and atomic scales. For example, many of the laboratories require temperature variations at the research work station of less than $0.01^{\circ} \mathrm{C}$. This is expected to require abnormally large amounts of air circulation in the laboratory spaces.

The design of the Gaithersburg laboratory is expected to be completed in April, 1995 with construction completed in June, 1997 and occupancy in early 1999.

\section{Montana State University, Economic Renewal and Technology Transfer}

The grant has just been awarded and no definite plans have been made to date on the building to be built.

\section{Columbia University, Geochemistry Building}

This is to be a new $6000 \mathrm{~m}^{2}$ facility on the campus of the Lamont-Dougherty Earth Observatory along the Hudson River just north of New York City. Comprehensive planning has been completed for this building by the Craxton Collaborative/Ehrenkrantz and Eckstut Architects [23]. Building construction is scheduled for early 1995 with occupancy in mid1997.

The collection of technologies to be incorporated into this facility is impressive. They include fully daylighted laboratories, an absorption chiller plant, desiccant system for latent loads, air-to-air solar preheat for the air delivery system, fumed hood design for all the laboratories with occupancy sensors tied directly to a central energy management system, maximum use of recycled materials and detailed plans for commissioning of the building envelope. The building is estimated to result in 60-70\% energy reduction compared to use of conventional technology in a similar building. The consultants are still examining the 
possibility of coupling of the building to the ground and using wind turbines for additional energy savings.

\section{Summary}

NIST's 20-year old energy conservation programs led the way to the new Green Building Program. With the commencement of the Green Building Program, NIST is emerging as the leader of designing buildings using environmentally safe materials. The two-phase program includes laboratory-based activities, as well as national demonstration projects. These buildings demonstrate green technologies, identify new technologies, and demonstrate the cost-effectiveness of using green materials for construction.

\section{Acknowledgment}

The author expresses gratitude to Janet L. Land for her support and assistance in writing and editing this paper. 


\section{References}

[1] ASHRAE Algorithms

[2] ASHRAE Standard 90

[3] President William J. Clinton and Vice President Albert Gore, Jr., Technology for America's Economic Growth. A New Direction to Build Economic Strength, 1993, Superintendent of Documents, Government Printing Office, Washington, DC.

[4] K.T. Feldman, Jr., "Advanced Insulations for Refrigerated Shipping Containers," ASHRAE Journal, pp 42-46, February, 1993.

[5] "New R\&D Consortium to Test Interoperability of BACnet Products, "Energy User News, Vol. 18, No. 11, November, 1993.

[6] A.K. Persily, et al., "Diagnostic Techniques for Evaluating Office Building Envelopes," ASHRAE Transactions, Vol. 94, Part 2, 1988.

[7] R.A. Grot, et al., "Evaluation of the Thermal Integrity of the Building Envelopes of Eight Federal Office Buildings," NBSIR 85-3147, Gaithersburg, September, 1985.

[8] R.A. Grot, et al., "Measurement Methods for Evaluation of Thermal Integrity of Building Envelopes," NBSIR 82-2605, Gaithersburg, November, 1982.

[9] A.K. Persily, "Envelope Design Guidelines for Federal Office Buildings: Thermal Integrity and Airtightness," NISTIR 4821, March 1993.

[10] D.M. Burch and W.C. Thomas, "MOIST: A PC Program for Predicting Heat and Moisture Transfer in Building Envelopes - Release 2.0," NIST Special Publication 853, Gaithersburg, September, 1993.

[11] D.M. Burch and W.C. Thomas, "An Analysis of Moisture Accumulation in a Wood Frame Wall Subjected to Winter Climate," NISTIR 4674, Gaithersburg, October, 1991.

[12] D.M. Burch, "An Analysis of Moisture Accumulation in Walls Subjected to Hot and Humid Climates, " ASHRAE Transactions, Vol. 99, Part 2, 1993.

[13] A.K. Persily and W.S. Dols, "The Relation of $\mathrm{CO}_{2}$ Concentration to Office Building Ventilation," Proceedings of the ASTM Symposium on Air Change Rate and Air Tightness in Buildings, Atlanta, April, 1989.

[14] A.K. Persily, "Tracer Gas Techniques for Studying Building Air Exchange," NBS Interagency Report 88-3708, February, 1988. 
[15] A.K. Persily, "Ventilation Rates in Office Buildings," Proceedings of ASHRAE Indoor Air Quality 89, San Diego, April, 1989.

[16] A.K. Persily and W.S. Dols, "Field Measurements of Ventilation and Ventilation Effectiveness in an Office/Library Building," Indoor Air, Vol. 3, pp 229-245, 1991.

[17] A.K. Persily, W.S. Dols, and S.J. Nabinger, "Air Change Effectiveness Measurements in Two Modern Office Buildings," Indoor Air, Vol. 4, pp 40-55, 1994.

[18] A.K. Persily and R.A. Grot, "The Air Tightness of Office Building Envelopes," Proceedings of the ASHRAE Conference on Thermal Performance of Exterior Envelopes of Buildings III, Clearwater Beach, Florida, December, 1985.

[19] R.A. Grot and A.K. Persily, "Environmental Evaluation of the Portland East Federal Office Building - Preoccupancy and Early Occupancy Results," NBS Interagency Report 89-4066, April, 1988.

[20] A.K. Persily, S.W. Dols, and S.J. Nabinger, "Environmental Evaluation of the Federal Records Center in Overland Missouri," NISTIR 4883, August, 1992.

[21] G.N. Walton, "CONTAM93," NISTIR 5385, March, 1994.

[22] J. Gallagher, et al., "NIST Thermodynamic Properties of Refrigerants and Refrigerant Mixtures Database (REFPROP), " Version 4.0 User's Guide, NIST Standard Reference Database 23, Gaithersburg, November, 1993.

[23] Croxton Collaborative/Ehrenkrantz \& Eckstut Architects, "Lamont-Doherty Earth Observatory of Columbia University Planning Report: Master Plan, Green Guidelines and Conceptual Design," New York, January, 1994. 


\title{
The American Institute of Architects \\ Committee on The Environment
}

\author{
Harry T. Gordon, AIA \\ Principal, Burt Hill Kosar Rittelmann Associates \\ Vice Chairman, AIA Committee on the Environment
}

\section{Formation}

In response to growing concerns about the impact of the building industry on the global environment, AlA formed the Committee on The Environment (COTE) in 1990 to increase awareness of the relationship between the designer and the built environment. As one of the fastest growing AIA professional interest areas, the AIA COTE now has 62 state and local components, and about 1,600 members.

\section{Mission}

The mission statement of the AIA Committee on the Environment is:

To Create Sustainable Buildings and Communities by Advancing, Disseminating and Advocating Environmental Knowledge and Values to the Profession, Industry and Public

We have structured our activities around the three processes identified in the mission statement:

Advancement: $\quad$ To promote research, education, and professional development that advances the knowledge and understanding of sustainable design.

Dissemination: To create a model information clearinghouse for disseminating knowledge of sustainable design.

Advocacy: To effect national, regional, and local policies and programs to encourage sustainable design.

\section{Major Accomplishments}

Since its inception, the AIA COTE has successfully undertaken major environmental initiatives, including:

- Development and publication of the Environmental Resource Guide (ERG)

- Development and sponsorship of Building Connections, a series of three videoconferences, with the theme of Linking Economy and Ecology for a New Prosperity. The subjects of the videoconferences were (1) Energy and Resource Efficiencies, (2) Healthy Buildings and Materials, and (3) Sustainable Communities. The videoconferences were seen by over 10,000 people nationwide and the tapes are now available through AIA.

- $\quad$ AIA World Congress - The theme for the international conference was Architecture at the Crossroads: Designing a Sustainable Future. Held in June 1993 in Chicago, IL, the meeting was the first major international meeting to focus on environmental issues since the Earth Summit held in Rio de Janeiro, Brazil, and was attended by over 10,000 people from 80 countries. 
Plenary presentations were made by:

- $\quad$ AIA President, Susan Maxman, FAIA

- $\quad$ UIA President, Olufemi Majedodunmi, Hon. FAIA

- $\quad$ Southern California Edison CEO, John Bryson

- $\quad$ His Royal Highness, The Aga Kahn, Hon. FAIA

- $\quad$ Ontario Hydro Chairman and CEO, Maurice Strong

The culmination of the World Congress was the signing of the Declaration of Interdependence.

During the World Congress, winners of an international Ideas Exploration: $A$ Call for Sustainable Community Solutions, were exhibited. This international competition, sponsored by the AIA and the International Union of Architects (UIA) attracted over 400 entries from 50 countries exploring interdisciplinary solutions to sustainable habitat problems.

- Greening of the White House - the AIA coordinated the efforts of over 100 multi-disciplinary experts to produce a Feasibility Study investigating all opportunities to employ energy saving and environmentally sound technology in all White House facilities and operations (including the Old Executive Office Building). Currently AIA is assisting in the planning of pilot projects to demonstrate the most successful recommendations.

- COTE developed a brochure for building owners, titled, Healthy, Productive Buildings: $A$ Guide to Environmentally Sustainable Architecture. The brochure is available from AIA, and addresses site planning, energy use, indoor environment, materials selection, and recycling/waste management.

- $\quad$ Cote sponsors annual International Symposia on environmental topics, drawing speakers and audience on design and environmental topics. The themes of the symposia are:

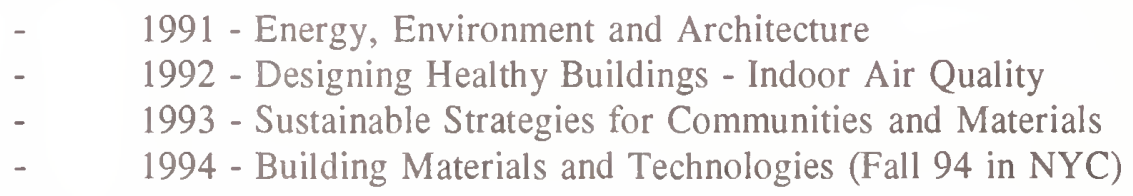

Proceedings of the symposia are available from AIA.

\section{Current Initiatives}

During 1994, the AIA COTE will continue to publish and expand the $E R G$, and complete the following projects:

- At the AIA Annual Convention, held in Los Angeles during May, there will be a series of workshops and presentations addressing environmental topics and a display of energy and environmental design tools.

- $\quad$ Publish a quarterly newsletter for COTE members

- $\quad$ Conduct a roundtable and publish a white paper addressing Incentives for Increasing Energy Efficiency in Building Design (with funding from the Energy Foundation) 
- $\quad$ Publish a white paper describing the Energy Responsive Building Design Process (with funding from Southern California Edison)

- Publish a Glazing Design Handbook detailing energy efficient glazing guidelines (with funding from Southern California Edison)

- Publish an Energy Efficient Products Catalog (with funding from the Energy Foundation through the AIA Association of Collegiate Schools of Architecture Council on Architectural Research)

- Conduct an Energy Design Tools Workshop (with funding from the U.S. Department of Energy, through the AIA Association of Collegiate Schools of Architecture Council on Architectural Research)

\section{AIA Environmental Resource Guide}

With substantial support from the U.S. EPA, AIA is developing and publishing the Environmental Resource Guide, a quarterly subscription service, composed of: Overview of Critical Issues; Case Studies and Special Reports; and Bibliographic Resources and Contacts. The environmental topics addressed in the ERG include:

$\begin{array}{ll}- & \text { Site Design and Land Use } \\ \text { - } & \text { Natural Resources } \\ \text { - } & \text { Energy } \\ \text { - } & \text { Recycling and Waste Management } \\ \text { - } & \text { Building Ecology }\end{array}$

Material reports have been published or are being prepared for 25 major construction materials or building systems, including:

$\begin{array}{lll}\text { Concrete } & \text { Aluminum } & \text { Steel } \\ \text { Steel Framing } & \text { Wood Framing } & \text { Tropical Woods } \\ \text { Plywood } & \text { Particleboard } & \text { Insulation } \\ \text { Sealants } & \text { Glass } & \text { Plaster and Lath } \\ \text { Linoleum } & \text { Vinyl Flooring } & \text { Gypsum Board Systems } \\ \text { Carpet Systems } & \text { Paint } & \text { (8 new materials scheduled for 1994) }\end{array}$

In the preparation of these material reports, AIA has developed an improved Material Life Cycle Assessment (LCA) methodology, which has the following additional characteristics (compared to prior LCA methods):

- $\quad$ Includes Quantitative and Qualitative Information

- $\quad$ Adds "Use Phase" and Transportation issues to LCA

- Identifies energy savings benefits of materials

AIA has an LCA Methodology Report in preparation, which will be available to ASTM and others working in the life cycle assessment area. 


\title{
THE U.S. GREEN BUILDING COUNCIL'S \\ INITIATIVES TO IMPROVE THE ENERGY AND ENVIRONMENTAL EFFICIENCY OF THE "WHOLE BUILDING ENVIRONMENT"
}

Presentation by:

\author{
Michael Italiano, General Counsel \\ NIST/USGBC Green Building Conference \\ February 1994
}

I trust everyone can hear me here with the mobile microphone. This is about as high-tech as I'll get for a lawyer.

What I'll cover are the programs of the U.S. Green Building Council and the Council's decisionmaking process on national policy issues relating to Green Buildings.

Last week I was in New York City talking about green buildings before the HOK Architectural firm, the 5th largest in the country, and their sustainable development committee; it was a very enlightening experience. Architects, by nature, are exciting, innovative, idealistic, with a strong commitment to green buildings. It was a very productive meeting, and I left with a sense of enthusiasm. Unfortunately, the next day I had to speak before the Annual Meeting of the Bar Association on the same topic in front of 150 lawyers. It was quite a different experience.

The first question by a lawyer was, I believe, four minutes in length and most everyone had no idea what the question was when he was done; my answer was simply "no"! I couldn't imagine if the 400 people or so here today were all lawyers! It's good to be before the Architectural Building community.

\section{Introduction and Overview}

An important question we need to ask is "Why are we here today?" I think we are here because there is a strong public demand for environmental and energy efficiency in the built environment. According to EPA for at least the past three or four years, there has been one hundred twenty billion dollars annually spent on the environment. This is being done because there are some 30 federal statutes relating to environmental protection. On average there are about 10 separate statutes at every state level. This legislation has taken since the 1970's to accumulate. They have been enacted because of strong public demand for environmental protection. Public opinion polls have shown for the last five years that support for environmental protection exceeds $90 \%$. It is a very popular national commitment. There are no more debates over whether we need to stop pollution. Those have long gone, and this is being recognized by the building community.

The Council receives daily requests for environmental information on products from the national media and consumer groups. What do we do until standards and criteria are developed? That is the difficult question. I think those that objectively respond to the public's increasing demand for 
green information will profit and flourish. Those that do not, I think, will become obsolete.

The council believes that the best way to respond to this strong public demand is through, timely, valid, and consensus decision-making.

\section{What Is The Green Building Council?}

The Council is the only non-profit, balanced, consensus coalition in the Building Industry working to improve environmental and energy efficiency of the "whole building environment." What do we mean by that? We mean site development, the things that go into planning for buildings, wastewater treatment, water use, construction design, planning and operation of the building, and the use of building materials. What's the life cycle history of those materials? What is the effect on indoor air? What happens to the building when the design life is exceeded? Is it renovated? Is it destroyed? What happens to construction debris? Most of these waste materials in a building go to landfills. This is the "whole building environment." The council takes that view of the whole building environment and has as members the major groups involved in the building industry: building products manufacturers, environmental groups, building owners and operators, managers, contractors, architects and engineers, government, utilities, real estate firms, professional societies, and universities. The important part of this membership is that it is a consensus process, weighted by the Council bylaws so the voting is balanced, and each group has specific voting rights. The Council's priority is to initiate, develop, and accelerate the implementation of green building policies, programs, technologies, and standards on a national basis.

The Council structure is fairly simple. We have officers and committees, but the true decisionmaking function is with the Policy Board where there is weighted voting of all the represented members.

\section{What Is A Green Building?}

What do we mean by a green building? Essentially they are structures that are designed, renovated, constructed, operated and demolished in an environmentally and energy efficient manner. Green building concepts include energy efficiency and conservation, air quality, including indoor air quality, resources and materials efficiency, environmental performance, and improved environmental quality in the air, water, and on the land.

\section{U.S. Green Building Council Accomplishments}

Some of the programs that have been initiated by the Council include: (1) the ASTM standard practice on green buildings which was approved in the initial subcommittee ballot; all the negatives were resolved yesterday; (2) we have initiated life cycle assessment standards in ASTM for building material manufacturers; (3) working with ASTM we have obtained a grant for accelerated life cycle standards development on a national basis; (4) we have completed, through EPA, and Public Technology, Inc. which is the research arm of local government, The Sustainable Building Guidebook; (5) we have established a working relationship with over 17 
federal agencies; we think its very important that they participate and be involved; (6) the Council has also initiated a green building residential standard yesterday at our subcommittee meeting under the lead of The Alliance to Save Energy; (7) we have initiated a green building benefits study; (8) we testified before EPA on environmentally preferable product guidance. This guidance will have a major impact, not only in the building industry, but on all manufactured products in the United States; (9) we have worked with EPA and provided a suggested voluntary indoor air partnership program comparable to Green Lights. EPA is convening an initial meeting and we will be there with them next Tuesday; and (10) we have also initiated a Green Building Fund that will be run by the Chief Executive Officer of Herman Miller, Inc. and CEO's of all our entities, similarly to the high priority given to green buildings and the environment by the White House project. Establishing a top corporate level commitment is extremely important and one of the recognized principles defined under pollution prevention standards.

\section{ASTM Green Building Standard Practice}

Let me take a minute and talk about the ASTM green building standards. Their purpose is to provide a framework for design, construction, operation and demolition of commercial buildings. The strategy is important. The commercial standard incorporates key components of green buildings in the architectural plans and work documents, and will be incorporated into building codes.

To those of you who are not familiar with ASTM standards they have been under development since 1898. ASTM is an open, democratic process and has a long history in the building industry. The building we are in today probably has 50 or so ASTM standards, ranging from the tensile strength of steel, compaction of concrete, hardness of back fill, and specifications for PVC pipe. The building industry has developed over 600 ASTM standards and incorporated them into the building codes through a consensus mechanism.

Some of the important considerations for green building standards relate to both the building site and the building. For the site we have considerations for water conservation, such as xeriscaping. Conservation of water is important in reducing runoff, recharging aquifers, and reducing erosion. We have suggested requirements for wastewater treatment. It is important to minimize the generation of wastewater, especially in new construction. Loadings of wastewater into our coastal and estuarine waters are one of the primary causes of coastal water quality degradation. We have requirements for the site for energy efficient outside lighting. We also have water efficiency standards inside the building that comply with the Energy Policy Act. Water conservation in the building is extremely important because it increases the efficiency of wastewater treatment. The less wastewater you generate the better the systems perform, the more removal. We also have about 30 indoor air quality practices for building owners and managers.

Significantly, yesterday the Subcommittee voted to eliminate smoking from commercial buildings consistent with EPA's definition of secondary smoke as a class A carcinogen. The building standard also covers energy efficiency, utility rebate programs, and reducing plug loads 
which is the accumulation of electrical use inside the building.

\section{ASTM Life Cycle Assessment Standards}

The Council has also initiated on a unanimous basis life cycle standards in ASTM by determining what are consensus good commercial practices for building product manufacturers. The standards cover the whole building, the product including its life cycle history, and the environmental and energy impacts with the ultimate goal of identifying what is environmentally preferable. It is based on existing consensus developed through EPA and Society of

Environmental Toxicology and Chemistry (SETAC) reports. Dr. Jim Tshudy who is the head of Armstrong World Industries Environmental Product Innovation Center, chairs this ASTM effort. There are a number of standards being developed, including an overall "guide" for what should be life cycle assessments by corporations, a "practice" defining the corporate inventory process, and "practices" defining how you conduct "impact assessment" and "lifecycle improvement". The standards define assumptions, how you deal with uncertainties in data, and how you make judgments. We need to separate out those judgments. What is a political judgment? What is something that is technically-based? The improvement standard, obviously, is the most important. How do companies change their manufacturing process to improve the overall environmental and energy efficiency "life cycle", of those products?

This is a schematic that identifies the continuous improvement process in life cycle evaluation. Let's take a quick example for any building product. What we are looking at is a whole history of that product, ranging from resource extraction, mining, environmental and energy impacts, including transportation from the mine to the manufacturing facility. What are the impacts there? What are the releases to the environment? What is the energy use in that facility? What are the impacts in transportation to the market place and to the building? What are the impacts at the impacts at the building? What then is the overall fate of those products? Where do they end up? In looking at that overall life cycle approach we believe that this is the most objective way of defining what is environmentally preferable.

\section{Defining Green Building Benefits}

The Council is also working on green building benefits. This is obviously an extremely important area, and I think that worker productivity and the improved productivity of people in the building is the most important issue facing the building industry. From those Council members that have developed and built green buildings, we know that the productivity gains are tremendous. We are developing a protocol for obtaining benefits data. Then we can go to the investor and constructor of the building and say "This is what you are going to save, these are the benefits." That's essential in order to get green buildings into the mainstream.

\section{Environmental Labelling, Rating Systems, Full Cost Accounting and Taxes on Pollution}

And, then, finally, the Council is looking at emerging issues that we will be debating on March 8 th at the American Institute of Architects. We know that these are issues that need a lot of discussion and objective analysis. Product certification and environmental labeling is obviously 
very important. Do you use life cycle evaluation? You have legal requirements by the Federal Trade Commission and all the Attorney Generals. The law says "These evaluations and claims by companies on what is environmentally preferable have to be based on competent scientific evidence. You have to look at the whole life cycle of the product. You can't just look at one part of it." These are existing legal requirements.

There are a number of rating systems in the United States. We need to evaluate them. They are increasing in use. Do they really give you a good measure of how green that building is? I think we need to be sure of that without slowing down the rating process. Information provided to the consumer must be accurate and competent.

And, finally, the most controversial issue, although one that you will hear more about at the major speech tonight by Paul Hawken and Bill McDonough, in part based on Paul's book Ecology of Commerce, is full life cycle costing, full cost accounting, and the cost of pollution. Paul has recommended in his book that these costs be taxed on the polluting activity and be placed into the economy over a 20 -year period. Obviously, this is very controversial because historically, the United States has not accepted effluent or pollution charges even though they are used in Europe.

A good example of how this might work is with municipal refuse. A number of the communities in the United States and Toronto today place a higher fee on garbage than other communities. They incorporate the costs for groundwater pollution. Most landfills leak in the United States causing cleanup and groundwater monitoring costs. When you take your garbage out, it doesn't take that into account. The 15 or 20 communities in the United States that have increased tipping fees and per bag cost, based on full cost accounting, have found substantially less waste going to landfills.

\section{Conclusion}

That concludes my remarks. As a final premise we need to recognize that we are here today because there is a public demand for these issues to be evaluated, discussed and resolved. Buildings, productivity, energy and environmental efficiency are a huge investment in the country, and we think that a deliberative debate with decisions on a consensus basis in an expedited manner, is going to be very effective. Thank you. 


\title{
LIFE CYCLE ASSESSMENT
}

\author{
Mary Ann Curran \\ Pollution Prevention Research Branch \\ U. S. Environmental Protection Agency \\ 26 W. Martin Luther King Drive \\ Cincinnati, Ohio 45268
}

Abstract. Life-Cycle Assessment (LCA) is a technical, data-based and holistic approach to define and subsequently reduce the environmental burdens

associated with a product, process, or activity by identifying and quantifying energy and material usage and waste discharges, assessing the impact of those wastes on the environment, and evaluating and implementing opportunities to effect environmental improvements. The assessment includes the entire lifecycle of the product, process or activity encompassing extraction and processing of raw materials, manufacturing, transportation and distribution, use/reuse, recycling and final disposal. LCA is a useful tool for evaluating the environmental consequences of a product, process, or activity, however, current applications of LCA have not been performed in consistent or easily understood ways. This inconsistency has caused increased criticism of LCA. The EPA recognized the need to develop an LCA framework which could be used to provide consistent use across the board. Also, additional research is needed to enhance the understanding about the steps in the performance of an LCA and its appropriate usage. This paper will present the research activities of the EPA leading toward the development of an acceptable method for conducting LCA's. This research has resulted in the development of two guidance manuals. The first manual is intended to be a practical guide to conducting and interpreting the life-cycle inventory. A nine-step approach to performing a comprehensive inventory is presented along with the general issues to be addressed. The second manual addresses life-cycle design.

\section{Introduction}

LCA has quickly become a popular topic found at environmental conferences and meetings at an international level. Environmental LCA, which accounts for and evaluates environmental releases and energy use, is a rediscovered concept used to look at a product, process, or activity from cradle to grave. While interest in this approach continues to grow, there remain questions on the methodology and its applicability that must be addressed before LCA is an effective evaluation tool.

\section{What is LCA?}

In August 1990, a model depicting the current state of LCA's was developed during a workshop sponspred by the Society of Environmental Toxicology and Chemistry (SETAC). The model arose from the realization that existing approaches were only inventories of energy usage and pollutant releases. Since that workshop, LCA has been commonly described as a threecomponent process consisting of: 1) an inventory of the inputs and outputs associated with the full life cycle, 2) the translation of these inputs and outputs into environmental impacts, and 3) the identification of opportunities for lessening the total impact on the environment. A complete LCA would 
include conducting all three components.

This model is sometimes referred to as the "3 I's." A fourth "I" which stands for "Initiation" was later added in further discussions among lifecycle experts. Initiation precedes the other three components and includes defining the purpose and the scope of the study. The initiation step is especially promoted within the European community and in Canada. More details are given below.

SETAC has hosted three additional life-cycle workshops on impact analysis, data quality issues, and Code of Practice. For information regarding the proceedings, call the SETAC Foundation at 904/469-9777.

The stages that must be included in a complete 1 ife-cycle assessment are 1) Raw Material Acquisition, 2) Manufacturing (subdivided into Materials Manufacture, Product Fabrication, and Filling/Packaging/Distribution), 3) Use/Reuse/Maintenance, and 4) Recycle/Waste Management. The labels for the stages are flexible. The important consideration is that the study must be comprehensive by accounting for activities from cradle to grave. The goal of a complete, quantitative 1 ife-cycle inventory is to create a mass balance which accounts for all the inputs and outputs to the overall system. Changes made within the system, for example switching to non-toxic solvent, may result in transferring pollutant between media or it may create upstream or downstream effects.

LCA is a useful tool for identifying such tradeoffs, however, current applications of LCA have not been performed in consistent or easily understood ways. This inconsistency has caused increased criticism of LCA. The EPA recognized the need to develop an LCA framework which could be used to provide consistent use across the board. Also, additional research is needed to enhance the understanding about the steps in the performance of an LCA and its appropriate usage. Research activities of the EPA's Pollution Prevention Research Branch in Cincinnati, Ohio, are leading toward the development of an acceptable method for conducting LCA's. This research has resulted in the development of a guidance manual for conducting 1 ife-cycle inventories. ${ }^{2}$ The manual is intended to be a practical guide to conducting and interpreting a life-cycle inventory. The inventory guidance manual presents a nine-step approach to performing a comprehensive life-cycle inventory along with the general issues to be addressed.
1) Define the Purpose
2) Define the System Boundaries
3) Devise a Checklist
4) Conduct a Peer Review
5) Gather Data
6) Develop Stand-Alone Data
7) Construct a Mode1
8) Present the Results
9) Interpret and Communicate the Results

A copy of the manual can be obtained from the EPA's Center for Environmental Research Information (CERI) by calling 513/569-7562 and asking for $E P A / 600 / R-92 / 245$, or a photocopy can be purchased from the National Technical Information Service (NTIS), PB\#93-139681, by calling 703/487-4650. 
Within the life-cycle "community," there is general agreement on the major elements that should be included in a life-cycle inventory. However, decision points occur in the process of accounting for energy and environmental releases which lead to apparent differences in methods. How these decision rules are addressed can greatly affect the outcome of the study.

An example of one of these decision rules can be seen in the allocation of releases among co-products. For example, a typical process results in multiple products. In this example, our process makes $1,0001 \mathrm{~b}$ of product $A$ and $500 \mathrm{lb}$ of Product $\mathrm{B}$. One simple way of allocating the environmental releases from the process among the products is using weight basis. Therefore, two-thirds of the releases would be attributed to $A$ and one-third to Product $B$. However, weight basis is not the only possibility. Allocation could also be done by market share as well as other ways.

Other EPA Life-Cycle Activities

The best understood part of LCA is the inventory process. However, without Impact Analysis, evaluation of the data is limited to a "less is best" approach, i.e., reduce the total releases and energy usage rates as much as possible. EPA's Office of Air Quality Planning and Standards is developing a document which addresses 1 ife-cycle impact assessment (LCIA).

Also, the EPA's Office of Solid Waste is investigating the issue of 1 ife-cycle data quality and needs. They have prepared a draft framework for evaluating LCA data quality and translating this information into a usable format. The framework is still under development.

Life Cycle Design

The purpose of life-cycle design is to promote environmental impact and risk reduction by incorporating the life-cycle concept into the design stage. Together, the EPA's Risk Reduction Laboratory and the University of Michigan produced a framework for life cycle design. ${ }^{3}$ The manual adopts a systemsoriented approach based on the product life cycle. A multilayer matrix is proposed to balance environmental, performance, cost, cultural, and legal requirements. The second phase of this project is underway. AT\&T and AlliedSignal are working with the University to demonstrate two Iife-cycle designs. Lessons learned from the demonstrations will be used to revise the guidance manual.

\section{LCA Applications}

The decision to perform an LCA is usually based on one of several objectives. There is a strong interest by individuals in the private sector to use LCA information to judge the "environmental goodness" of products within categories or base a product labelling program.

Why are manufacturers interested in performing or sponsoring LCA's and methodology refinement? There are many reasons that can be speculated about, although no formal survey has been conducted. For discussion purposes, these 
reasons are listed below from the most localized to the most global, those benefiting society as well as the company bottom line:

- Product improvements ana7ysis (DFE, P2, ZDM);

- Monetary savings by prioritizing investment activities;

- Analytical tool for implementing corporate quality initiatives (TQM);

- Supporting product market claims;

- Responding to competitor claims;

- Developing a broader understanding of product environmental

implications;

- Product stewardship program;

- Multi-national pressures (labelling/recycling).

Direct benefits to the company typically are associated with using LCA as a tool to help implement other strategic programs. These include such activities as Design for the Environment (DFE), Pollution Prevention (P2), and Zero Discharge Manufacturing (ZDM), where a life-cycle inventory can be employed to broadly benchmark a starting point as well as to track progress. In conjunction with cost and finance analysis methods, life-cycle inventory can be used to decide which projects represent the most cost-effective investments. Moving into more external applications, life-cycle inventory is being considered to support, in a factual way, product claims made by a company about their products and to evaluate environmental claims made against a product by a competitor. Finally, companies are motivated to employ LCA because front-end suppliers and downstream users are increasing their inquiries about products wanting defensible information to pass along to their customers and because, at least in Europe, U.S. manufacturers are being required to supply information to support labelling or take-back of their product. More companies are realizing that their operations are only on part of a larger system, and that what seems to be a ready "fix" for them may cause unanticipated effects upstream (on suppliers) or downstream (on consumers). (This is the "one man's ceiling is another man's floor" concept.) Companies are also beginning to accept wider responsibility for their actions as they relate to the environment. LCA offers the necessary information to ensure that local improvements really are global improvements and not just shifting burdens to someone else.

The Future of LCA

EPA will continue its research efforts to develop LCA as a useful tool for industry to use in evaluating and improving products and processes. We will continue to investigate possible approaches to carrying out the impact analysis component, however, this appears to be a much longer-term research area. A more immediate need is to identify the major methodological differences within 7 ife-cycle inventories and begin developing consensus.

Continued research is also needed in the area of "streamlining" since the LCA process can be very time consuming requiring thousands of data points. Streamlining will possibly occur as more assessments are conducted and "blocks" of data become available for future studies. For example, information on the production of commodities, such as polyethylene, are being developed. A somewhat more product-oriented version of this approach is also feasible. A modular data set on a standard cardboard carton of specified dimensions, obtained from a peer-reviewed publication or a quality-assured 
data base, may be plugged into any system where such a carton is used.

A second approach to streamlining may exist in a type of "life-cycle review" where environmental consequences are identified where they occur in any of the life-cycle stages. The occurrences of these releases or impacts can be identified and accounted for through available literature, industryspecific data or through the use of an expert panel. While this approach appears to have merit, especially in product design activities, an exact procedure for performing a life-cycle review which yields verifiable results is yet to be developed.

\section{References:}

1. Society of Environmental Toxicology and Chemistry, "A Technical Framework for Life Cycle Assessments," December 1991.

2. EPA, "Life-Cycle Assessment: Inventory Guidelines and Principles," Risk Reduction Engineering Laboratory, Cincinnati, Ohio (EPA/600/R-92/245).

3. EPA, "Life Cycle Design Manual: Environmental Requirements and the Product System," Risk Reduction Engineering Laboratory, Cincinnati, Ohio (EPA/600/R92/226).

This material has been funded wholly or in part by the United States Environmental Protection Agency under contract 68-C0-0003 to Battelle. It has been subject to peer and administrative review and it has been approved for publication as an EPA document. Mention of trade names or commercial products does not constitute endorsement or recommendation for use. 


\title{
GREENING THE WHITE HOUSE
}

\author{
William D. Browning \\ Dianna Lopez Barnett \\ Green Development Services \\ Rocky Mountain Institute \\ 1739 Snowmass Creek Road \\ Snowmass CO 81644-9199
}

\begin{abstract}
The White House, which recently celebrated its 200th birthday, has had a long tradition of demonstrating technological innovation. In keeping with that tradition, the Clinton Administration has initiated a comprehensive analysis, design, and implementation program to improve the energy and environmental performance of the White House and Old Executive Office Building. The effort, led by an inter-governmental-agency team, consists of six components -- audit, feasibility study, early actions, demonstration spaces, long term initiatives, and technology transfer/outreach. Some of these components have been completed and others are being implemented to improve energy and water efficiency, make appropriate use of renewable energy sources, reduce waste streams, improve indoor air quality, and improve building comfort and performance. All of the measures are to be implemented without disrupting the facility's operations and in a way that respects the historic and security concerns of America's most famous house. This paper provides a general outline of the Greening the White House project.
\end{abstract}

\section{Introduction}

"For as long as I live in the White House, I want Americans to see it as a symbol of clean government, but also a clean environment... We're going to identify what it takes to make the White House a model for efficiency and waste reduction, and then we're going to get the job done."

President William Clinton, Earth Day Address, April 1993

The White House, which celebrated its 200th birthday in 1992, is frequently viewed as an unchanging symbol of America. While the symbolic value remains unchanged, the building itself has actually undergone dramatic changes. The White House is one of a complex of buildings that has constantly evolved to meet the needs of the President, his staff and the American people. The Greening of the White House builds on a long tradition of installing state-of-the-art technologies into the fabric of the White House complex. From the central heating installed during President Van Buren's term, to the water closets, gas lighting, elevators, and air conditioning added later, the White House has frequently been a showcase for innovations. 
The Greening of the White House project was announced as part of President Clinton's Earth Day Address in April of 1993. The Office on Environmental Policy initiated the project with the advice of eighteen environmental and energy organizations. An intergovernmental-agency team led by the Office on Environmental Policy, and the Department of Energy's Federal Energy Management Program was charged with the task of analyzing the energy and environmental performance of the buildings, studying feasible measures to improve performance, and then implementing recommendations for the White House and Old Executive Office Building.

The Greening project is interesting and challenging because of the complex variety of uses in the White House complex. The uses include roughly a half million square feet of office space, a museum with 1.2 million visitors annually, three restaurants (two of which are fast food, one four star), a conference center with several events daily, an 18 acre botanic garden, a bed \& breakfast, and finally a private residence. The White House complex consists of the East and West Wings, Executive Residence, and the Old Executive Office Building. It has four key agencies who manage aspects of the complex -- the General Services Administration, the National Park Service, the Office of Administration, and the Executive Residence staff. There are a number of organizations housed in the complex. It is also the office of the Vice President, and the office and home of the President and his family.

The age of the buildings in the White House complex varies. George Washington laid the corner stone of the White House in 1792. The building was, however, not completed in time for the first President to take occupancy. President John Adams became the first occupant of the house in 1800. The White House was burned to a shell in 1814, and rebuilt in 1815. In 1902, an area that had been greenhouses and stables became a temporary building for the West Wing. It was substantially expanded in a more permanent form in 1909, and underwent a major renovation in 1934. The East Wing was built in 1902 and substantially expanded in 1941. The East Wing expansion was intended to serve partially as a museum; however, the outbreak of World War II caused the area to become offices, a use that continues today. In President Truman's term, the White House was completely gutted down to the original sandstone walls because of structural instabilities, and the interiors were rebuilt between 1948-1952.

The White House Executive Residence is the portion of the complex most people think of when they think of the White House. The first family, of course, lives in the Executive Residence. In addition, the Executive Residence contains the ceremonial spaces used for visits and special events with dignitaries and officials. These are also the primary museum spaces and the location of public tours. In addition, there are several meeting spaces and rooms for special events. Finally, in order to support the operation of the building, there are many service and maintenance spaces. These areas include kitchens, laundries, even a paint shop.

The East Wing which is primarily office spaces, also includes a theater. The West Wing has a combination of uses. The President's Oval Office is located in the West Wing. There are also meeting spaces, offices, the White House media office and the Navy Dining Mess.

The grounds of the White House have many uses and functions. In addition to the wellknown Rose Garden, there is the First Ladies garden, which also serves as an organic kitchen garden for the Executive Residence. Several President's have planted trees on the grounds during their terms of office. The oldest of the existing trees was planted by President Jackson. There are also tennis courts, a swimming pool, a running track, and maintenance facilities, all screened from public view. 
The Old Executive Office Building is the former home of the departments of War, Navy and State. Begun in 1871 and completed in 1888, it is the largest granite building in the world. Built during a period of great concern about fires, the building fabric is predominantly stone, with cast iron architectural detailing, both inside and out. The only wood in the original construction are the doors, mahogany window frames, handrails, and office floors. The building has two large internal courtyards and was originally designed to use daylighting and passive cooling to the extent possible then.

Any measures chosen to improve the energy and environmental performance of the White House complex must respect the historic fabric and symbolic nature of the buildings, as well as meet the Secret Service's security concerns.

\section{Energy and Environmental Audits}

In June and July of 1993, the Inter-Governmental-Agency Team conducted comprehensive audits of the energy and environmental performance of the White House complex. The energy audit team, led by the Department of Energy, included Lawrence Berkeley Laboratories, the National Renewable Energy Laboratory, and Rocky Mountain Institute (serving both as a technical advisor and as the American Institute of Architects' public liaison). The environmental audit team, led by the Environmental Protection Agency, included the General Services Administration, District of Columbia, and the Institute for Environmental Auditing. The audit process conducted detailed reviews of records and billing, research on building histories, and investigation of site conditions.

The energy audit team gathered sufficient information on current energy and water use to assess the opportunities for efficient use of these resources. The audit team determined the different types of energy supplying the complex, collected billing information, interviewed facilities management staff, and inspected the site. The audit analysis and recommendations focused on readily-achievable, cost-effective, innovative techniques that could be transferred from the White House to other buildings. The energy audit studied the main types of energy end-use, including the building shell or "envelope", lighting, plug load and heating, ventilating and cooling (HVAC), walls, roof, windows, and doors, that buffer the interior living and working areas from outside temperature extremes and weather. Plug load refers to all items that are plugged into the electrical system, from office equipment to refrigerators. Kitchen use of energy was addressed separately. The energy team also studied the efficient use of water resources. The opportunities for reducing energy loads, including improving the building envelope, were addressed before assessing the mechanical system requirements or other means of meeting these energy loads. This was done because increased lighting efficiency and smaller plug loads would allow the building to use smaller more cost effective HVAC systems, and would increase the potential for cost-effective use of solar and renewables.

The in-depth audit conducted by the EPA examined the overall environmental performance of the White House complex. The audit examined the complex's compliance with various federal and local environmental acts and regulations. Opportunities for pollution prevention were also investigated. Materials flows, waste streams, and purchasing patterns were studied, and procedures for conducting White House events were analyzed. A review of the management systems examined the decision making process and chains of command. The audit also recommended several areas for potential retrofits. 
An audit report detailing the results of both audits was turned over to the White House complex's facilities staff. The audit information was also used in the subsequent feasibility study.

\section{AIA Feasibility Study}

One of the most unique aspects of the Greening of the White House was the Feasibility Study, sponsored by the American Institute of Architects. In particular, its process for encouraging interaction among design professionals and holistic design significantly contributed to the success of the project. In July 1993, a comprehensive study of energy and environmental measures for the White House complex was organized by the American Institute of Architects, and was partially funded by the Corporate Conservation Council of the National Wildlife Federation. Over ninety participants came together for this weekend feasibility study in Washington DC. What emerged from this gathering was a model design process and a report of the experts' recommendations that will lead to an integrated design to improve the White House's efficiency, performance, and environmental responsiveness.

The participants in the feasibility study were all recognized experts within their respective fields, and were selected because they could contribute a unique approach to the study. These experts were also charged to look outside their own fields of expertise and to examine everything about the project with an eye towards possible interactions and interdisciplinary solutions. Each of these experts was assigned to one of twelve teams to address the challenges and opportunities presented by the White House. The topic areas included: building envelope \& glazings, lighting, plug loads/equipment, heating \& cooling, materials/finishes/fixtures/furnishings, indoor air quality, water, grounds/landscaping, operations/maintenance, procurement, materials/recycling, and cultural change/human factors.

Teams were directed to work closely with other teams where the problems or solutions identified by one would affect another. The teams were grouped into four main categories: energy, building ecology, water and landscaping, and materials streams. Further interaction among these groupings was encouraged by several individuals who "floated" from team to team. As the three day workshop gathered steam, the individual participants all quickly realized the value of understanding the issues evolving in other groups, and how the recommendations their teams made affected all the other teams. The entire group met periodically to convey findings to all the participants.

Following the weekend, a Feasibility Study Report was written by the participants of the study and turned over to the Office of Environmental Policy. This report contains recommendations for:

- Improving the performance of the White House and Old Executive Office building

- Capturing energy and resource efficiency opportunities

- Improving the building ecology and

- Improving the relationship to the outdoor environment.

The recommendations had to emphasize cost-effectiveness and produce the best performance using "state-of-the-shelf" technologies.

The recommendations for improving energy efficiency focus on the building envelope's thermal performance, lighting design, plug loads, space heating, and space cooling systems. As an example of the scope of recommendations the report concluded that, 
improvements in glazing technologies may provide opportunities to improve the envelope's thermal performance, while new lighting technologies can provide superior lighting levels while using much less energy. Office equipment and appliances on the market today have the potential to reduce plug-loads without reducing the level of service. Considering efficiency technologies to address the heat gain from windows, lighting, and then plug loads, can lead to opportunities to downsize cooling capacity. In addition, improvements in the design and sizing of mechanical systems can increase human comfort and productivity while reducing energy use and adverse environmental impacts.

Recommendations for improving the building ecology address materials issues and indoor air quality. The recommendations emphasize using sustainable and environmentally preferable products, materials and techniques, and providing for a healthy indoor environment for the White House.

Recommendations for capturing resource savings and improving the environment focus on the interaction between the buildings and the site. The recommendations recognize the value of efficiency and of cascading, multiple uses for water and energy. They propose restoring a native landscape characteristic of the region.

The recommendations addressing behavioral issues target procurement, operations and maintenance. The recommendations include making changes in the procurement processes, evolving operation and maintenance procedures, and reducing materials streams into and out of the building complex. One theme that emerged from the feasibility study was the issue of the use of the buildings over time, and how that use affects the use of resources like water, energy, materials and air. Another theme was the recognition of the critical importance human behavior will play in establishing change. Understanding the importance of both themes can support technological improvements that will simultaneously provide for a high quality of life for building users and a positive environmental impact.

Many of the opportunities identified in the feasibility study involve an interaction among systems. To ensure an appropriate use of technology, there must be an integrated design and implementation process that includes:

- Implementing a comprehensive planning process

- Addressing environmental issues and improving quality of life

- Monitoring and reducing consumption

- Improving human health in the indoor environment

- Evaluating and improving the process

Many technological initiatives intended to improve the energy efficiency and environmental performance of the White House were identified and recommended. Final decisions about the use of new technologies will follow guidelines suggested by the comprehensive design initiatives. The individual technologies would then be used as tools, and not as the end themselves. They would be chosen because they can best move the buildings toward efficiency and sustainability.

Some of the recommendations from the feasibility study urge the use of demonstrations of technology. Most of the recommended improvements, however, will have little or no impact on the visual appearance of the buildings. The primary, visible change might be improvements in the quality of lighting that will make affected spaces more pleasant and will promote user productivity. In addition, the recommended changes will achieve the greatest long-term value and effectiveness if the people of the White House, from long-term facility maintenance staff to recent political appointees, are involved in the process, are 
supportive of the implemented changes, and are well-informed about how to use and maintain the new technologies.

If the recommendations from the Feasibility Study report were implemented it would result in an environmentally sustainable White House, one that can significantly decrease resource consumption over the long term.

\section{Early Actions}

A number of early actions are already in progress, or will soon be implemented in the White House and Old Executive Office Building. These actions must result in environmental improvements and energy efficiency and meet one of three requirements: they are easily and quickly done, they have no or low cost to implement, and they are required for regulatory compliance. The categories for these actions include: lighting retrofits, water efficiency measures, installation of energy-efficient appliances, and measures to improve the building's thermal performance.

Many specific actions are possible to improve energy or environmental performance. As an example, the windows at the Old Executive Office Building are currently being replaced. Before the Greening of the White House project began, those windows were going to be single-paned windows. Changing the specification from single-paned glazings to double glazings in the retrofit will significantly increase the thermal performance of the building.

Ancther example of the type of early action possible would be the replacement of the refrigerator in the White House with a "Golden Carrot" refrigerator. The term "Golden Carrot" refers to the design competition that resulted in the commercial production of superefficient refrigerators that have been designed to use $25-50 \%$ of the energy used by existing models. In addition, they do not use chlorofluorocarbons (CFCs) in the refrigeration cycle or in the foam insulation. Replacing the White House refrigerators is in line with the call by the Administration's Global Climate Change Action Plan to eliminate CFCs and reduce energy use.

The process of implementing the early actions has begun. The changes made are, in general, based on the recommendations of the energy audit, the environmental audit, and the feasibility study, although some are being made by staff initiatives.

\section{Demonstration Spaces}

Several spaces within the White House and the Old Executive Office Building were chosen to serve as demonstrations of the possible improvements that would result from a comprehensive energy and environmental retrofit. The designs for the retrofits in these spaces integrate daylighting, efficient systems for lighting and cooling, efficient equipment, improved indoor air quality, the use of environmentally responsive building materials, and in some cases, reemphasizing the original, historic design intent.

The demonstration spaces allow the recommendations for Greening the White House to be tried and evaluated before full scale implementation of the recommendations in the entire complex begins. The scope of these demonstration spaces will allow the complex's tenants and the public to see what is possible and what the Greening project can accomplish. The improvements in these spaces should also serve to increase interest in the project, and act as a catalyst to begin the important changes possible through the Greening project. The type 
of spaces under consideration are office suites, bathrooms, and other spaces that allow for comprehensive demonstrations.

Preliminary design work on the demonstration spaces has been completed by a design team coordinated by the Department of Energy and the American Institute of Architects. Budgeting and scheduling decisions for these spaces are pending. The schedule for construction is likely to link completion of some spaces and "ground-breaking" events for others to activities for Earth Day 1994.

\section{Long Term Initiatives}

Long term initiatives focus on goals rather than specific actions. The importance of the long-term initiatives is to ensure that the measures that can move the White House to sustainability become ingrained and permanent. Many of these goals are aimed at directly involving all the players and users within the White House complex in the Greening project and process. Operations, maintenance, and procurement practices are a few areas in which change can occur through increasing environmental awareness. As an example, the use of low or no-volatile organic compound paints was an issue considered by several of the feasibility study teams. Recommendations were made to phase-in these paints. This is a short-term action that can be implemented quickly in some areas, although there are historical and special usage concerns. If procurement practices are also changed over the long-term, and the maintenance staff and other personnel are educated about the reasons for using these paints, then the search for sustainable designs can become ingrained.

One of the long-term goals is to educate all of the staff to increase their knowledge about the implications of choices and decision processes. To further the idea of the "participatory process" most of the retrofit work is to be done by facilities staff. This will help in many ways. The facilities staff may come to accept the new environmental standards as normal operating procedure. In addition, they will have the opportunity to learn new techniques, enhance their current skills, and understand new technologies through their direct involvement in the design, installation, and operation of the new systems. It is important to note that it is the people who work in the White House complex who are really in a position to identify and make changes, and who are key to the long-term success of the project.

The National Park Service is charged with developing a comprehensive plan to manage and operate the White House complex and the adjacent President's Park. The plan will consider many of the long-term initiatives addressed by the feasibility study, and, when completed, should serve to protect the historic nature of the site while making its operations more sustainable.

\section{Technology Transfer and Outreach}

\section{"I want to make the White House a model for other federal agencies, for state and local governments, for business, and for families in their homes."}

President William Clinton, Earth Day Address, April 1993

Several steps are being initiated to communicate the results of the Greening of the White House Project to the public, and to encourage its replication in federal, state and private buildings. The inter-governmental-agency team will continue to work with National Park Service staff on mechanisms for telling White House visitors about the implementation of measures. The Federal Energy Management Program of the Department of Energy is 
looking at such other sites as San Francisco's Presidio as transfer sites for the process. The AIA is assembling a design tool called, "Workshop in a Box" that can be used to replicate the audit and feasibility study for other buildings. A component of this project will be an interactive CD ROM disk that would allow viewers to "tour" the White House and zoom in on its windows, or lights, or any other interesting feature, and to get explanations of the technology geared to their interest level and education. Communicating the lessons learned from Greening of the White House and transferring the information to the public is crucial to the long term success of the project.

\section{Conclusion}

The White House has, in the past, served as a showcase for events in our country's life. With the Greening of the. White House, it will once again serve as an important symbol, this time as the showcase of environmental responsibility.

The integrated design process that led to the recommendations for Greening the White House is itself an important tool that can easily be employed in considering how to improve the performance of any facility. Interactive design is fostered by assembling all the relevant players in the design field (architects, lighting designers, mechanical engineers, utilities, interior designers, water efficiency experts, etc.) along with on-site managers and the people responsible for the on-going maintenance for the buildings, at the outset of a project, to discuss and design across boundaries. Having all the experts work together can lead to serendipitous discoveries that are often overlooked in a more conventional and linear design process.

The Greening of the White House can potentially decrease the White House's resource consumption by $50 \%$ or more. It also strongly supports the current Administration's leadership role in environmental protection. The Greening of the White House project should create an environmentally sustainable, model White House, and a world-class environmental showcase.

"Before I ask you to do the best you can in your house, I ought to make sure I'm doing the best I can in my house."

President William Clinton, Earth Day Address, April 1993 


\section{Our Future and the Making of Things \\ 16 February 1994}

\section{William McDonough}

Hello, everyone. I think I know about half of the people in this room. I'm very honored to be invited to come and speak with you; the Green Building Council is something of which I am very fond. I remember meeting David Gottfried who was working with the contractor when they built my firm's design for the Environmental Defense Fund offices in Washington. I suppose this is when he got the environmental bug, and started thinking about the issues this meeting is addressing. If so I'd love to take credit for his splendid contributions to the cause since that time. And I would also like to thank everyone, especially David, Mike Italiano, Lynn Simon and the Herman Miller company for their courtesy and sponsorship.

I notice Molly Olson from the President's Council for Sustainable Development is here; this is a signal of how important the issues we're talking about really are. It is a signal of their importance to our country, their importance to our industries, and their importance to our children.

Tonight I'd like to talk to all of you as heroes, as leaders, and as designers. I approach environmental matters from the perspective of design and I'd like to think of all of you as our colleagues in design. So tonight's talk is about design from my perspective. I'd like to talk about design as the first signal of our intentions, because I think a lot of people don't quite realize what design is, and that we are designing all the time.

Thomas Jefferson was a designer. He designed the Declaration of Independence. In designing the Declaration of Independence he was concerned about his seventh generation. We are, literally, Thomas Jefferson's seventh generation. We can remember Kennedy's remark at his first cabinet meeting when he said, "There hasn't been a greater assembly of minds and intellects in the White House since Thomas Jefferson dined alone." If Thomas Jefferson were alive today, given his interests and proclivities, he would be calling for a Declaration of Interdependence. I called for a Declaration of Interdependence in a speech I gave at Jefferson's Rotunda at the University of Virginia about three years ago, and was subsequently picked up by the World Congress of Architects for their 1993 convention. It was very clear to me that this is what he would be doing, given his interests in natural history in human history and social history.

If we look at the history of rights, as Roderick Nash has done, we can see, going back in western culture, the Magna Carta in 1215, the rights of white, noble males; we go to the Declaration of Independence and we have white, land-owning males; we have emancipation; we have suffrage; we have the Civil Rights Act; and then in 1973 the Endangered Species Act. The first time in our history that something which is not human is recognized as having the right to exist. There are now discussions about an Endangered Ecosystem Act. We have to respect human rights, and 
we have to respect the rights of nature. I would like to look at how we can design with these rights in mind, in a way that is profitable and propitious for us all.

People who have heard me speak before will forgive me, I hope, but they know I can't resist talking about Emerson and his trip to Europe after his wife died in the 1930's. He went over on a sailboat and returned on a steamship, and remarked upon the return voyage that he missed what he called the "Aeolian kinetic". If we abstract this for effect, he went over on a solar-powered, recyclable vehicle, operated by craftpersons working in the open air practicing ancient arts, and returned in a steel rustbucket putting oil on the water, smoke in the sky, operated by people working in the darkness shoveling fossil fuels into the face of a boiler. Now, these ships are designed objects. Who designed these things? We designed these things. We're still designing steamships. We need what I'm calling "A Boat for Thoreau." I don't know what it looks like either, and it's especially complicated because Thoreau really didn't travel that much. When asked why he didn't travel often, he said, "I have traveled widely in Concord."

In 1936, Emerson was writing a series of essays for Harvard on "Nature." He was trying to discover what is "natural." If human beings are natural, therefore are all things that we make natural? His conclusion was that nature is all those things that are immutable; things that are unchangeable by human intervention, the oceans, the mountains, the leaves. That was then, this is now. We now recognize that we are in a position to mutate the oceans, the mountains, and the leaves. I think Thoreau knew this. So our mindset is now different than at the beginning of the Industrial Revolution. In order to solve these problems we have to reflect on a thought attributed to Albert Einstein: "No problem can be solved by the same consciousness that created it." We are going to require a shifting and changed consciousness, and we must design our solutions based on this new consciousness.

To begin we must take the information we have today and look at each other and every field of human endeavor and adopt an attitude of unconditioned mutual respect. We must say "Negligence starts tomorrow, here we are now, and this is what are we going to do to redesign this." Where do we begin? Can you imagine asking somebody or some organization to design an industrial system for your country that produces four billion pounds of toxic waste and puts them into the air, the soil, and the water every year? Can you imagine designing a system with that as a criteria? This is what we have. We have to redesign almost everything.

Yes, we have to reduce; yes, we have to reuse; and yes, we have to recycle. But first we have to redesign. We have a design emergency, and not enough people who know what to do. Herein lies the major opportunity for the next industrial revolution. You have to be the leaders of this revolution.

As I mentioned we must start the redesign by getting our information on the table. What kind of information are we getting? We're getting information about persistent toxification of a planet. Our industrial system is essentially poisoning the very place in which we live. We're finding endocrine system disruptions: disruptions in reproductive systems documented by scientists. They are seeing that estrogen-like substances, for example, are locking into our reproductive systems and sending mixed signals, or the wrong signals and creating mutations. They're 
finding fish in the Great Lakes that don't reproduce, developing into masculinized females, feminized males, or hermaphrodites. The Danes have reported male sperm counts have dropped $50 \%$ worldwide since 1940 . We're now recognizing that our energy systems and chemicals are creating threats to global climate, et cetera, et cetera.

Well we must take this kind of information, examine its implications, and become serious about developing a vision, while working with this information in a more positive way. I'd like to look at that working design structure. What is the work we need to be doing? A lot of the great work that's going on in the environmental field really has to be looked at as transitional now, because "end of the pipe" philosophy just begins to minimize the damage. This is valuable, but we should really be working toward the vision of a place where we can design effectively within nature, not against nature. So I'd like to look at that.

Fortunately, nature is here as a model and a mentor. We can actually look at nature and see its own design principles and characteristics and use them to guide us. There are three fundamental characteristics of natural design. First, waste equals food. There is no such thing as waste in nature. The concept of waste does not exist. Don't just minimize waste; eliminate the entire concept of waste.

Second, nature does not borrow from the future. It uses current income. I certainly don't know how many of your businesses can work off of capital reserves; I don't know many architects who can. We need to work from current income. Nature works with current solar income, our buildings, our processes have to start to look at how they can work from current solar income and natural energy flows.

Third, nature loves diversity. The characteristic of nature that allows us not to go into complete chaos is this highly complex, interactive, diverse system where no two things are alike, including us.

How do we start to integrate these principals into human designs? I will mention a few processes in a minute and show how we start to look at that, but before I do, I'd like to bring up something important to the conceptual framework of our future and the making of things. This is a new way of looking at products. Because if waste equals food and there is no such thing as waste, then all you have are products. One thing's waste is actually a product, all "things" are seen as products. What kinds of products are we going to have? There are three essential types of products, according to my friend Michael Braungart of the EPEA in Hamburg, Germany. There are consumable, there are service products, and there are unmarketables, unsellables.

A consumer product is something you can literally consume, it's shoe polish, it's toothpaste, it's food, it's natural fibers. It's something that goes back to the soil without persistent toxins, without endocrine disruption, without mutogens, carcinogens, or heavy metals. It's something that becomes soil. We need more of these products. We need to replenish our soil. So consumer products should be literally consumable, and they should be healthy. 
When I came to this country from the Far East the one thing that shocked me the most was that we didn't seem to have people with lives in America any more; we had consumers with lifestyles. I'm always shocked to hear on television the consumers this, the consumers that.

How do you consume a television? One can't consume a television set. We want the service of a television set. It's a service product. It provides astonishing service, but if we look at the thing itself, it's essentially hazardous waste. If I covered up a standard television set here and said I've got this great item but before I tell you what it can do for you, let me tell you what it is and you tell me if you want this in your house. It has 4300 chemicals, it has 9 to 18 grams of highly toxic mercury, it has an explosive glass tube and we think you ought to put it at eye level with children and encourage them to play with it. That's what a television set is.

Now, whose food is this waste? Well, it's the food of the electronics industry. whose food is a chair? It's the food of the furniture industry. These products need to go into closed life cycles. A life cycle has to be considered not as a cradle to grave, which is the typical protocol. The very terminology "cradle to grave" portrays our current misunderstanding of the life cycle concept. It should be "cradle to cradle." That's what we're looking for. We need to change lifecycle protocols, all analyses for life cycle form "cradle to grave" to "cradle to cradle." Otherwise we wind up with life cycle analyses that don't help us, because either they're irrelevant, unfocused or useless as design tools. When industries researched the plastic bag versus the paper bag, they conducted life cycle analyses from either side. The plastic bag people said, well, they're better because when they go into landfills, they take less space; the paper industry said, we're solar driver fiber, and how do you evaluate and compare carcinogenic health risks from dioxins with petrochemicals anyway? Talk about cradle to grave analysis! Have we answered the "consumer's" question "which is better?" yet? The answer is you don't need either of them. You use a string bag, you design something that is reuseable, or truly compostable without danger.

We should be using life cycle analysis as a design tool. We need to develop an industrial system that designs products that go back into a closed loop. When you finish with your TV you should take it back to the store where you bought it and say, "thanks for the service." We have to design for disassembly. Paul tells me when Hewlett Packard designed for disassembly, their original product assembly times improved dramatically. If ninety-three percent of the resources we use to make things is "waste" then only seven percent ends up in the products. So our system is 93 percent inefficient. As Amory Lovins points out, "Any system that doesn't use feedback is stupid."

Unsellables are things that are poisonous, that we can't recycle, we can't reuse. These include heavy metals, toxins, mutagens, carcinogens, radioactive waste. These things should be stored, not made, until we figure out what to do with them. Why would you make a product no one would buy? That should be the question.

So what do we do now? We should use life cycle and risk assessment as design tools, with "knock out" criteria when danger is found, not as simple palliatives. We need real design criteria. We see the piastics industry recycling plastics into park benches, which is good news for the homeless, but bad news for the rest of us, because this is essentially what is known as 
downcycling. We're taking these products and reducing them to their lowest common denominator. They have unknown effects in fire. We start to see them in famous "green" buildings as countertops, which are used basically to apologize for disposability. The percentages of recycling are not high enough in many cases. We need to look at new materials that can be infinitely recycled and studied very carefully for their chemical composition and environmental impacts.

We're working with a fabric design company to design and develop fabrics from compostable fibers with no persistent toxins or bioaccumulatives. One of the first questions we were asked about making environmental fabric was whether we should consider a mix of PET fibers and cotton; a recycled material and a natural material. Nineteen percent of the world's pesticides are going into cotton; it's typically irrigated; and there are also a lot of social and soil problems associated with cotton. So if you combine recycled fibers with a natural fiber, do you have a truly consumable product? No. Do you have service product? No. You've ended up in a hybrid state. So we're designing a compostable fabric with natural fire retardancy. It's proposed composition includes natural and high tech fibers which are all safe in the compost heap. The result is a very high tech fabric that wicks moisture away from your body, keeps you cool, and is completely non-toxic. Completely. Natural indigo is toxic, but the chemical industry has only recently developed an indigo which is safe for humans. This is the kind of thinking and industry that we need to see.

If you look at the standard product, you get what Michael Braungart calls "products plus." You get the product, which is what you want, plus something else you don't want. Take, for example, a nickel. It's currency plus. Michael tells me that twenty to thirty percent of the women in Germany are evidencing nickel allergies; 2 to $3 \%$ of the men. They don't know the reason for the disparity. One thing we know about nickel is that it's an allergen, and a lot of people are sensitive to it. It's also a mutagen. It alters your genes. Nickel was in blue jeans. Companies are taking it out. They got the message, change your jeans, not your genes. So we have to look at this and say, here's a product, but it's a product plus. What you want is the currency. You're getting the currency plus allergies, plus mutated genes. Do we need the pluses? No. Give us the product, not the pluses.

We helped navigate the design of a store for WalMart in Kansas. We worked with the Andersen Corporation and with WalMart to develop a skylighting system which allows natural light into their retail space. We calculated that if large retailers skylit all their stores it would require approximately half a mile of skylights in production per day. That's a new industry. This store's roof is made of wood which comes from sustainable forestry in Virginia and in Oregon from forestry projects which we identified as supporting what Roy Keene calls "a complex and diverse vegetative association dominated by large trees." Another of the problems with current large scale retail projects is after five years they get abandoned. We set up the concept that generic building types should be designed to be converted into housing in the future. We need to take the "embodied energy" and human effort in these generic buildings and design them to be reused in the future. We raised the height of the building's ceilings, and set it up so it could take second floors and include housing in the future. This is something that the WalMart Corporation actually liked when they heard it. We were told that by the design team that we'd lose the whole 
project on this idea, but WalMart's reviewers were intrigued because they didn't know what to do with these dead buildings and this presented a potential real value added.

The question really is, couldn't we be doing these things inside our towns, and use this massive distribution system to better affect making products, things, communities and cities? That's the real question, and here we're looking at the very powerful steamroller of retail circumstances that is affecting massive change. Shouldn't it be interested in looking at the way products themselves are made? Their own people are recognizing what a disaster our packaging systems are because they're now allowing packaging to be removed at the store. They see it, it's there every day, so they have 20 unit recycling separation. They see mounds and mounds of garbage show up every hour. The paybacks from our work were real; for example, there have been significant sales improvements and energy savings attributed to the daylighting.

At the Heinz Family Office and the Rodale Press building we're having fresh air delivered to everyone's breathing zone. The cost turns out to be minimal when you consider the amortized cost in terms of increase in productivity, benefits in health and reduction in owner liability for the building owners. The economics are actually quite astonishing. These are real clients with nuts and bolts companies. WalMart is certainly not known for being a wild spender, and these kinds of interventions are making dollars and sense.

In Chattanooga, we're moving the city to develop zero emissions industrial zones. Zero emissions. Amazing things happen when you start to consider the concept of zero emissions industry. It means that you could have solvents in closed loops, for example. We've been told Dow Chemical in Europe is moving effectively to solvent leasing. They don't sell cheap solvents that would just be evaporated into the atmosphere. They actually sell a high quality solvent service and close their own loops inside the factories. Zero emissions. Pitney Bowes Company has pledged to become a zero discharge company by 1995 . We wish them well and have great hopes...

Zero emissions is a fantastic idea, because it allows business to get on with business within a simple regulatory imperative. It also means you can locate industries next to housing, people can walk to work, people can live next door, because we aren't poisoning things. Once you start to look at zero emissions, you realize that because you have no downstream effect, you have no upstream effect. You start to look upstream to see what other people are doing to you instead of what you're doing to someone else, and it creates a fantastic change in the way we can plan our cities and towns, and it will affect every characteristic of our life and work.

In Pittsburgh, with Carnegie Mellon University, we're exploring the concept of a window factory to produce super efficient windows and weatherization services for the citizens sponsored by the City itself, the banking community, the industrial community, and the local work force. Essentially we're talking about freezing taxes, not people, and using the economic vehicles that are available to a city to actually produce zero emissions plants which recycle the windows of the town into new windows that are highly efficient. The energy efficiency in this system pays for the program, creates local industry, provides local jobs. Essentially we're mining our present 
inefficiencies, so our citizens and our cities stop exporting capital for fossil fuels which creating meaningful employment of all kinds in their own community.

These are just a few examples, and there are people in this room that are obviously major heroes in this kind of work. There are a lot of people here who have been dealing with these types of things for a long time, and the fact that you're all gathered here together, that you're supporting the Green Building Council, is really terrific, and most important. Because we do need to set a vision and an ethic if we are to find a way for human beings to discover their appropriate place in the natural world. Because, unfortunately, the present system of production and design will not allow us to pass on a place that our children deserve.

Thank you. 


\title{
Audubon House
}

\author{
Jan Beyea \\ Chief Scientist \& Vice President \\ National Audubon Society \\ New York, NY
}

Audubon's 100,000 sq. ft. Headquarters renovation in New York City offers an exciting example of green design. It was designed for $60 \%$ energy savings as compared to a code-compliant building calculated over a 3-5 yr. period. Building materials were chosen to reduce impacts to occupants, as well as to reduce upstream and downstream impacts. A goal was set of $80 \%$ diversion of trash to recycling and composting, A high premium was put on good air quality and developing a pleasant work environment.

Lots of information is available on this case study, including 2 videos, a book published by John Wiley, brochures, and magazine articles.

I have been asked to speak from the point of view of the enlightened owner or "client." Even though Audubon is non-profit, our perspective as a client was more traditional than people might anticipate. We wanted to own our headquarters, instead of renting; we wanted to reduce costs; and we wanted to generate interest in the project. We were impressed with the rebate possibilities the local electric utility company was offering. Ironically, we failed to anticipate one of the most compelling reasons for green design, namely improved worker productivity -- a benefit we never expected.

Like other clients we had a number of constraints. We had financial constraints and we had to maintain a corporate image. They led us to make certain threshold choices.

First, a decision was made to renovate, rather than build a new structure. The reasons were partly financial, partly related to our desire to be good environmentalists. The most far-reaching decision we made was to make cost criteria a major factor in our choices of green products. We decided we would act as if we were an enlightened profit making institution-- with a focus on the bottom line. We would try to make decisions that could serve as a model for nonenvironmentalists.

And so our goal became a "competitive" renovation, one that could come in at a market price. We wanted our headquarters to be aesthetically pleasing, functional, and as green as possible, while still meeting financial criteria

Ironically, people can't believe that we worried about costs. This lesson has taught me that, until real profit-making organizations follow our lead, few will believe that green design can be done cost-effectively. But there is a catch. If a profit-making company says it is building "green", who will believe it? 
Perhaps, a partnership between a green organization and a profit-making corporation is the best way to avoid such suspicion. In fact, Audubon is looking for appropriate partners who will work with us to improve the structures they build or renovate. We think this cooperative approach will be persuasive to the many who lack an understanding of the potential that green buildings have to bring financial returns in reduced energy costs and benefits to employees.

To return to the story of Audubon House: After looking at lots of possible buildings for our renovation, we found one that had been neglected for decades, but had a rich architectural history.

The next steps were to choose an architect and then an engineering firm. Audubon's CEO, Peter A.A. Berle, conducted a number of interviews, finding that most candidates had no idea of what it might mean to build green. The Croxton Collaborative, on the other hand, had an intriguing vision and got the job to direct the renovation.

If you analyze the words I use to describe the building, you will realize that the Croxton firm was able to inspire the client with its philosophy of integrated, off-the-shelf design.

Flack and Kurtz had the right engineering background, and agreed to participate, even though this was a relatively small job for them.

Specifications were written by the Architect, designer and engineers, and the job was put out to competitive bid. Once the winning bid was accepted, the team was broadened to include the contractor.

Obviously, green design is going to require a team. Normally, building professionals keep to their own separate domain, which blocks the opportunity to find synergisms between lighting, interior design, energy, and air quality. To get our professionals to work synergistically, we found it helpful to bring the members together early and constantly repeat our goals as the client.

We like to think we built a holistic, completely integrated team. Led by the Croxton firm, the group involved architects, interior designers, engineers, environmental consultants, a recycling expert, a project manager, and an owner's representative.

Holistic design to the team meant attention to a number of factors:

In Energy, we considered both fuel source and energy efficiency options, choosing:

o natural gas as both a heating and cooling source

o a high efficiency gas heater/chiller

o high insulation in walls and roof

o heat mirror windows

o efficient use of outside light (daylighting)

o task lighting with high efficiency fixtures to minimize energy waste

o motion sensors to control lights 
We examined materials for

o toxic components

o impacts during manufacture

o impacts upon ultimate disposal

and narrowed down our choices to

- use of natural materials for rugs and padding, when it made practical sense.

o domestic hardwoods and rain-forest woods approved by the Rain-Forest Alliance.

\section{When it came to indoor air quality, we chose to}

- eliminate glues and adhesives, unless absolutely necessary

o use paints with no VOCs

o minimize formaldehyde (formaldehyde served as our "indicator" chemical)

o bring in significantly more outside air

o install extra air filtering

o locate input air ducts away from pollution sources

o design ducts to minimize bacterial growth

We also considered other employee comfort measures

o making maximal use of natural light

o reducing lighting glare

o using solid state ballasts to reduce light flicker

0 installing operable windows

As for recycling and source reduction, we chose to

o "Reuse" the building by choosing to renovate, rather than build a new structure.

o Recycle removed steel \& concrete

o make use of recycled content in building materials

o require multiple separations of trash for recycling

0 install recycling chutes to give us flexibility for the future

o design for in-building composting (which has not yet been installed)

o install water-saving devices

When it came to cost, we

o set environmental priorities to help maximize our environmental return within cost guidelines.

o used some of the dollar savings projected from energy measures to offset other green costs 
All in all, holistic design meant an integrated attention to hundreds of details not usually part of the design process.

The team effort went pretty smoothly, although pitched battles developed over some issues. Green design raised new tensions that needed to be resolved by the team or as a last resort by the owner. For example, the architect \& designer continuously identified new technologies and products that became available after the specifications had been bid. To bring some discipline to the process, the team established a $10 \%$ excess cost threshold that had to be met before modifications to the design would even be considered.

Subcontractors were initially resistant to the special requirements contained in the specifications and kept presenting substitutes that would have saved them money and with which they were familiar. After holding a wine and cheese party at which the goals of the project were explained, the atmosphere brightened. Although subcontractors still put substitutes forward, they had learned that the substitutes had to meet environmental performance goals.

The end result was a renovation that came in at market rates for New York City: \$120/sq foot. We did learn, however, that City regulations required additional expenses. The cost of strengthening the street in front of our building raised the total cost to about $\$ 140 /$ sq foot.

Over all, there was only a few percentage point increase in first cost. To keep first cost down, some of the traditional glitz that would go into a renovation was dropped and more resources were put into items that couldn't be seen, like devices and products to provide better indoor air quality.

So far, the building has been a splendid success. It looks great. Employees and visitors love it. Our extraordinary efforts to eliminate volatile organic compounds (VOCs) have contributed to the feelings of well-being that the building generates. I first realized we were successful in this regard, 2 months before we moved in. Workers were painting and laying the rug, when I suddenly noticed that couldn't smell anything, even in the midst of construction. A few days later I came back to the site and was furious to detect a single odor. "What is that smell?" I demanded. It turned out to be coming from adhesive for bathroom tiles, which although the lowest emitter we could find in its class, was still noticeably out-gassing.

We are learning that the luxury of a healthy environment makes one very sensitive to odors. Employees become conscious of smells and irritations previously ignored. It's much like the U.S. experience with smoking, which people no longer tolerate as willingly as they did when it was allowed everywhere.

To me the most important lesson of Audubon House is that Homo Sapiens doesn't need to tolerate an indoor environment filled with toxic chemicals.

It's great to work in a green building. In our former offices, I would feel tired at the end of every day, a fact I attributed to my advancing age. Fortunately, that was not the reason. In our renovated headquarters, I feel just as productive at the end of the day, as I did at the beginning. 
A combination of factors may be involved: low background lighting, which cuts glare, elimination of 60 cycle flicker in lights, elimination of odorous chemicals, higher than normal exchange with outside air, higher than normal internal air changes, and higher filtration. We do not have the data to disentangle the relative contributions to the improved workplace quality.

Although it is too early to tell by examining employee records, my own personal increase in productivity is notable and the phenomenon is confirmed by ample anecdotes from other employees.

As one begins to play with the numbers it begins to look like productivity increases are going to be the prime economic driver for green buildings, not the promise of energy savings. We may see engineers recommending solid state ballasts primarily to cut annoying flicker, and recommending more efficient devices, such as fans, primarily to reduce distracting workplace noise.

At Audubon House, recycling is right on target. We expect no trouble in meeting our $80 \%$ diversion goal, as we complete our gradual phase-in of the planned 12-category sort. One important learning is that it is generally more convenient to have one location at the workspace that can hold all recyclables temporarily before they are moved to a centralized location.

As for composting, we have engineers from different disciplines fighting over the wisdom of installing the planned basement composting system. Our (traditionalist) HVAC engineers sent a formal letter expressing their opposition, because the "gases are uncharacterized" and might compromise the high level of indoor air quality. In a rather testy response, I pointed out that there would be more composting going on in the stomachs of our employees. We would be in deep trouble, if the HVAC system couldn't handle that level of gases.

I now have composting engineers talking to HVAC engineers, and am hopeful that the negotiations will be successful. If not, we can fall back on vermicomposting (worm composting).

We have had a difficult time figuring out how to smoothly integrate bicycle riders into the life of the building. It seems that those hardy individuals who like to bike to work do not like traditional hours, making it difficult to provide the level of security we need in New York City for off-hour access to bike-storage locations.

Our gas heater/chiller has worked very well. We have proved that a non-cfc coolant can handle the hottest days in New York City without a problem. Our energy evaluation has just started. However, we recognize that energy savings are probably irrelevant, when compared with the likely savings in worker productivity that we are getting from the improved quality of the environment. 
Some advice based on our learnings:

Recognize that you can't do everything.

Realize that there is limited information on what is really green, so you have to do best you can.

Cut the green design problem down to size by prioritizing.

Learn from trusted environmental sources what are national, regional and local environmental priorities. Focus on the environmental priorities. For example, based on regional concerns with proposed hydropower mega-projects in the Canadian wilderness, we put a high priority on minimizing low electricity use, thereby favoring on-site cooling with natural gas.

Be practical, settle for a $90 \%$ solution, rather than squandering resources to achieve perfection.

Bear in mind that green management is as important as green design.

Once a building is built or renovated, new challenges arise, like finding green methods for cleaning rugs and removal of graffiti.

We have learned that green technologies, like traditional technologies, can be installed incorrectly and must be monitored.

Clearly, there is a need to develop educational strategies appropriate for the green building manager

Where do we go from here?

It is Audubon's goal to get others to copy our lead. We want to work with corporate partners in a visible way to demonstrate that profit-making companies can benefit from green design. As we work with these companies, we will be sure to help them get credit for the work they end up doing. After all, if an improved public image is a motivator for green design, then all of us involved in promoting the philosophy have to develop ways to ensure that green clients receive public attention.

As we and others, try to persuade companies or clients to embrace greener designs, we should emphasize potential productivity improvement. The fact is that we've been poisoning ourselves in our buildings. EPA estimates that $\$ 60$ billion is lost per year from sick building syndrome, which translates to $\$ 600 / y r$. per employee. In fact, there's more at stake here than just, "Sick Building Syndrome." There's a "Tired Building Syndrome," as well, with a total impact that has not yet been estimated. 
Finally, as we promote green design, we will tell all who will listen about the bottom line of our case study: An enlightened client can profit from a green design, if the client picks a good team, gets them together early, sets clear priorities as to what the company is willing to do, gets professional environmental guidance or uses a respected building assessment protocol, makes sure a plan is in place to capitalize from the leadership role being taken, and recognizes that green management is as important as green design.

As we all know, we're living at a critical time for the planet. We have become so technologically powerful that we are altering the entire climate system. Designing and constructing greener buildings is a key response to the challenge of climate change. Of course, we're inventing the rules as we go along, but that's what makes it an exciting time to live.

The green building approach provides a way to help both the environment and the economy. These win-win situations are particularly important in tough economic times. Builders can do the "right thing" environmentally and still save dollars.

We all need to work together to find more enlightened clients and help them to be successful. 
DESIGN AND IMPLEMENTATION OF A SUSTAINABLE UNIVERSITY STUDENT IIVING LABORATORY

\author{
Sharon R. Stine \\ College of Environmental Design \\ California State Polytechnic University \\ 3801 W. Temple Ave. \\ Pomona, CA 91768-4048
}

\begin{abstract}
A major student learning/living facility for the interdisciplinary study of regenerative practices opened January 1, 1994 on the campus of California State Polytechnic University (Cal Poly) in Pomona, California. Rnown as the Center for Regenerative studies, students work, live and learn about regenerative technologies as integral parts of their daily lives. The Center incorporates opportunities to practice and study technologies dealing with energy, water, shelter, food production and waste disposal. The physical order and visible form of the Center's buildings and the landscape are important to its success. The interactive relationship between the physical facilities, and the environment, the technological design and human behavior are all part of the education, demonstration and research purposes of the Center.
\end{abstract}

\title{
Background.
}

Many of the practices that establish the physical and biological support for modern civilization--that provide food and shelter and dispose of waste--were developed during a time when supplies of energy and material seemed unlimited. The result is a technological base that requires immense inputs of energy, water, nutrients and a range of other materials. Regenerative practices are concerned with the means for supporting and nurturing human life within the limits of available renewable resources and without environmental degradation. The technologies are largely small in scale, self-renewing in their basic operation making use of on-site resources, internal recycling, solar energy and biologically based processes and provide immediate feedback to permit human interaction.

There has been a separation of disciplines that makes it difficult to engage in joint exploration of the many potential interactions, for example housing is separated from agriculture and both are separated from waste disposal. The center, as a university-based setting for education, demonstration and research in regenerative technologies, is a multidisciplinary program where activities that traditionally belong to various disciplines are integrated. The academic curriculum is designed to develop broad conceptual understanding along with applied working knowledge of the practices and technologies involved. An undergraduate minor is 
currently offered with joint majors and degree programs under development. These emphasize creative thinking in the use and development of regenerative practices and exploration of their far-reaching social, ethical and economic applications.

\section{The site}

Adjacent to the Cal Poly campus, the Center encompasses a 16 acre site on land previously used for livestock grazing. North of the site just beyond the campus is Interstate 10, eight lanes of thousands of cars burning irreplaceable fuel and increasing pollutants in this smoggiest region in the nation. To the east is Pomona, one of many cities in the most rapid growing area of Southern California known as the Inland Valley. Directly to the south and adjacent to the Center is one of Los Angeles Counties large landfills, a mountain of trash that grows daily until its expected closure within the next five years. To the west are the lands of a local community college and its adjacent 'bedroom' community residents of which commute daily to jobs as far as fifty miles away.

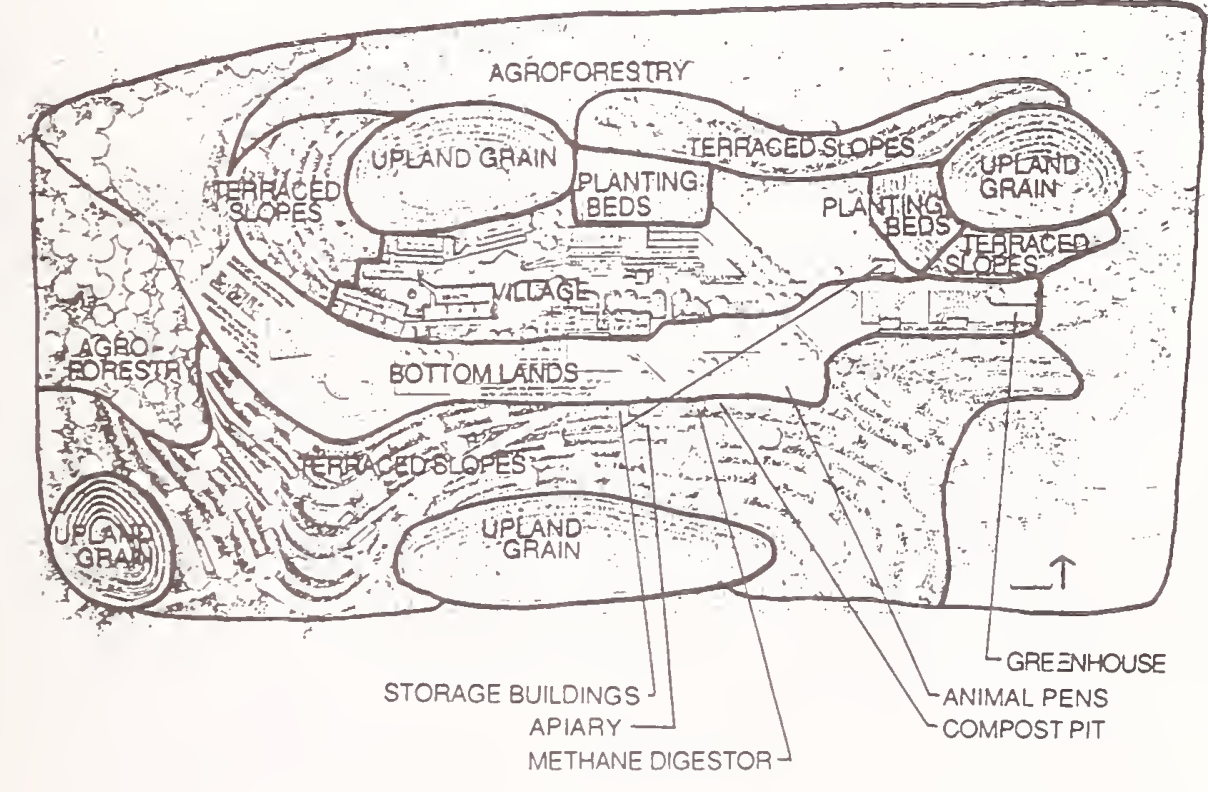

Fig. 1 CERIER FOR REGLIERATIVE LAKD USE

The Center's 16 acres include a narrow valley that runs through its length in the east-west direction and forms a defined spine. Land slopes up to four rounded knolls on its north and south sides. The only drainage received in this valley is from the hills that rise from its edges. These north or south facing slopes are between five and thirty percent grade. Southern California black walnut trees (Juglans californica) are scattered 
on the slopes. Hawks, squirrels, snakes, and rabbits are part of the living systems in this valley.

Wind is usually low in velocity with a typical peak at 12 miles per hour in the afternoon. The prevailing breezes are from the southwest in the summer and northwest in the winter. The average insolation measured during the summer of 1993 was $6.8 \mathrm{kWh} / \mathrm{m} 2 /$ day. Rainfall is typical of this region, dry during spring, summer and fall months with most moisture occurring during January and February and not exceeding 20 inches per year. Many years recordings are less than 10 inches of precipitation. During the summer of 1993 daily high temperatures averaged 30 degrees Celsius while during the winter months low temperatures were recorded at 3 degrees Celsius. Relative humidity recorded during the summer of 1993 averaged 608 .

\section{Village Design}

It is the design of the community village and its landscape that gives visible form to the ecological approach and values of the Regenerative studies program. The Center can be viewed as an ecosystem through which energy, water, nutrients and other

WATER

ENERGY

NUTRIENTS

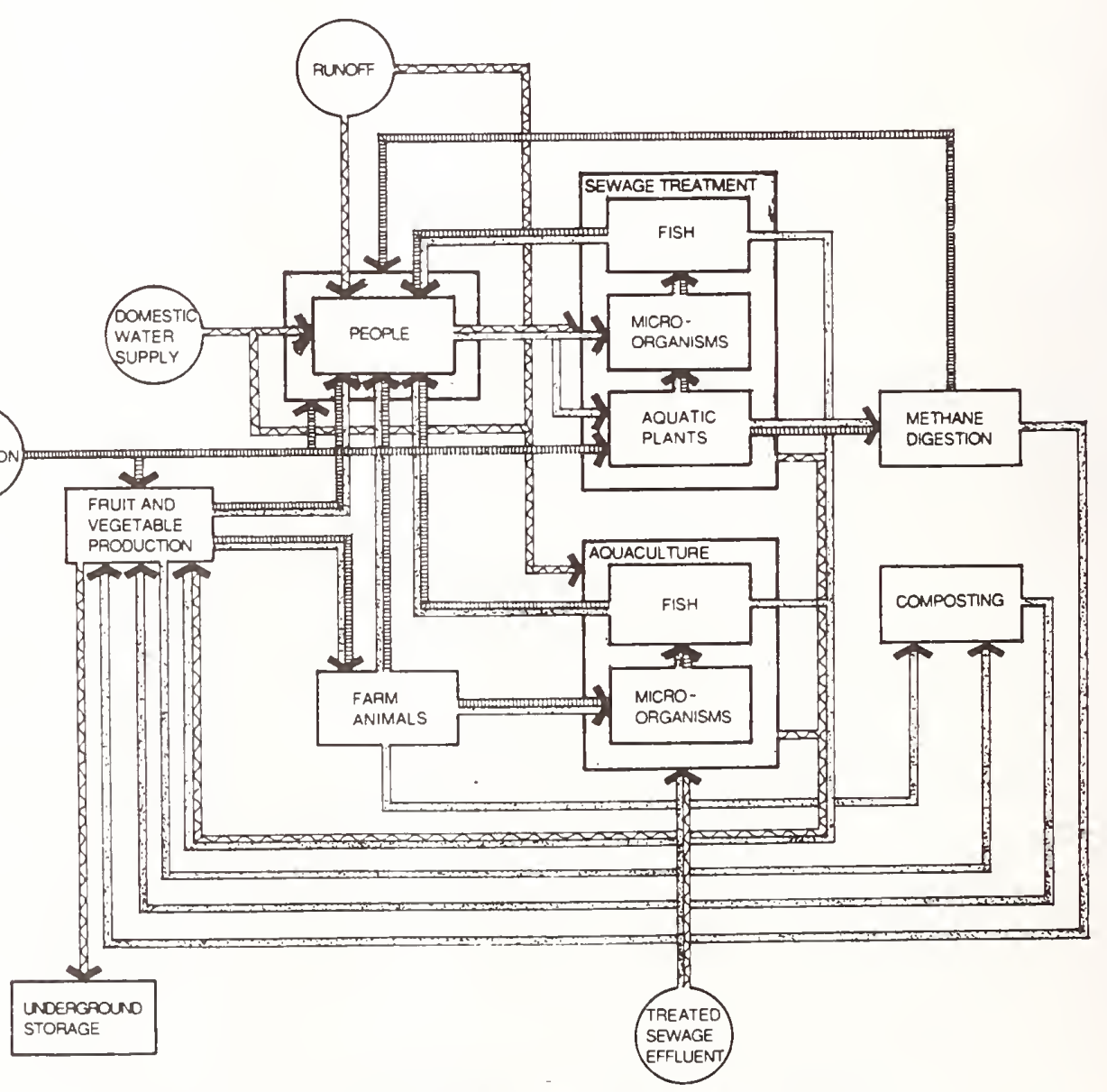

FIg. 2 FLOW OF ENERGI, NUTRIENTS AND WATER 
materials flow in continuous and consistent paths. These flows provide each community member with basic life-support

requirements. The Center's design attempts to make optimum use of energy and materials available on the site and minimize the use of off site imports. It also seeks to provide maximum recycling of water and nutrients. Collecting material in any amounts that might be damaging is avoided.

The Center currently houses the first group of twenty students who represent majors from all six of the University colleges. In this first phase, the village area provides approximately 14,000 square feet of student and faculty housing, kitchen and dining commons area, seminar classrooms and dry laboratory space. In future phases, the village area will eventually include housing for 80 students, visiting faculty and guests, as well as additional classroom areas, administrative and faculty office space, and greenhouse and laboratory facilities.

In addition to sheltering the Center's resident students, three purposes combine in shaping the village form. These include the relationship of the buildings and the land, the optimal use of available solar energy and the reinforcement of social interactions.

\section{Buildings and the Land}

In order to fit the buildings to existing land forms, they are clustered in linear forms that either nestle into the hillside or edge the aquaculture ponds. Overall, the design attempts to

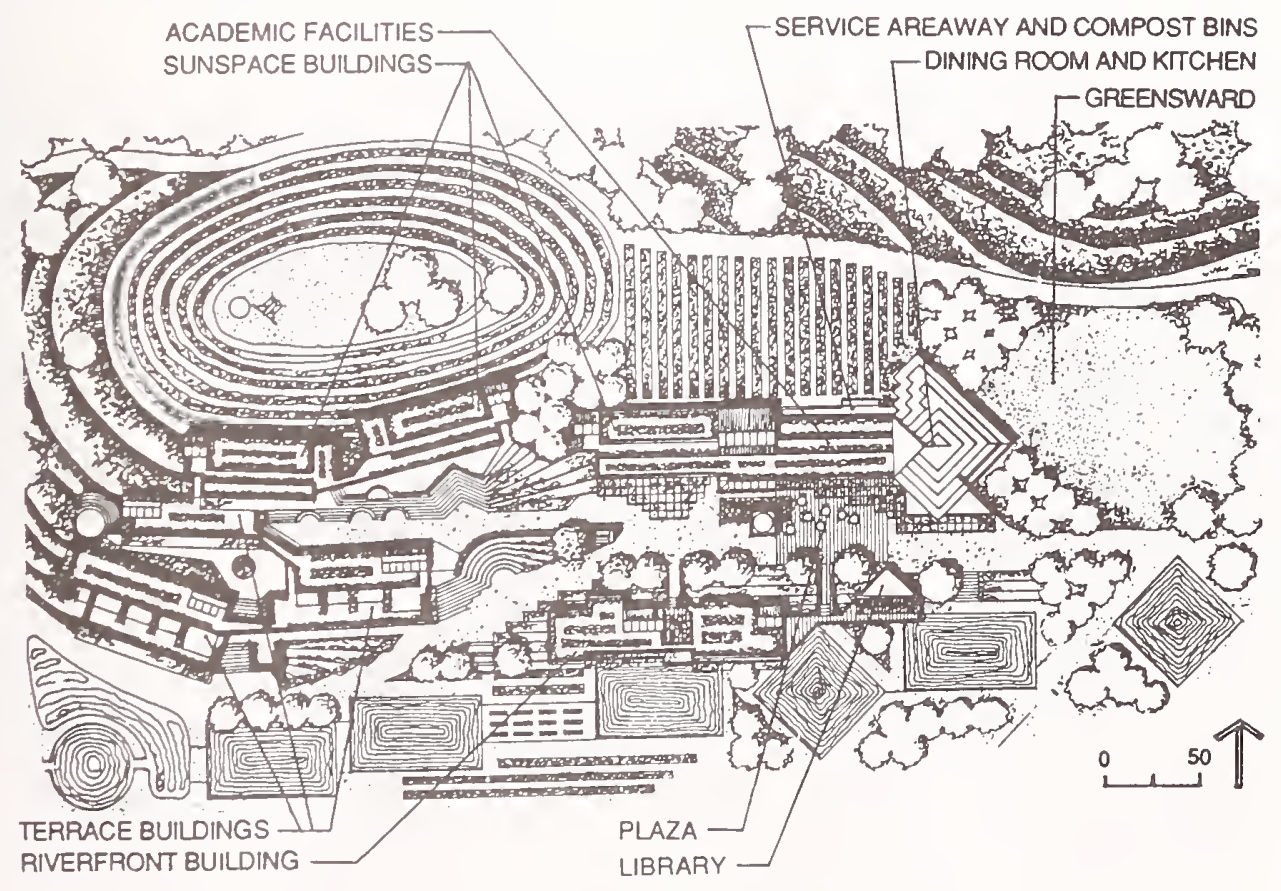

rig. 3 VILTAGE PLAN 
reflect a close relationship to the earth as these structures follow existing contours. The buildings step up the slopes like the agriculture terraces that will surround them. When possible, grading has been minimized and solar orientation maximized.

All of the buildings are designed to be responsive to their environment. A raised structure known as the Riverfront Building
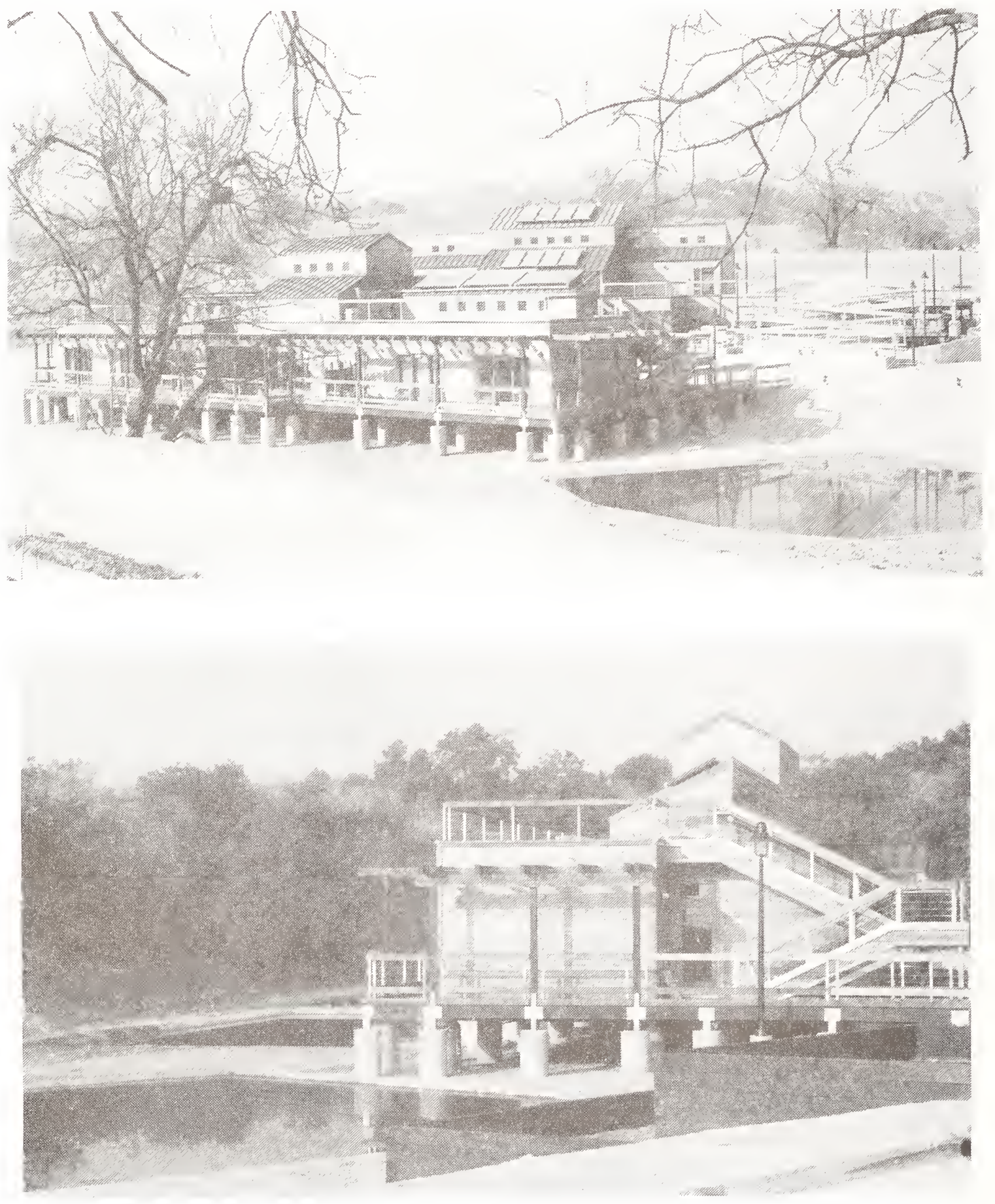

FIG. 4 RIVERFRONT BUIIDING 
is located on the valley bottom at the edge of aquaculture growout ponds. Supported on piers, this building has very little thermal mass. Its form takes advantage of the potential cooling effect of the ponds surface evaporation and the cool ground air circulation underneath.

In contrast, the earth-sheltered Commons and Sunspace buildings have heavy thermal mass and are tucked into the hillside. The
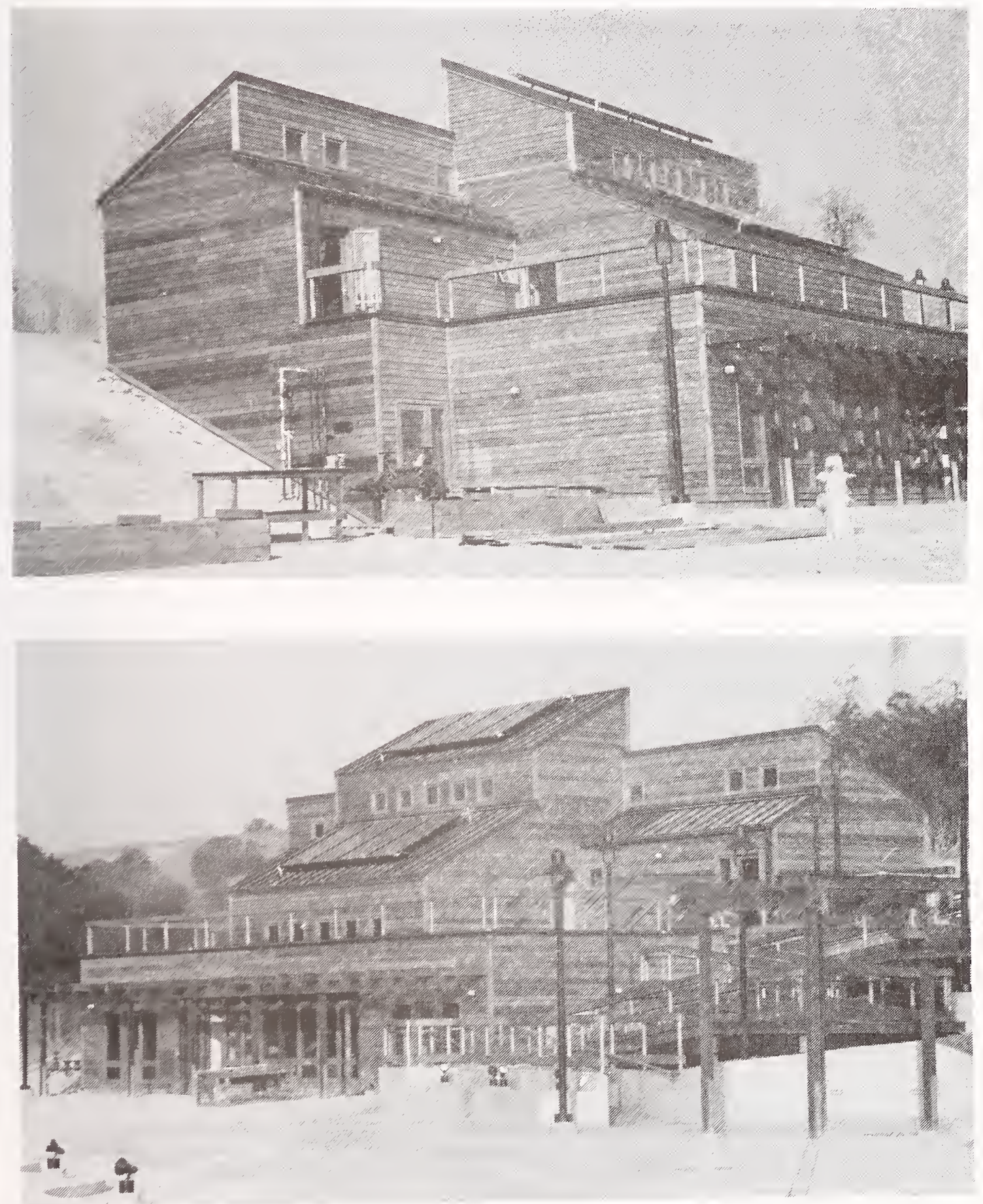

Fig. 5 SUNSPACE BUILDING 
upper portions of these earth-sheltered structures are above grade in order to allow for cross-ventilation. The roofs on all buildings are designed to support the functions of the land surface they now replace. For example, on these roofs, water is collected and guided into infiltration basins, gardens provide food, and solar panels heat all of the domestic water.

\section{The systems}

Energy. The major sources of energy input into the community will be primarily active and passive solar, biomass and some wind. All of the buildings incorporate both passive and active solar systems. Solar energy will provide space heating, electricity, domestic hot water and will be used to heat aquaculture ponds, a methane digester and a crop dryer.

Initially, a conventional electrical source services the site, however, a solar Park is being developed as a part of the overall regenerative design of the center. Electricity will be supplied from a $3 \mathrm{~kW}$ two-axis tracking concentrating photovoltaic collector and two $5 \mathrm{~kW}$ dish/Stirling collectors used as student/faculty research tools. Additional flat plate photovoltaics and a wind generator will satisfy the remaining electrical demand which includes pumping irrigation water and power for electric vehicles. Also, incorporated into the energy design will be electric and digester gas-fueled farm machinery and vehicles for limited transportation between areas of campus.

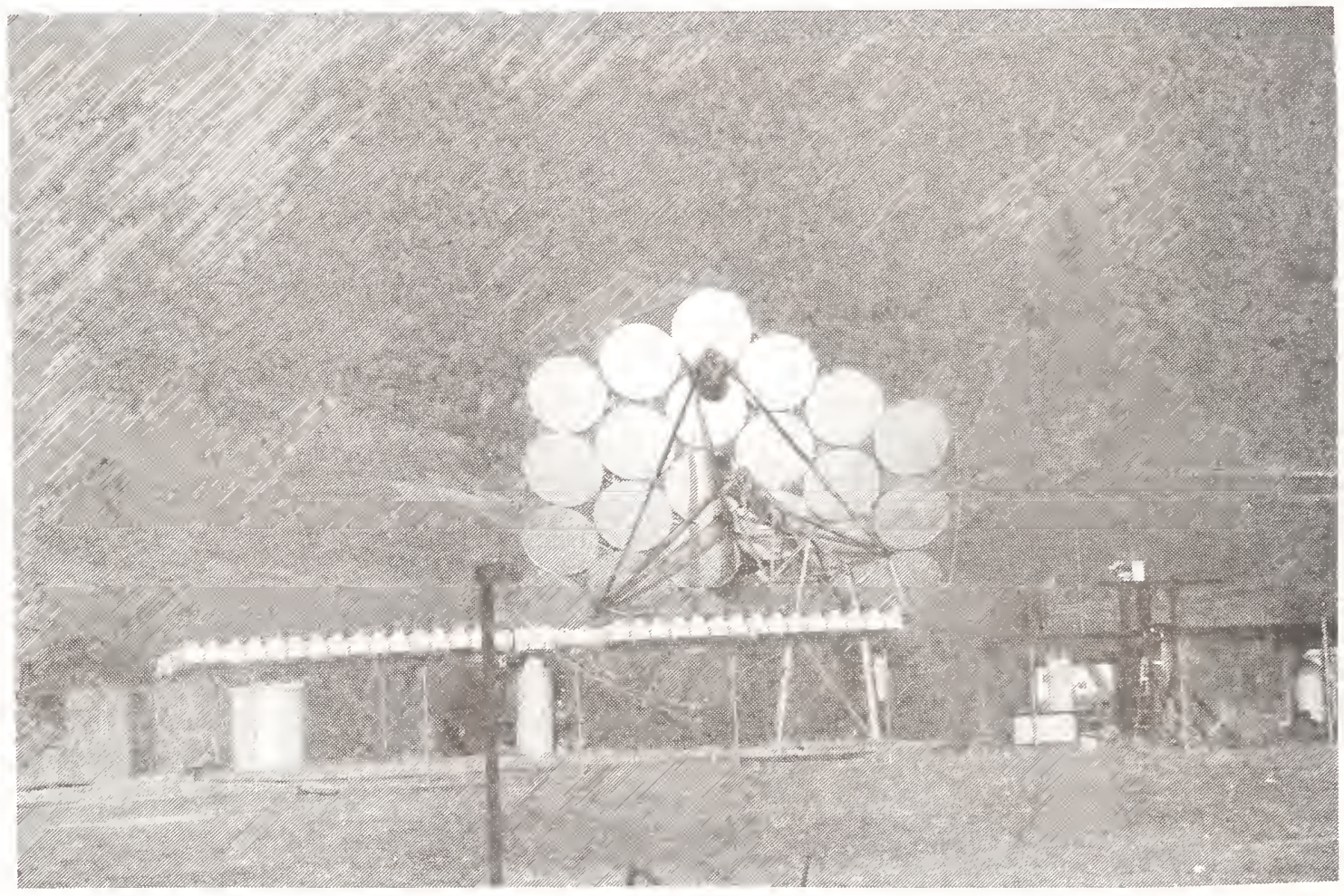

Fig. 6 SOLAR PARK 
The buildings are designed to take advantage of the natural heating and cooling conditions that exist on site. The living spaces are heated by direct solar gain and all have crossventilation. Air flow can be directed by using operable awning windows at the bottom, transfer grills and high operable clerestory windows. Towers on the north side are raised above the roof level to draw air through the building using the chimney effect. Floors are exposed concrete slabs and roof/wall insulation exceeds California Title 24 requirements. Outdoor trellises will be covered with deciduous food producing vines to shade the windows from summer sun but allow insolation to pass through and warm the buildings during the winter. Conservation and monitoring will be important components of the overall energy component of the center.

Water. Rain water, domestic water and treated effluent are the three sources of water. The valley functions as a highly controlled manmade river that includes a reservoir of reclaimed water that feeds a series of aquaculture ponds. These ponds nurture initial carp and Tilapia culture. This system produces large amounts of protein in a small area. The waste processing and recycling functions of the ponds are also important since animal wastes and feed plants will be used to produce organisms eaten by the fish. The use of potable water is minimized by efficient fixtures and the use of reclaimed water in toilets, rooftop drip irrigation systems and agricultural irrigation.

Eoed. Particular attention will be given to agricultural practices that protect and enhance the soil, reduce energy consumption in the use of fertilizers and chemicals, and maximize multiple use and recycling. Plants adapted to the climatic and topographic site conditions will be used. Diversity of plants will be optimized rather than reduced. A few animals will be on site for milk, eggs and some meat. As part of the entire system, recycling of nutrients in animal wastes and feeding animals with various crops and crop residues is an important part of research and demonstration. Plant selection will emphasize growing food for consumption by the residents. The kitchen will include emerging technology in relation to food preparation and storage. Energy use will be continually monitored in this shared cooking and dining area. In general, food production will function in the self-renewing ways of our natural ecosystems.

Waste, Residents will recycle or reuse materials. There is no trash service to the site. An outdoor recycling area is located behind the commons Building. If not reused on site, glass, plastic and aluminum are collected here, weighed and then recycled by the city of Pomona's program. A compost pile is used for organic green waste from food preparation. This product then enriches soils on site. Currently residents are trying to reduce packaging they bring on site by bulk and selective purchases. 
The selection of building materials and products included considerations of toxicity in production and use; recycled and/or recyclable components; the impact on non-renewable resources; support of renewable industries, and capabilities of long-term low maintenance and sustained life. Natural products such as cedax, Douglas fir, and copper roofing were carefully chosen as appropriate enduring building materials. Interior materials were selected to protect indoor air quality and reduce processing. The contractor used as much scrap as possible even recycling aluminum cans from work crew lunches.

\section{Human Interactions}

Student residents in this community are expected to carry out the tasks necessary for their day-to-day living. Learning regenerative practices and technologies is a part of maintaining the community. An often overlooked factor is that technologies can be successful only to the extent that the people involved are willing to adopt them. Implementation of any sustainable system typically requires personal acceptance and changes in lifestyle. In some situations, the changes may run counter to years of accepted cultural practices. For example, here in Southern California automobiles are an important part of our culture. Not having cars available on site at the Center was one of the first problems related to energy use, regenerative practices and lifestyle that residents faced immediately after moving in.

A design goal of this program is to involve residents in a continuous process of making choices that impact their life style, such as gasoline vehicle use. Direct human interaction is required rather than automatic controls. For example, to heat and cool buildings, switches can't simply be on timers and thermostats in remote locations, accessible only to designated campus maintenance workers. The Center's buildings are to be 'worked' by the residents. Windows at many different heights have to be systematically used to provide climatic comfort. Washing clothes means weighing the load, measuring the amount of water and energy used in order to better evaluate the total process. Iiving in a more regenerative way becomes a process of knowing what to do, of making choices based on feedback from systems and from the other residents. It is a continuous evolutionary process that builds on the complexity of people-their needs, the environment-it's potential degradation, and the technologies appropriate in scale for the tasks.

Decisions, although frequently made by individuals, are also embedded within a community who share in the results of the choices being made. The seemingly simple decision of what kind of soap to purchase becomes complicated by issues of cleanliness standards, potential pollution caused by product production, or ability to recycle used soapy dishwater in the community garden. Gathering spaces to accommodate groups of various sizes are 
designed to facilitate this kind of social interaction and decision making processes.

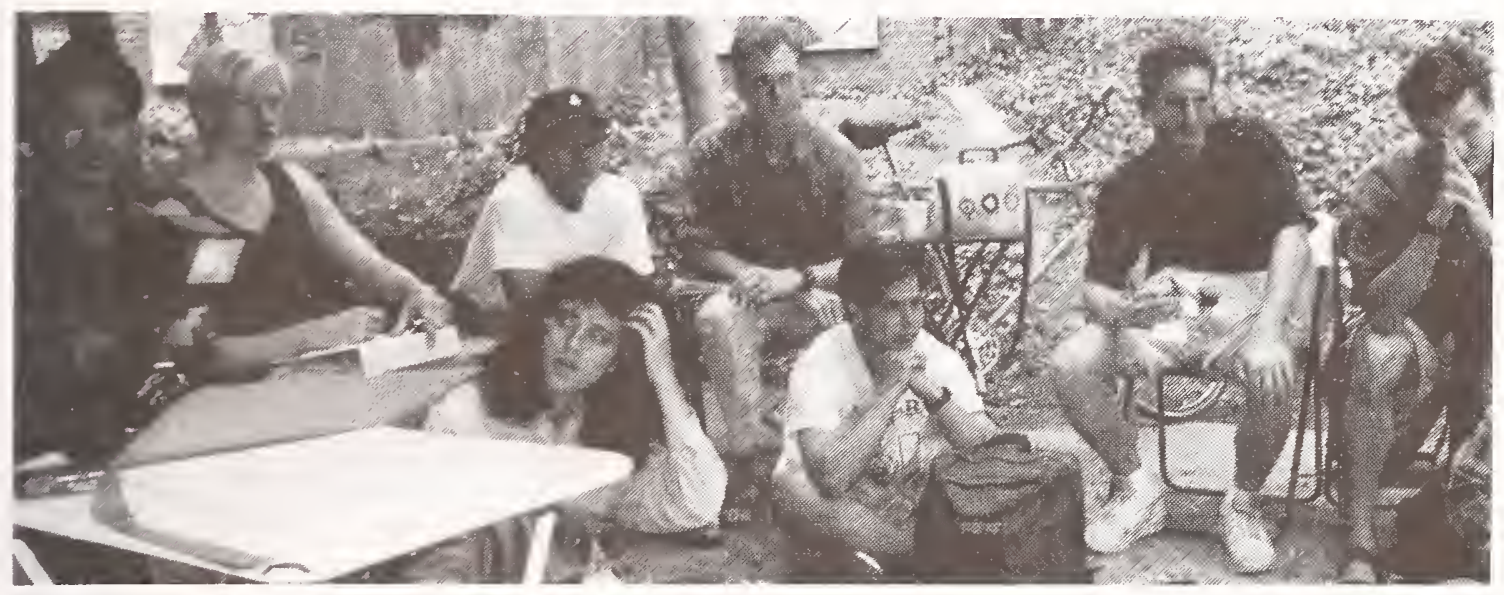

Fig. 7 CENTER RESIDENT STUDENTS

The overall design attempts to facilitate attachment to the center as a built form. Although individual privacy and personalization is accommodated in the double occupancy the sleeping areas, it is hoped that the Center as a whole begins to feel like 'home' to the community. The selection of exterior building materials was based on warm, humanistic and low-maintenance features. The interiors were left unfurnished and without equipment. Students are currently a part of the selection process for furnishings and kitchen equipment. In this way, they are learning about emerging regenerative technology, empowered to make important decisions about their own living area and ultimately may develop a sense of ownership and attachment to the buildings and their environment.

At the core of any change we attempt is the most important factor, ourselves. Without learning in a 'hands-on' way how to live with systems that are regenerative, we are missing a critical lesson. It will be in the day-to-day collective tasks and responsibilities of the people at the Center where the design of the physical and human features are integrated. Through this integration of all systems, we begin to understand what is involved in designing and building regenerative environments. It is hoped that these lessons will be carried forward into the future careers of our students. 


\section{BIBLIOGRAPHY}

Lyle, J. T. Regenerative Design for sustainable Development. NY: John Wiley and Sons, 1994.

Iyle, J. T. et. al. Design for the Institute for Regenerative Studies-A Iandiab Project. California state Polytechnic University; Pomona, CA. 1987.

Stine, S. R. and W. B. Stine. Sustainable Energy Practices and Design for a University Living Laboratory. American Solar Energy Society Conference Solar '93 . Washington, D. C. 1993.

Stine, W. B. and Lyle, J. T. Energy Use and Conservation

Practices At the Institute for Regenerative studies, California State Polytechnic University, Pomona Report IRS 92-001, 1992. 


\title{
Sustainable Design Options for the \\ U.S. Fish \& Wildlife Prairie Learning Center
}

\author{
Susan Reilly, P.E. \\ Enermodal Engineering \\ 1554 Emerson St. \\ Denver, Colorado 80218
}

\begin{abstract}
U.S. Fish \& Wildlife received a grant from the National Institute for Science and Technology to demonstrate sustainable design at the Walnut Creek Wildlife Refuge and Prairie Learning Center in Prairie City, Iowa. Nine different options were investigated. In reviewing the options, U.S. Fish \& Wildlife chose those solutions that demonstrated the practice of sustainable design at this facility, rather than opting for solutions which served primarily as demonstrations. A combination of four of the options were recommended for the grant. The options combine daylighting, specification of more sustainable building materials, energy-efficient system design, and the use of biofuels.
\end{abstract}

\section{Introduction}

The vision for the Prairie Learning Center was already one with a strong emphasis on sustainable design: The prairie will dominate the site, not the structures being built on the site. The Learning Center itself is a one-story, 35,000 sqft, earth-bermed building. Half of the facility is designed for office space, the other half is an exhibit area with some laboratory space. Also on site are research quarters and a maintenance shop. Daylighting, groundsource heat pumps, high-performance windows, an energy management system, and a gray water system have been incorporated into the design.

Enermodal explored nine options for the grant money:

1. Daylighting the Exhibit Area

2. Demonstration of Renewable Resources: Wind, Solar, and Biofuels

3. Biofuels: Vehicle Fuel and Stand-by Generator

4. Cogeneration

5. Sustainable Building Materials

6. Energy Efficiency

7. Integration of Mechanical System with Fire Protection Water Storage

8. Solar: Photovoltaics

9. Electricity from Methane at Metro Solid Waste Landfill

Our initial analysis of the options showed that options 4 and 8 , cogeneration and photovoltaics, are cost prohibitive. Option 2, the demonstration of wind, solar, and biofuel technology, was eliminated because of the relatively high operation and maintenance requirements. With option 7 , the coupling of the air conditioning system to the fire water 
storage, two different systems would have been necessary rather than one for the Learning Center which rendered this option impractical. Presently, the land fill site is producing electricity from methane (option 9). The utility is currently paying the producer slightly more than what electricity costs the facility so it does not make sense to buy electricity from the landfill. However, collaboration opportunities are being discussed although they will more than likely not affect the grant.

Our final recommendation combines the strongest features of options $1,3,5$, and 6 covering daylighting, biofuels, sustainable building materials, and energy efficiency. One of the driving factors in pursuing these options is their practicality as compared to the other options. The following discusses these options in more detail. Also included is an overview of the selection process undertaken on the heating, ventilation, and air conditioning system.

\section{Option 1 - Daylighting the Exhibit Area}

Daylighting is the introduction of natural light into a building to provide lighting, comfort, and a reduction in electric lighting and cooling requirements. Daylighting has been shown to increase productivity and reduce absenteeism. All buildings have glass through which sunlight penetrates. If the lights are dimmed at the windows and the incoming sunlight does not cause the person at the window discomfort then you would have a daylit building. But today less than $5 \%$ of all buildings employ daylighting.

Approximately $48 \%$ of the electricity consumed by the Learning Center is attributable to electric lighting. Through a comprehensive daylighting design, this electricity consumption could be reduced by over 50\%. The energy savings translates into dollar savings $(\$ 11,000$ per year), peak demand savings, down-sizing of the HVAC equipment, and a reduction in air pollution. The significance in reducing peak demand is the avoidance of having to build another power plant. The electric utilities in lowa have been mandated to offer demand-side management (DSM) programs to reduce peak electricity demand to delay building new power plants.

Clerestories, selective glazings, and controls will be used to daylight the open office area, the resource center and the multi-purpose room. Daylighting the exhibit area presents a greater challenge. Originally, the lighting and equipment or receptacle (plug load) power density for this area was specified as $10 \mathrm{~W} / \mathrm{sqft}$. ASHRAE Standard 90.1-1989 prescribes a lighting power density of $2.6 \mathrm{~W} / \mathrm{sqft}$ for exhibit space and a receptacle power load of $0.75 \mathrm{~W} / \mathrm{sqft}$. We have recommended a combined power density of $2.5 \mathrm{~W} / \mathrm{sqft}$. This goal does not account for the daylighting potential in this space. In addition, occupancy sensors and daylighting controls will be installed. Some of the costs for this system will be offset by lighting rebates from Midwest Power and downsizing of the heating and air conditioning system. 


\section{Option 3 - Biofuels}

Biofuels include soydiesel, methanol, and ethanol. The biofuels are typically combined with diesel or gasoline to produce cleaner burning fuels for the transportation sector. Currently there is a considerable amount of research and development work on new technologies to use biofuels in Iowa. Anaerobic digestors produce methane which can be burned in any internal combustion engine, such as stand-by generators. At Iowa State University work is underway to study the burning of sweet sorghum and switch grass to produce energy. Gasifier technology is another technology being developed in Iowa that holds some promise. Almost all of this work is in the research stage and does not have enough of a track record to qualify it for use on this projact.

Biofuels could be used to run the site vehicles and the stand-by generator. Biodiesel and ethanol are the first choices. Biodiesel is a mixture of diesel and soydiesel (methylsoyate). Biodiesel does not require that any modifications be made to equipment unless it is running on $100 \%$ soydiesel. A blend of $20 \%$ soydiesel and $80 \%$ diesel has been recommended, although soydiesel has been used in much higher proportions $(40 / 60 ; 100 \%)$. This has been shown to reduce particulate, hydrocarbon, nitrogen oxide, and carbon monoxide emissions. A timing change needs to be made to the engines to realize a reduction in nitrogen oxides, otherwise there will be a $5 \%$ increase in the $\mathrm{NO}_{\mathrm{x}}$ emissions. The present cost is $\$ 1.50$ 'gallon for the $20 \%$ biodiesel blend.

Iowa is the second largest producer of ethanol in the United States. Presently the buses in Des Moines, Iowa and Cedar Rapids, Iowa run on mixtures of ethanol and diesel. Engines running off of ethanol and diesel could just as easily run on ethanol and biodiesel. With $16 \%$ methylsoyate (soydiesel), $20 \%$ ethanol, and $64 \%$ diesel, you would have vehicles running off of almost $40 \%$ renewable energy. This fuel combination would also cut emissions down to 1998 levels. To run diesel engines off of ethanol there are modifications that need to be made. The modifications cost between $\$ 5,000$ to $\$ 10,000$ depending on the vehicle.

Soydiesel could also be used for the stand-by generator and/or the fire pumping. Soydiesel costs around $\$ 3.00 /$ gallon, but when mixed with diesel this cost can be brought down to around $\$ 1.50 /$ gallon. As for storage, there are no additional requirements as compared with storing diesel. Research continues on the shelf life of these fuels, and more information will be available within the year.

Of the biofuel options - biodiesel, ethanol, and methanol - biodiesel appears to be the most practical of the three. Biodiesel is a mixture of diesel and soydiesel, and does not require that any modifications be made to equipment unless it is running on $100 \%$ soydiesel. The approach we would take with this option is to run all diesel vehicles on the $20 \%$ biodiesel blend and based on performance possibly go to the higher soydiesel blends in the future. In addition, the stand-by generator would run on the biodiesel when necessary. There is also potential for heating the Maintenance Shop and Research Quarters with the biodiesel. 


\section{Option 5 - Sustainable Building Materialls}

One criteria for specifying sustainable materials is avoidance, reuse, then recycle. Our recommendations covered shell construction, interior finishes, equipment specification, and material specification. Here are a few examples of our recommendations concerning specific building elements. We also strongly recommend the development and implementation of a plan for disposal of construction waste and a plan for operation of the building.

We proposed designing the roof to accommodate soft insulation and recommended an EPDM membrane roof rather than modified bitumen. ASHRAE 90.1 prescribes insulation levels at the roof of R-22 for this region and U.S. Fish \& Wildlife recommended R-30. If this insulation is rigid board EPS, $945 \mathrm{MBtu}$ of energy will be consumed to produce the insulation. If this insulation is cellulose, $32 \mathrm{MBtu}$ of energy will be consumed. And if this insulation is fiberglass, $240 \mathrm{Mbtu}$ of energy will be consumed (see Figure 1). It will take 30 times as long to recover the energy used to make the rigid board insulation in building energy savings than it does for cellulose insulation. Quick calculations show that with cellulose insulation the embodied energy is recovered by this building in less than 1 year. With rigid board insulation the embodied energy will not be recovered for more than 9 years. In addition, the rigid board insulation materials are all petroleum based and use environmentally detrimental blowing agents.

The architects spent a few days on the design of this flat roof for soft insulation. The major concern was the potential for condensation on the inside of the roof and thermal gradients within the steel deck. The final design shows 6 inches of semi-rigid fiberglass insulation above the steel deck. Sprayon cellulose with borax fire retardants will be used for the walls.

For the floors, finished concrete slab is specified everywhere possible. We also recommend using tile made from recycled glass as a baseboard. As for the wall studs, neither steel or wood are fabulous options given their production processes and steel is difficult to effectively insulate. Alternatives such as honeycomb products and plastic studs were investigated; however, the honeycomb product costs 3 to 4 times wood studs and the plastic costs 5 to 6 times the wood. We recommend specifying wood from sustainably managed forests, using recycled wood and wood products made from wood wastes and fast-growing softwoods (e.g. OSB), and specifying engineered wood products for structural applications (LVL, Parallam, I-Joists with an OSB web, Finger-Jointed Lumber-Glulams). 
The above discussion does not address water use at the facility because of the grey water system being designed for the facility. Nevertheless low-water consumption fixtures should be specified. Toilets account for the largest portion of water use at the facility and toilets which require no more than 1.6 gallons of water per flush are recommended.

\section{Option 6 - Energy Efficiency}

Our recommendations concerning energy efficiency focused on the equipment and controls for lighting, and supplying and conditioning the air for the building. In the design phase of the project ground-coupled heat pumps were selected to meet the Refuge's cooling and heating loads. The ground-coupled heat pumps competed with other mechanical system options on the basis of life-cycle costs, operations and maintenance, fuel availability, aesthetics, and environmental factors. The choice came down to either gas absorption or the heat pumps (see Table 1).

Table 1 - HVAC System Comparison

\begin{tabular}{||l|l|l|l|l|l|l||}
\hline \hline Alternative & $\begin{array}{l}\text { Life-Cycle } \\
\text { Cost }\end{array}$ & $\begin{array}{l}\text { Fuel (Natural } \\
\text { Resources) } \\
\text { Elec. }\end{array}$ & $\begin{array}{l}\text { Pollution } \\
\text { (See } \\
\text { Attached) }\end{array}$ & $\begin{array}{l}\text { Greenhouse } \\
\text { Gases / } \\
\text { Ozone } \\
\text { Depletion } \\
\text { (CFC, } \\
\text { HCFC) }\end{array}$ & $\begin{array}{l}\text { Impact on } \\
\text { Surroundings }\end{array}$ \\
\hline $\begin{array}{l}\text { Gas } \\
\text { Absorption }\end{array}$ & $\$ 1,382,153$ & $\begin{array}{l}521,619 \\
\mathrm{kWh} \\
\text { Heat Pumps }\end{array}$ & $\begin{array}{l}49,258 \\
\text { Therms }\end{array}$ & $\begin{array}{l}\text { Less } \\
\text { Detrimental }\end{array}$ & $\begin{array}{l}\text { None } \\
\text { (Cooling } \\
\text { tower water } \\
\text { treatment) }\end{array}$ & $\begin{array}{l}\text { Excavation } \\
\text { for Gas Line }\end{array}$ \\
\hline $1,297,237$ & $\begin{array}{l}893,656 \\
\mathrm{kWh}\end{array}$ & & $\begin{array}{l}\text { Worst of } \\
\text { the } \\
\text { Alternatives }\end{array}$ & HCFC) & $\begin{array}{l}\text { Excavation } \\
\text { for Ground } \\
\text { Coil }\end{array}$ \\
\hline \hline
\end{tabular}

1 Shows gas and electricity use for HVAC systems without heat recovery. Source: Gordon Gumeson Report

2 Air Pollution from burning the fuels is given in the attached tables. For all air pollution types, except for the hydrocarbons (HC), the all-electric heat pump alternative has higher emissions. This assumes coal-fired electricity.

Relative to life-cycle costs, the heat pumps cost $\$ 85,000$ less than the gas absorption system over a 20 -year life. The first cost for the heat pumps is also $\$ 70,000$ less than for the gas absorption system. In terms of fuel use, Iowa is actively promoting programs to delay the need for new generating capacity through the reduction of $\mathrm{kW}$ demand. The peak demand for the gas absorption system is less than half that of the heat pumps. Both alternatives use fossil fuels and their are trade-offs between mining and the abundance of each of the fuels. The air pollution emissions for the heat pumps are higher in all categories, except for the hydrocarbons. The heat pumps also require the use of CFC's or HCFC's which are greenhouse gases and deplete the ozone. There may be some concern with the chemicals 
used to treat the cooling tower water, but they do not compare with the problems with CFC's and HCFC's. As to the impact on the surroundings, both alternatives require excavation.

The gas absorption system is preferable from an environmental standpoint. At a 7\% discount rate, the annual worth of the $\$ 85,000$ difference in life-cycle costs is $\$ 8,000$. U.S. Fish \& Wildlife agreed that the environmental impact is worth $\$ 8,000$ annually. However, given the $\$ 70,000$ first cost differential between the two alternatives it was decided that the heat pumps would be acceptable environmentally if more money and effort was put into improving the energy efficiency of the building shell and systems.

Ventilation and lighting consume over $60 \%$ of the energy used by the Learning Center. ASHRAE Standard 62-1989 sets the ventilation requirements for acceptable indoor air quality for commercial buildings. A system is designed for the maximum number of people in a space, although it does not need to provide this volume of outdoor air at all times. The control of the outdoor air intake and operation of the supply and return air fans need to be optimized. There are a few alternatives (e.g. $\mathrm{CO}_{2}$ sensors) for controlling the percentage of outdoor-air intake which could be readily incorporated into the energy management system. Additional design effort is warranted for control of the HVAC system in the exhibit area so that nighttime loads are reduced and so that the fans are not running at $100 \%$ all of the time.

The proposed lighting design specifies some of the most efficient lighting available on the market along with controls for dimming and turning on and off lights. While this is an important first step the lighting should be designed to below $1 \mathrm{~W} / \mathrm{sqft}$ in the administrative area and to less than $2.5 \mathrm{~W} / \mathrm{sqft}$ in the exhibit area. We also recommend the use of high pressure sodium lights for outdoor lighting and that more attention be given to the outdoor lighting.

Finally we strongly recommend commissioning this building. Commissioning is the process of verifying that the building is built to specifications and that all systems are working as agreed upon. This means verifying the operation of all controls and assuring that the indoor air quality is acceptable. Many of the larger utilities are using this tool to verify energy savings and so there may be another collaborative opportunity with Midwest Power.

\section{Conclusions}

Implementation of most of the recommendations appears to be straight-forward. Many of the concepts were adopted early on, such as daylighting. What became clear though is that daylighting is a design tool that is not commonly practiced. Along the same line, existing equipment can be modified to burn biofuels; however, it is not widely available nor proven. Because this is a federal project, problems also arise in locating at least three U.S. sources of a product. We are seeing the market for products which are more environmentally sensitive grow, and with this we expect to see the availability of products grow. Reliability is also an issue and the market will slowly weed-out the less durable products. These examples show that there is additional time and money involved in providing alternatives that afford the same level of confidence. 
This is an educational process. The design teams involved in these projects have all begun to question their design solutions and discover alternatives that are more environmentally benign. Perfect solutions do not exist, although sustainability is nurturing new ideas and pushing us to re-evaluate conventional design practices.

\section{Acknowledgements}

Enermodal wishes to thank U.S. Fish \& Wildlife and OZ Architecture for bringing them onto this project, and for their cooperation and assistance in evaluating the options. We also wish to thank the National Institute for Science and Technology for their support of this project. 


\title{
ARCHITECTURE, ETHICS \& THE ENVIRONMENT
}

\section{An Exploration of Nature \& The Human Spirit}

\author{
John A. Clark \\ The John A. Clark Company \\ 4315 50th Street N.W. \\ Washington, DC 20016 \\ Neal I. Payton, AIA \\ School of Architecture and Planning \\ The Catholic University of America \\ Washington, DC 20064 \\ David Tice, President \\ Post Office 6777 \\ North American Resource Management, Inc. \\ Charlottesville, VA.
}

\begin{abstract}
Haymount is a new town planned with the belief that Sustainable Development is based upon a Trilogy of: ecology, sociology and economics. The design embodies a holistic approach to the healing of nature and the human spirit. When complete, the town will contain 4000 homes, 250,000 square feet of retail space and a half-million square feet of office/commercial space. At the same time, Haymount will employ state of the art techniques in wastewater, stormwater and wildlife management, utilize non-toxic building materials and techniques, practice energy and water conservation, and accomplish all of this in a manner that discourages use of the automobile while encouraging pedestrian life and community vitality. Yet, Haymount is not a philanthropic exercise. Rather it is a sound business proposition with excellent profit returns to the investors.
\end{abstract}

\section{INTRODUCTION}

Located on Virginia's Rappahannock River, 50 miles south of Washington D.C. in Caroline County, Virginia, Haymount is a new town planned with the belief that Sustainable Development is a Trilogy; of ecology; sociology and economics. Its design represents a holistic approach to the mending of nature and the human spirit.

Haymount replaces a pesticide and herbicide intensive farming operation with a model of sustainable community resulting in lower total pollutant loadings to the river. It combines a program for natural resource protection and pollution prevention with a transportation program and a strategy for promoting a vital community life.

The developed area of Haymount is compact, preserving over two-thirds of the 1700 acre site as perpetual forest and wildlife habitat while allowing pedestrian access to basic needs in town 
within a five-minute walk. The project also includes state of the art facilities and techniques in wildlife, stormwater and forest management, wastewater treatment, organic farming and landscape gardening.

\section{HISTORICAL CONTEXT}

In preceding decades planners and sociologists have identified the human toll exacted by our culture's reliance on technological progress. Though great strides have been made in science and its application, even to the point of prolonging and enhancing human life, the increasing specialization required by a technologically based society has had the effect of fragmenting our civilization. Social solutions were attempted as remediation in the early 60 's followed soon after by an environmental response. However, neither has proven successful on its own. There is neither an exclusively environmental nor social strategy to our problems, and thus, to balance nature and the human spirit in one place and form, a holistic solution must be sought. It is a vision that embraces both an environmental and social contract.

For example, North American land use zoning requirements typically promote low density suburban sprawl across large areas of undeveloped land, destroying natural habitat and necessitating automobile transport to fulfill every human need. The environmental costs associated with this pattern, in terms of emissions and non-point source pollution, are obvious. Less apparent, but equally destructive however, this is a pattern that undermines the social fabric of the nation by isolating families from one another, grown children from their parents, employees from employment and economic classes from one another.

At the same time, the micro-pattern represented by the housing and workplaces within these environments are equally damaged both by the use of materials and by their techniques of assembly that are potentially toxic to inhabitants. For example outgassing of urea formaldehyde, volatile organic compounds (v.o.c.'s) in paints and stains, and resins and chemicals used in the manufacture of plywoods and subsidings are known toxins. Coupled with advances in building envelope technology, the result is a severely degraded indoor air quality (i.a.q).

\section{ENVIRONMENTAL AND SOCIAL GOALS}

The environmental goals embodied in Haymount are stated as follows:

*Design with Humility \& Acknowledge the complexity of Nature.

*Accept Environmental Responsibility for our work.

*Nurture the connection between nature \& the human spirit.

*Design with sustainable objectives as a requisite.

*Design with flexibility to allow for environmental technology advancements. 
The social goals stated the following:

*Respect \& Involve current citizens.

* Provide Sites for spiritual life in design.

* Provide Sites for Civic Life of Community.

*Avoid Privatization of Public Amenities.

* Provide Affordable Housing \& Avoid economic segregation.

* Preserve Cultural Heritage \& provide access to Archaeological Information.

These goals gave the project its founding principles and allowed for a clarity of thought in the assembly of the design team.

\section{PROCESS}

The architecture and town planning firm of Duany \& Plater-Zyberk was engaged to create the master plan of the town. Employing an innovative design technique known as a design Charrette, the team, and all parties to the project gathered on site and worked intensely for a period of a week to ten days. Assembled there were design professionals as well as practitioners from the fields of science that have input to the project. Both opponents and proponents from the local citizenry were also on-hand. This efficient process avoids the problem of missing data or input and gives all parties a voice in the process.

The team members had the task of assembling the base information.

*Boundary Survey \& Topographic mapping

*Forestry mapping of all trees and plant life.

*Wildlife identification

*Wetlands delineation

*Archaeology

*Water Quality

* Waste Water Treatment

*Stormwater Treatment

*Potable Water

* Recycling

*Traffic Studies \& Mass Transit Alternatives

*Fiscal Impact

The final result was a plan that addresses all identified concerns as described below.

\section{NATURAL RESOURCE PROTECTION AND POLLUTION PREVENTION}

The wildlife conservation component of Haymount is illustrative of the extent to which ecological planning in integrally webbed to all aspects and features of the town's design. Before the first street was planned, consultants evaluated the potential presence of endangered and threatened species, including ones considered by biologists to be sensitive, but not legally 
protected, such as species at the edge of their native range. 302 such species were identified and, in keeping with the holistic approach of the development, all life requisites for these were considered, including, where relevant, breeding cover, foraging and perching habitat, escape cover, food sources (and their respective habitat requirements) water and related factors.

For example, an American Bald Eagle was located and a leading raptor expert designed a management plan for not only the nest, but for the entire eagle habitat. Habitat is also provided for a whole range of animal species. The project's developed areas will contain an additional 50,000 planted trees and shrubs of native vegetation, improving and increasing habitat for most species and providing shelter for migrating song birds.

The design of Haymount not only protects these species, but will, in some cases actually increase habitat suitability. It accomplishes this in a number of manners. An inventory of all trees $18^{\prime \prime}$ or larger in diameter was made in the ares suitable for development. This data was mapped and analyzed with forest growth models to project future changes that could be expected in diameter growth, tree density, and mortality - factors which affect the future landscape for homes as well as wildlife. This information was incorporated into site development plans to protect as many specimen trees as possible. Additional measures to improve habitat suitability include: protection of key wildlife corridors, wetlands and other sites; the design of green spaces as connections between habitats; planting specifications that establish extensive canopies of native species chosen for their utility to wildlife; stormwater management designs to create additional wetland habitats; water quality protection measures, including controls over fertilizers and pesticides; and an environmental education area and program to build a strong community commitment to conservation and habitat improvement.

Haymount employs biotechnical stormwater control measures that employ vegetation as primary and / or secondary structural elements to manage run-off, secure soil, and protect water quality. These techniques capture and treat non-point source pollutants allowing natural aquifer recharge and eliminating ground or surface water impairment. Wildlife benefits of these techniques are exceptionally adding important cover and food habitat. The full range of Best Management Practices (BMPs) employed include: constructed wetlands, porous pavement, fascines, grass and block parking areas, grassed swales and biotechnical slope protection techniques. Considered as a whole, they represent a strategy that has seen considerable refinement in the last decade, but has been used successfully for over one hundred years and has proven effective not only for erosion control, but also for nutrient reduction, soil infiltration, stream or river restoration and wetland creation.

Ecological considerations govern the delivery of Haymount's potable water. The intake system consists of a shallow vertical well with a series of horizontal fingers which extend under the riverbed. It is an advanced technology that avoids disturbance the aquifer, the river bottom and the riverbank, thereby preserving groundwater, aquatic vegetation and fish.

The wastewater treatment is also "state of the art." Combining sequence batch technology, advanced tertiary treatment and constructed wetlands, discharged water will be cleaner than that which is withdrawn from the river! The treatment plant was designed to create additional wildlife 
habitat, function as an educational tool for wildlife and environmental awareness, and even serve as a civic park.

The Haymount Organic Farm is more than a memory of agriculture. It replaces the destructive pattern of chemical agriculture that has occurred here for the last 40 -years. The crops produced will provided sustainable, regionally produced agriculture for residents of Haymount and the surrounding area.

The regulation of public and private plantings is crucial to the making of place, the nurturing of wildlife and the preservation of environmental integrity. Thus, Haymount's form is governed by a landscape code that encompasses a number of components. These include: a tree program that requires the use of mostly native species of trees and shrubs for landscaping, reducing both the need for watering as well as fertilizer and pesticide application. A program of organic and natural predators is to be implemented as part of an integrated pest management program.

Recognizing that wildlife, atmospheric conditions and hydrologic influences do not follow property boundaries, Haymount's environmental program is without borders. The Haymount Environmental Manager, employed by the developer will, among other things, provide technical assistance to all landowners in the broad ecological region around the project. This professional assistance, mandated in the proffers offered voluntarily by the developer to the county, includes: on-site stewardship advice, as well as workshops for technology transfer. It is noteworthy that, before ground was even turned at Haymount, the environmental management team secured over 1000 acres of conservation easements, was successful in designating several historic districts and assisted in the development of numerous land stewardship plans.

Standards governing the energy performance of buildings, as well as construction and conventional materials recycling, hazardous materials disposal and the use of non-toxic building materials complete the effort in natural resource protection and enhancement. These standards, issued as a set of guidelines and regulations will be administered by the environmental manager will also provide yearly lawn soil tests, garden consultations and manage the public grounds and open space.

\section{TRANSPORTATION}

Haymount's transportation system assures environmental, economic and social sustainability through a design aimed at congestion mitigation and programs aimed at reducing vehicle miles traveled (VMT) per household and vehicle household trips (VHT). These goals will be met by establishment of: a pedestrian and bicycle friendly environment supplemented by a timed transfer shuttle bus system; a mixed-use pattern of land development that includes major employment opportunities; reduced commercial parking requirements; and programs to encourage employers to institute transportation demand management (TDM) programs.

The creation of the pedestrian friendly environment, critical to the success of this development, is made possible by Haymount's town plan which centers on the paradigm of the "five-minute walk." In essence, no residence is greater than 1350 feet (or 1/4 of a mile) from a town or village 
center and a shuttle bus stop. This allows residents the choice of walking for some their trips reducing both VMTs, but more importantly, "cold starts," the greatest component of auto source pollution. Yet another important element of the plan is that it allows for congestion mitigation (limiting air pollution still further by reducing idling time) and for reduced road width by adopting a configuration typical of prewar North American towns and villages. It is a model that eschews the "modern" cul-de-sac pattern of development which isolates one community or institution form another and makes pedestrian access to major thoroughfares circuitous and difficult while forcing all vehicular traffic onto oversized, overcrowded connector roads and arterials. Haymount, instead, employs a street layout characterized by a series of linked grids. This allows a more even distribution of traffic by providing alternatives for pedestrian, bicyclist and driver alike.

A viable pedestrian constituency is made feasible by such large scale plan considerations, but it is assured in the details. For example, working within Virginia DOT regulations, streets and roads, described in a one-page drawing of possible street types that specify carriage widths throughout the project, are less then normal in standard subdivisions. This creates, in effect, streets that feel better to the pedestrian because of their greater degree of spatial enclosure. The proportion of building height to street width is specified as is the alignment and spacing of trees. Curb radii, also described in this drawing, have been minimized, further enhancing pedestrian safety by shortening the distance a pedestrian must walk to cross an intersection. The introduction of alleys reduces the need for curb cuts thus minimizing opportunities for automobiles to cross sidewalks while, at the same time, enhancing on-street parking opportunities. All of these characteristics help to produce an environment of reduced vehicle speed, enhanced pedestrian comfort and, coincidentally, auto safety, by reducing the principle cause of traffic mishaps: excessive speed. It is not that inadequate facilities are allowed for the car, merely the pedestrian and bicyclist are given equal opportunity as the automobile operator to feel comfortable on the street. An added benefit of reduced road widths is the reduced storm water runoff that results from decreasing the amount of impervious surfaces.

The resident whose transportation needs encompass an area greater then 1/4-mile radius has access, at the end of a short walk to a shuttle bus system that will connect and provide timed transfers to the Virginia Railway Express commuter line into Washington D.C. at the nearby Fredericksburg station. This business will also provide regular intra-community transport for the elderly, the young and those who choose not to own an automobile. Bus stops have been carefully designed to be commodious and safe. Located in village centers adjacent to convenience stores, as well as at employment centers, schools and civic institutions, their design has been considered as part of an extensive program of "civic art," a place where one may actually enjoy the wait for the bus.

The transportation issue cannot be solved solely by reducing car trips with mass transit. The commuter rail and shuttle bus will capture half of the car trips for work related travel. A serious effort to provide workplace jobs is the most important aspect of traffic capture. A goal of 1.2 jobs per household has been set to reduce the number of vehicle miles travelled (VMT). An economic development plan with advanced communications is being implemented. Fiberoptic capabilities have been planned for the project with satellite downlink. The buildings are 
designed to be the workplace of the 21 st century. The inclusion of interactive media, a digital office communication system and a design for high worker productivity is underway. An active recruitment effort of companies is being undertaken to meet these employment goals.

\section{A VITAL COMMUNITY LIFE}

The post-war North American suburb is a model of social and economic segregation. Enforcement is assured by several means. Zoning Laws, which mandate large-lot subdivisions and separate low-income pod developments while simultaneously prohibiting accessory housing, and a mixture of land uses and lot sizes are primarily culpable. Segregating uses by great distances, for example, these ordinances increase land and development costs while virtually mandating the use of automobile for every errand, increasing the separation of individuals from one another. This isolation is further assured by the "common wisdom" of the market, which assumes that, despite two hundred years of development history to the contrary, citizens today will only live in neighborhoods composed of nearly identical families. An obvious and tragic result of such enforced homogeneity is that changes in one's own family, such as children growing up, and parents growing old, simply cannot be accommodated within the existing suburban framework.

Haymount addresses these fundamental shortcomings through its housing and land use mix, its pedestrian friendly environment and its provision for a range of civic institutions and amenities which nurture community life. For example, affordable housing is to be constructed in every section of the development, and available in a range of forms, thus recognizing the diverse constituency for affordable housing: elderly residents, young people, single parents, couples and families of limited incomes. Achieving this throughout the development is to be accomplished with the provision of housing sizes and types that range from 440-square foot apartments over shops and offices, through detached cottage units, to duplexes, apartments buildings, townhouses and single family housing. Twenty-two different housing types are available and, recognizing the vitality created by diversity, they range in price from entry level to luxury. Across the price spectrum, this housing is offered for sale or rent.

The affordable housing in the community will not, however, serve the need of housing for the whole county. Thus the developer has instituted a community land trust to own, develop, lease and sell housing for residents in all areas of the county. This trust will work also with groups from religious institutions or other civic organizations to repair substandard housing. This foundation will provide the solution to the provision of decent affordable housing county wide. The first three years operation will be funded by the developer. This philanthropic endeavor will set a precedent that residents will expect future developments in the county to follow.

Another component of its social sustainability(and a key to its environmental sustainability as well) is its pedestrian friendly environment. Not only does this promote less intensive use of the automobile, it encourages a sense of community by providing for the establishment of relationships through chance and repeated encounters of individuals, as well as enhancing a sense of security by encouraging "many eyes on the street." 
Such an environment is assured through mechanisms described above and by urban and architectural codes, applicable throughout the project. Simply placing transit and mixed-use development in proximity to housing is not enough to assure that citizens will elect to leave their automobile at home, or even chose not to own a second car. The five or ten-minute walk must be a pleasant one that is visually and socially stimulating.

Principle among the codes that accompany the plan of Haymount are the Urban Regulations which set out, in a matrix of plan and section diagrams, the rules that govern those aspects of the private building types that are adjacent to and help shape the space of public life. In essence, this code is concerned with those characteristics that determine the "walls of the urban room." For example, (depending on lot and building type) they specify the percentage of a private building's street facade that must adhere to a common frontage line. Generally, they prescribe building use, placement, height, permitted encroachments (such as front porches, which are encouraged), and the location of parking for each of the eight different lot types and sizes.

Another matrix of codes intended to enhance urban coherence and pedestrian friendliness regulates configurations, materials and techniques of construction. The Architectural Regulations acknowledge the characteristics of the region that have developed over time as a result of climate, tradition and available materials, labor and technology and that have given the region its particular identity. It represents an effort at assuring the regionality, and sense of "place" that engenders long term commitments without prescribing a particular style or limiting a designer's creativity.

To further encourage sustainability, the spirit of community must be nurtured to form a web of connectedness between peoples and place. To achieve that end a number of programs are provided. Religious Institutions have been encouraged to locate in Haymount and their sites selected for their prominence within the plan. These locations will be donated to congregations of various religions and denominations as they come into the community. The sites must always be used for spiritual purposes or revert to a board comprised of all the leaders of these institutions. The town architect will complete the preliminary design at no charge to the congregation.

Parks also play a role in allowing for these bonds of community to grow. They will be designed and constructed by funds provided by the developer to accommodate a range of public uses: sports, leisure and public congregation. Civic space is critical to the reconnection of citizens in the public realm. One of these, a river park comprises $12 \%$ of the total river frontage. The rest of the frontage will be protected in its natural form and none will be privatized. It is for all county residents. Quarterly public festivals and concerts may take place in this riverfront park. The space is designed to encourage both planned gathering and spontaneous recreation. The park will be lined with restaurants, cafes, ice cream shops and small retail establishments.

Haymount will deed one elementary school to the citizens of Caroline County as well as an additional 13-acre school site. An 80-acre college campus has also been set aside. A Charrette process will involve local citizens, students, school board members, teachers, the board of supervisors, and nationally recognized educators in, not only the design of the school building, 
but a reordering of the curriculum of the school system. An education endowment will be funded by a percentage of the sale price of each new home in the community and will be administered by the Caroline County citizens. A library will also be provided by the developer to enhance educational opportunities.

\section{SUSTAINABILITY}

Haymount represents a holistic approach to sustainable design, reaching beyond the project borders and into the direct and indirect impacts of the community on the environment. Perhaps the most far reaching environmental component of the project is the sustainabilty program being developed. Using sophisticated ecologic and economic modeling developed by the management team, the floe of resources and transactions among all the major economic sectors and the commodity groups will be evaluated. This will include not only direct effects (for example the impact of healthy building materials), but indirect ones as well (including household expenditures). With the size of Haymount's economic contribution as a powerful leverage, the team will work with suppliers and other businesses to effect environmentally responsible voluntary agreements, and identify funding sources to assist businesses in the region to meet strict environmental standards.

Such a strategy is consistent with Haymount's overall environmental ethic described throughout the body of this paper. It is an ethic that accepts responsibility for the imprint and impact of its development on the landscape and the environment. The efforts outlined above: at programming, design, construction and management of the project, represent a commitment to control the total resource and energy flows that result from this development,-to design and manage the "project ecology," so to speak. The authors, acknowledge previous efforts in sustainable design, believe that Haymount is unprecedented in the extent to which it is far reaching. It is the first major effort to include such a holistic approach accounting for even the indirect effects of a project, and embracing an entire spectrum of environmental, social, economic and urbanistic concerns. 
Liza K. Bowles, President

NAHB Research Center, Inc. 400 Prince George's Boulevard Upper Marlboro, MD 20772-8731

Abstract. The Resource Conservation Research House, built by the NAHB Research Center and opened in 1992, was constructed with materials that conserve the nation's resources. The house is designed to stimulate interest in resource conservation in home building among home builders, home buyers, public officials, civic groups, and the media. In addition to products made from recycled materials, products and systems used to build the house are made from less costly materials, more durable materials, and materials that contribute to energy conservation during the lifetime of the house. A principal purpose of building the house was to test and demonstrate resource-conserving products and systems that now exist only in prototype or that are on the fringes of the market, and to help to move useful, cost-effective products of this type toward the marketplace mainstream.

\section{Introduction}

Home building, and the operation of homes after they are built, involve substantial use of important resources. The National Association of Home Builders (NAHB) and its wholly-owned subsidiary, the NAHB Research Center, are giving increasing study and priority to the relationship of home building and home usage to a sustainable environment.

This interest led to planning, design, and construction of the Resource Conservation Research House by the Research center. Products selected for the house met resource-conservation criteria in one or more of three areas.

- Materials:

Includes recycled content, utilization of lower-value resources, and durability.

- Installation:

Includes environmental, energy, and waste-generating features of installation.

- Operation:

Includes conservation of resources in operation, life cycle costs, reliability, and maintenance. 


\section{Products and systems}

Products and systems used in building the house are described in the Research Center's publication, Resource Conservation Research House Information Guide.(1) They included the following:

\section{Concrete Foundation Forming system}

The house's foundation utilizes a stay-in-lace insulated concrete foundation forming system. The system consists of inner and outer panels that contain 10 percent post-consumer recycled polystyrene from such products as fast food "clamshell" containers. The forms are held together with forming ties made of reprocessed polypropylene from industrial and consumer sources.

Cement is poured into the cavity between the inner and outer panels, creating a poured-in-place foundation with integral interior and exterior insulation.

\section{Steel Framing, Reconstituted sliding}

The house is steel-framed, which reduces the requirement for wood. Two-thirds of the steel used for framing is recycled from scrap sources such as old cars. All steel scrap created in the construction process was recovered.

The house's hardboard siding is composed of recovered wood fiber and roundwood that are byproducts of sawmill operation.

\section{Floor and ceiling Products}

The vinyl flooring material does not require underlayment. In addition, a 3-inch band of adhesive is applied around the perimeter of the room and under the seams, rather than the conventional full spreading of adhesive, resulting in substantial reduction in adhesive use.

Ceiling tiles or panels are made with wood fiber containing 22 percent recycled newsprint. Other tiles and panels contain 22 percent recycled newsprint and 25 percent recycled mineral wool.

\section{Insulation}

Spray-applied wall insulation and loose-fill attic insulation are made from recovered newsprint. Insulated wall sheathing, as well as foundation form panels, contains 10 percent post-consumer recycled polystyrene, and utilize CFC replacements which reduce ozone depletion potential 94 percent. 
Copper is used in the water supply, drain, waste, and vent lines; the roof flashing; the gutters and downspouts; and in a fire sprinkler system. Over 70 percent of copper tubing and fittings is made of recycled copper.

Copper is also used in a direct expansion earth-coupled heat pump. Such heat pumps take advantage of the stability of earth temperatures as opposed to air temperatures, to operate at lower energy cost.

\section{Wallboard; Roofing}

Wallboard is made from gypsum, perlite, and about 15 percent by weight recycled waste paper. This stouter board is designed to eliminate the need for taping joints in the finishing process.

The roofing panels contain 52 percent plastic resin from recycling of old computer housings. The panels combine an irregular appearance, similar to cedar shakes, with a Class A flame protection rating. They can be installed more quickly than shakes and are claimed to be virtually maintenance-free.

\section{Energy-Efficient Windows}

Energy-efficient windows have a frame and sash made from a composite material of polyester resin reinforced with fiberglass and finished with a polyurethane coating. The inner core of the frame and sash is filled with high-density fiberglass insulation. The windows have a low-E coating, and the space between the dual panes is filled with argon. The windows provide an R-value of 3.39 in double-hung units and 3.22 in casement or awning units.

\section{Deck, Railings, Trim}

A wood substitute material, made of 50 percent wood fiber and 50 percent post-consumer recycled polyethylene, was used for deck materials, railings, landscape timbers, and trim. The wood fiber comes from industrial sources such as old pallets, the polyethylene from consumer sources including recycled grocery bags. The materials, designed for nonstructural uses, can be sawed, planed, sanded, and milled; can be attached with nails, screws, or glue; and can be painted, stained, or coasted. It is resistant to ultraviolet damage, water damage, soil acidity, and insect infestation.

\section{Solar Products}

Solar products include a solar hot water system, photovoltaic systems for energy-efficient lighting and electric power, and a liquid radiant barrier spray-applied to the underside of the roof sheathing which is designed to reduce cooling loads. 
The garage is built on a frost-protected shallow foundation insulated with extruded polystyrene board containing 10 percent post-consumer recycle. Frost-protected shallow foundations offer substantial savings over conventional foundations employing footings that extend below the frost line.

The lawn was seeded with grass seed mixed with mulch manufactured from post-consumer waste paper.

\section{Recycling}

A kitchen recycling center provides for convenient separation of recyclable waste products at their point of use. The system, based on a new design developed by the Research center, features recycling bins located under half of the kitchen sink, which can be opened and closed without the use of hands. The location of the bins provides convenient access from the sink, stove, and refrigerator, where most waste is generated. The system is designed for easy adaption to both new and existing homes.

\section{Construction site waste}

A study of construction site waste that was conducted while the house was being built produced recommendations to manufacturers and distributors for reducing packaging, possible on-site reuse and recycling of certain types of waste, and improved pickup and recycling of cardboard and lumber. Information from the study was incorporated into an NAHB Research Center publication entitled, Builders Guide to Residential Construction Waste Management. (2)

\section{References}

1. NAHB Research Center, Resource Conservation Research House Information Guide, Upper Marlboro, MD, 1993.

2. NAHB Research Center, Builders Guide to Residential Construction Waste Management, Upper Marlboro, MD, 1993. 
Performance of Building Envelopes

New Materials and Research Findings

\author{
J.D. Ned Nisson, Editor \\ Energy Design Update \\ 235 West 102 St., Suite 7J \\ New York, NY 10025
}

\begin{abstract}
Research over the past five years has led to an increased practical understanding of the performance of building thermal envelope systems, particularly for residential construction. For example, engineers at Oak Ridge National Laboratory and the University of Illinois demonstrated that the temperature differential across a ceiling can significantly affect the performance of certain low-density loose-fill insulation. Researchers at the National Research Council Canada demonstrated a similar affect in walls insulated with fiberglass and rockwool batts. NRCC scientists also demonstrated the impact of steel framing on wall thermal performance. Armed with this enhanced understanding, manufacturers, designers and builders have developed new products and building techniques for optimizing the performance of building thermal envelopes.
\end{abstract}

\title{
Introduction
}

The following excerpts from Energy Design Update describe several research projects that document the effects of environmental variables on the in-service performance of wall and ceiling insulation systems.

October, 1991

\section{BUILDING SCIENTISTS AND REGULATORS CALL FOR MORE REALISTIC INSULATION TESTING}

The small-scale laboratory methods now used to test insulation are not good indicators of actual in-service performance says research scientist Ken Wilkes of Oak Ridge National Laboratory. Speaking to a technical audience at the ASTM Symposium on Insulation Materials in Gatlinburg, Tennessee, Wilkes was one of several presenters to stress the need for more realistic testing of insulation materials and systems. Wilkes' remarks referred to his recent research which demonstrated the effect of air convection on the performance of loose-fill insulation in attics.

Similar pleas came from other sectors of the building community at the ASTM meeting. David McCaa of CertainTeed Corporation, presenting a paper on the effect of air intrusion into fiberglass insulation, called for new or modified test methods to evaluate whole insulation systems under simulated field conditions. CertainTeed is currently sponsoring a full-scale attic research program at the University of Illinois.

George Tsongas, professor of Mechanical Engineering at Portland State University, voiced strong concern that laboratory test results for reflective insulation which were presented at the symposium should not be adopted into handbooks without qualifying statements about field performance. Tsongas explained that his research shows poor field performance for reflective floor insulation because of air leakage. 
The most outspoken recognition of environmental influence on insulation performance came from the regulatory community. Bruce Nelson of the Minnesota Department of Public Service described how the Minnesota building code is being revised to include specific and stringent requirements to prevent air intrusion and thermal bridging in insulation systems.

August, 1990

MEASURED PERFORMANCE OF LOOSE-FILL FIBERGLASS ATTIC INSULATION THE OAK RIDGE TESTS

The preliminary results of a series of tests at Oak Ridge National Laboratory (ORNL) on cubed fiberglass attic insulation suggest that air circulation within the insulation may significantly reduce the apparent $\mathrm{R}$-value under cold attic conditions. At very low temperature $(-18 \mathrm{~F})$, the measured $\mathrm{R}$-value was $50 \%$ lower than the material's nominal Rvalue. These sensational results, now under peer review, could have serious implications concerning the relative effectiveness of loose-fill attic insulation in very cold climates.

The tests were performed in ORNL's new Large Scale Climatic Simulator (LSCS) -a full-scale test facility, capable of simulating a wide range of climatic conditions. The simulator is actually two chambers: an upper chamber in which outdoor weather conditions are simulated, and a lower chamber which simulates the indoor space beneath the attic. Each chamber can be individually controlled and heat flow can be accurately measured in either direction.

For the attic insulation tests, a full-scale house roof was constructed and placed in the upper chamber. Cubed loose-fill insulation was blown into the attic space to create a nominal R-20 installation. The R-value of the ceiling system was measured as the air temperature was varied from $-18 \mathrm{~F}$ to $145 \mathrm{~F}$. The attic ventilation rate was also varied in some of the tests.

Theoretically, when the temperature in an attic falls below a certain critical point, air begins to circulate within the insulation, causing a decrease in effective R-value. Once that critical temperature point is passed, further decrease in attic temperature theoretically causes progressive decrease in $\mathrm{R}$-value. The temperature at which this convection begins depends on several properties of the insulation including density and thickness.

Infrared scans at Oak Ridge showed indications of air circulation within the fiberglass insulation in the LSCS. The effect of the air circulation was that the effective R-value of the R-20 installation was reduced by $40 \%$ at $20 \mathrm{~F}$ attic air temperature and by $50 \%$ at $-18 \mathrm{~F}$ attic air temperature.

The Oak Ridge results imply that in very cold climates where attic temperature falls below 20F for a significant portion of the winter, some types of attic insulation may perform poorly. It's important to note, however, that the decrease in R-value only occurs below a certain temperature which will vary depending on material properties and insulation thickness. There should be no convective effect during moderate winter or summer weather conditions. 
June, 1993

THE EFFECT OF "MINOR" INSTALLATION DEFECTS ON BATT THERMAL PERFORMANCE

A research project at the National Research Council Canada has clearly demonstrated that if fiberglass batts are not properly installed, air circulation in and around the insulation can degrade the overall wall R-value as much as $14 \%$ at moderately cold $(23 \mathrm{~F})$ temperature, and up to $35 \%$ at extremely cold $(-31 \mathrm{~F})$ temperature, apparently due to air convection in the batts. Although the study report still leaves some unanswered questions about the practical meaning of these results, the data definitely underscores the importance of installation quality on performance for walls insulated with fiberglass and other types of batt insulation.

Past research studies have shown that major installation defects, such as full continuous airspaces on both sides of the insulation batt, can degrade thermal performance as much as $34 \%$. Partly in response to those studies, the Canadian National Building Code stipulates that unfaced batts "...shall be installed so that at least one face is in full and continuous contact with cladding, sheathing or other air-impermeable membrane." (Section 9.25.4.2).

But what about relatively minor installation defects? What if unfaced batts are installed so that they are in good contact with exterior and interior surfaces, except for small vertical gaps at the corners of the stud cavity? To answer that question, NRC researchers tested full-scale ( $\left.8^{\prime} \times 8^{\prime}\right) 2 \times 6$ walls with three different types of batt insulation and various size corner gaps. They then measured the actual R-value of the assemblies when exposed to varying temperature conditions using a "guarded hot box" (ASTM C236 test method).

The results showed that when the batts were installed perfectly, with no gaps at the corners of the stud cavities, the insulation system performed perfectly. The R-value of the wall with R-19 batts was R-16.8, which is what would be expected, taking into account the effect of the studs and other wall components. Even at $-31 \mathrm{~F}$, there was no evidence of air convection. In fact, the measured R-value actually increased slightly as the temperature dropped, which is expected since the R-value of all materials increases with decreasing temperature.

But when 3/4" vertical gaps were installed at the stud cavity corners, the R-value of the walls dropped considerably, apparently due to air circulation around and through the batts. At $23 \mathrm{~F}$ "outdoor" temperature, air circulation caused the effective R-value of the wall to drop $14 \%$ to $\mathrm{R}-14.4$. At $-31 \mathrm{~F}$, there was a $32 \%$ drop to $\mathrm{R}-11.4$.

The final report on the NRC tests states that there is no doubt that the observed loss of $\mathrm{R}$-value is due to air convection. One of the surprising observations was that although air convection apparently begins to occur between the inner and outer pairs of air gaps, it then spreads through the rest of the insulation.

The R-19 batts used in the NRCC tests were typical U.S. product with relatively low density ( 0.56 pounds per cubic foot average). To test whether higher density insulation would be less susceptible to convection, NRCC researchers also tested "medium density" R20 batts $(0.85 \mathrm{lb} / \mathrm{ft} 3)$ (Canadian product) and rockwool batts $(2.2 \mathrm{lb} / \mathrm{ft} 3$ density).

The surprising results showed that even the high density rockwool batt suffered convection when corner gaps were introduced. The installation defects caused a $6 \%$ drop in $\mathrm{R}$-value at $23 \mathrm{~F}$ and $17 \%$ at $-31 \mathrm{~F}$. The medium density fiberglass also allowed convection, with $26 \%$ loss of $\mathrm{R}$-value at $-31 \mathrm{~F}$. 
The NRC test results prove that sloppy batt installation causes poor performance and the study report stresses the need for installation quality control. The report suggests that instead of selecting insulation materials solely on R-value, contractors should also consider ease of handling and the ability to completely fill stud cavities. The new medium density batts, (3.5" R-15 and 5.5" R-21), sold by all the major manufacturers, may be a partial solution since they are stiffer and tend to fill the stud cavity better than the lower density R11 and $\mathrm{R}-19$ products.

The bottom line question about these tests is to what extent do they reflect real world conditions and performance? The test walls had vertical air gaps in all four corners of the stud cavities. How common is that? And how would the results compare if there were gaps only in the outer two corners? Unfortunately there are no definitive answers to either question.

When designing their experiment, NRC researchers tried to simulate typical installation defects, based on field studies performed in Canada and Sweden. However, Bill Brown at NRC, who supervised the project, explains that its very difficult to characterize "typical" installation quality. There are obviously many instances where batts are installed so that there are gaps at only one or two corners. Brown thinks that as long as one side of the batt is in complete contact with sheathing or drywall, air convection will most likely not occur -- at least not to the extent observed in these tests. He also notes that there should be no problem with kraft-faced batts.

Despite the uncertainty, these test results do provide insight on the importance of proper installation of batt insulation;

--When perfectly installed, fiberglass and rockwool batts perform perfectly.

--Sloppy installation can allow air convection, which will reduce performance as much as $14 \%$ at moderately cold (23F) temperature and up to $35 \%$ at extremely cold $(-31 \mathrm{~F})$ temperature.

--Higher density batts, such as the new "high performance" R-15 or R-21 fiberglass batts or rockwool batts, are less prone to convection, but they too will suffer from sloppy installation.

February, 1993

STEEL STUDS: THERMAL PERFORMANCE

Steel framing systems for homes are enjoying a surge in popularity in some regions of the country. Manufacturers tout several benefits including stable materials cost and ease of construction (once crews adjust to screwdrivers rather than nailguns).

The bad news is that research studies show that steel framing can be a thermal disaster. The conductivity of steel is about 400 times the conductivity of wood. Don Larson, director of research at the Center for Insulation Technology at Drexel University, estimates that the effective R-value of a 3-1/2-inch steel stud is R-0.0128, compared to R-4.5 for a wood $2 \times 4$. When installed in a 4 -inch wall, steel studs reduce the overall $R$-value by $30 \%$ to $50 \%$. 
The good news is that there are ways to overcome the thermal bridging problem with steel studs. At least one manufacturer of metal framing systems uses a configuration that reduces thermal bridging. And research results from Canada and New Zealand show that thermal breaks and modified stud design could also improve performance.

Bill Brown is a senior researcher with the Institute for Research in Construction at the National Research Council Canada. Using a full scale wall testing apparatus (ASTM C236 test method), Brown measured the actual R-value of three different walls built with steel studs and compared the measured R-value with the theoretical ideal R-value (no thermal bridging) for each wall.

In a 4-inch wall insulated with R-12 batts, gypsum board interior, and stucco exterior, the steel studs degraded the overall R-value from R-13 to less than R-7 -- a $49 \%$ reduction from the theoretical R-value of the wall without thermal bridging. The two other walls, which had brick and concrete facades, showed similar poor performance.

Brown's results are consistent with other published test results. J.R. Sasaki of the National Research Council Canada compared the performance of walls built with $2 \times 4$ wood studs against walls built with 4-inch metal studs. Both walls were insulated with 2 inches of polystyrene foam (R-8). The measured R-value of the steel-framed wall was R-7.1 with light-gauge studs, compared to R-10.1 for the wood-framed wall -- an R-value loss of $30 \%$. With heavy-gauge studs, the loss in R-value was even higher.

Don Larson at Drexel University measured the wall R-value of a steel-framed campus building using a large heat flow meter. Larson found that the average measured $\mathrm{R}$-value of the whole wall was only R-6.6 -- $43 \%$ lower than the R-value of the insulation alone (R11.7).

Adding thermal breaks should improve performance of walls with steel studs. Hans Trethowen, Senior Research Engineer at the Building Research Association of New Zealand, ran a series of laboratory tests to evaluate the effects of small thermal breaks on overall steel-stud wall performance. Trethowen found that by reducing the contact area between stud and gypsum board, the overall performance was considerably enhanced.

At least one manufacturer produces a steel framing system that reduces thermal contact between studs and sheathing. Advanced Framing Systems of Atlanta, Georgia uses horizontal "hat sections" on both sides of the studs. Since the hat sections have relatively small contact area with the metal studs and with the sheathing, thermal transmission should be reduced considerably. This has not been confirmed through laboratory or field testing.

One problem with the Advanced system and others like it is their unconventional design. Whereas most steel framing is built "stick for stick" so that crews can easily make the transition from wood to metal, the Advanced system is completely different and unfamiliar.

A simpler solution is to use rigid foam sheathing over the studs. Researchers are not in full agreement as to how effective this technique may be. Don Larson at Drexel told EDU that 1-inch extruded polystyrene, (R-5), installed over the studs, would probably add more than R-5 to the overall wall. By eliminating direct contact between studs and sheathing, the foam first "fixes" the thermal bridge problem, and then also adds to the overall R-value. Researchers at NRC Canada disagree, claiming that the steel studs degrade performance just as much with or without the foam and that R-5 foam simply adds R-5 to the wall. 
Finally, one approach to the problem that has not yet been tried for residential systems is to modify the stud web to remove some of the metal. For example, Sasaki at NRC Canada found that an "expanded channel" design reduced thermal bridging by $50 \%$
compared to regular steel studs. 


\title{
ENVIRONMENTAL BUILDING MATERIALS:
} What are they? Where are they?

\author{
Paul Bierman-Lytle, President \\ The Masters Corporation \\ Environmental Architecture and Construction Resource \\ Management \\ New Canaan, CT 06840
}

\begin{abstract}
During the 1970's the building industry witnessed a focus on energy-conserving building materials sparked by oil-price increases; during the 1980's attention to building materials that reduced or omitted pollutants became important as a result of the "Sick Building Syndrome" or indoor air pollution. Now, in the 1990 's, we are engaged with a more comprehensive definition of "environmental" materials and technologies. This definition encompasses both energyconserving products and so-called "non-toxic" or healthy products. But more importantly, it defines a new component, which I will call "resource management". As the world enters the 21st century, we are more aware that the world's resources are dwindling at rapid speed, and the need to conserve, to recycle, and to sustainably manage these resources is vital. The building industry has a primary role to play in this management. This role begins in the selection of materials and technologies used in building itself.
\end{abstract}

\section{Introduction}

As we near the year 2000 we will witness a change in the way our buildings look and in the materials they are built with. This change will probably occur not due to choice, but rather due to lack of choice. The inventory of conventional materials is running out; many in the building industry from architects to tradesmen are not aware of this phenomenon, therefore the conventional mode of design and construction still prevails. However, in ever subtle ways, the change is occurring. Wood products are reaching astronomical prices month by month; shortages are apparent in particular species. Products are required to show their chemical ingredients and show warning labels regarding toxic or hazardous potentials; standards to control toxicity are forcing some conventional products to shut down production. Materials made from recycled content or which demonstrate recyclability are entering the market-place with public support and media- 
endorsements. Regulations and building codes are requiring higher energy performance standards. Water drought

conditions demand water-conserving fixtures and are accepting grey water uses. It is estimated that the world will be depleted of accessible and affordable petroleum within 35 years. Model homes are being constructed to demonstrate resource management; in other words, how to get the most from as little as possible.

Environmental building materials and

technologies make up this new inventory. Some are age-old, some are conventional, off-the-shelf, some are recycled and some are new. Environmental materials address at least one, but usually all, of the following:

- energy conservation, either in performance or

in manufacturing

- health, reduces health hazards to the

manufacturer, to the installer, to the end-user

- resource management, conserves existing inventory of raw ingredients, follows sustainable harvesting, reduces global environmental hazards, including pollution, global warming, ozone depletion, conserves and renews water quality

- waste management, uses recycled content, is recylcable, minimizes waste, is biodegradable This seminar will explore these different categories of environmental materials and demonstrate what they replace, why they replace current materials, where they can be found, and what is ahead as we near the year 2000.

Evaluation Methods of Environmental Materials

There are many ways to evaluate whether a particular material is "environmental". In fact, a number of efforts are underway by certification companies to rate products according to specific environmental characteristics; other certification efforts attempt to verify the environmental claims of the specific manufacturer. The most important evaluation, however, is a study of a product's "cradle-tocradle" profile. Unfortunately, the ability to arrive at this profile is still in its infancy. Several university professionals and professional organizations, such as the AIA Committee on The Environment are pioneering this approach. The profile begins with a review of a product's origin, what raw materials are reguired to make it, where these come from, how much energy is consumed to make this acquisition, etc. The profile continues through the life of the product until it is either disposed of in the ground, in fire, in water, or is recycled. This profile is represented in a matrix of environmental criteria, including Natural Resources, Energy, Pollution, Health, Waste, Recycling, Life-Cycle Cost, Availability, Durability/Maintainability, to mention a few. It becomes obvious after seeing this matrix spread out that the answers required to fill it out are very hard to obtain. 
For example, most manufacturers are unaware of where some of their constituent ingredients come from, much less how much energy is consumed to acquire them. If a product is imported from overseas, enormous quantities of fuel are required to get it to its final installation. A product can demonstrate high environmental marks on the matrix in one category and be extremely poor in another category. For example, aluminum is an excellent building material due to its light weight, rust-resistance, conductivity, and recyclability; also, it is inert and therefore does not offgass toxic or noxious chemicals nor can it absorb smells or odors. However, it consumes enormous quantities of energy to make and its main constituent ingredient is bauxite, which is typically strip-mined from the rain forests. Despite the infancy and struggle of establishing these environmental profiles on building products, progress is being made rapidly, and the results are being published for use more quickly than ever before. Satellite photography offers us information about our global inventory of raw materials just as it shows us information about the pollution and environmental changes resulting from human's activities. These insights into our planet's stock and health will help us better prepare us for our role as "resource managers" as we near the 21 st century. Until these environmental profiles, or report cards, on products are widespread, those in the building industry can become better environmental consumers and purchasers without a suitcase of data on their side.

To assist the buyer in sorting out the thousands of products, we can create a "menu" of building and decorating products and technologies and divide this "menu" into four major categories; any building or decorating product or technology will fall into these four:

$\begin{array}{ll}\text { 1. } & \text { Salvaged } \\ \text { 2. } & \text { Conventional } \\ \text { 3. } & \text { Green } \\ \text { 4. } & \text { Recycled }\end{array}$

In addition, under each of these four categories materials are sorted into 7 divisions, which further assists in distinguishing components in the menu. These divisions are derived from the construction sequencing. They are:

$\begin{array}{ll}\text { 1. } & \text { Site } \\ \text { 2. } & \text { Structure } \\ \text { 3. } & \text { Einishes } \\ \text { 4. } & \text { Furniture } \\ \text { 5. Mechanicals } \\ \text { 6. Equipment and Technologies } \\ \text { 7. Maintenance }\end{array}$


Site would include natural resources existing on the building site, solar access, water resources and quality, radon levels, electromagnetic radiation sources, etc. Structure would include building structural products, such as wood, metal, concrete, roofing products, insulation, windows and doors. Finishes consists of flooring materials, paints, wallpaper, caulks and mastics. Furniture includes window treatment products, decorating materials, cabinetry, and furnishings. Mechanicals include plumbing, electrical, heating, air conditioning, and ventilation. Equipment and Technologies consist of appliances, fixtures, solar technologies, filtration equipment, etc. Maintenance covers filter and lamp replacements, cleaning products, landscape care, pesticide/insecticides, and air/water quality testing.

As noted above, a product, material, or technology to be considered as an environmental alternative must satisfy at least one, if not all, of the following: energy conservation, health, resource management, and waste management. To rate one selection over another requires more detailed "matrix" analysis. These analyses can be obtained today from several sources. And although each source may be flawed in areas, they are most helpful in allowing one to draw his or her own conclusions. We recommend Environmental Construction Outfitter's (ECO) Guidebook to Materials and Technologies, Volumes I-VI, available by calling 800-238-5008 or 212-334-9659 and AIA's Environmental Resource Guide, at 800-365-ARCH.

\section{Salvaged: Reusing the old in the same Use}

The starting point in good resource management or environmental material selection is to reuse what has already been made and used. This reuse saves enormous amounts of energy not required to mine, harvest, or otherwise acquire the virgin resource, fabricate, manufacture, or ship long distances; this, in turn, reduces air and water pollution which would have resulted in acquisition and production. In many cases, salvaged materials are very well made, both from craftsmanship to the quality of the materials used. Examples include salvaged slate for roofing, bricks, cobblestones, wood planking, timber, copper, steel, furniture, and all the myriad materials or products found in antique shops or salvage yards. Selection from these sources are excellent environmental choices and carry with them history and quality not available with new products. In most cases, salvaged materials are either inert (stone, slate, copper) and offgass no pollutants, or the materials are so old that the pollutant sources have already emitted their noxious gases.

Not all antiques or salvaged materials are environmental. Salvaged products to avoid include any products made with 
lead, mercury, or asbestos; products containing large quantities of petroleum by-products which could offgass or antiques which have been refinished with high voc (volatile organic compounds) finishes; products which are made from endangered animal skins or bones might indirectly encourage current illegal trade and animal destruction; products which are unsafe and therefore cause injury.

\section{Conventional: Using what is on the shelf}

Unknown to many vendors or manufacturers, several products already are used by the building trades which are very environmental. The producers or sellers are not aware of the environmental characteristics; therefore, they are not marketing these advantages. However, more recently, in the last 3-5 years, some recognition of these characteristics is being seen.

These products include natural linoleum, first made in 1894 in scotland, which preceded vinyl or asbestos sheet flooring. Natural linoleum is made without petroleum byproducts, is long lasting, resilient, insect proof, moisture proof, and emits no harmful gases. Other products include Medite I and II, exterior and interior fiberboard panels made without formaldehyde. For many years, Medite panels were sold for use as highway signs. When the manufacturer discovered that there was a new market for non-formaldehyde panels, they began advertising this special characteristic and, in fact, created Medite II, as an interior formaldehydefree alternative. Products frequently used and very environmental include: marble and other stone tiles, ceramic tiles, earthen pavers, adobe, plaster, and glass. In particular, are glazing products made with low-E, Heat Mirror, and argon-filled, raising their $R$-values to 8 and above. In furnishings and floor coverings, carpets made from 100\% wool, cotton, and jute have always been available, though hard to find without synthetic blends or latex backings. Natural untreated grass fibers, such as cocomat, bamboo, sisal, or coir, have always made excellent floor coverings.

The majority of conventional building and decorating products on the market today do not meet many of the environmental criteria. They either deplete endangered natural resources flagrantly, they pollute indoor air with hazardous chemicals or compounds, they utilize too much energy in production, they frequently are not durable and when their time is up they are not recyclable or biodegradable. As a result of increased awareness from many different viewpoints regarding this mismanagement of building resources, many newer products and technologies are being invented and created to offer alternatives to their conventional counterparts. 


\section{Green: Solving Environmental Problems and Challenges}

Green materials and technologies are creations attempting to solve environmental problems and challenges today and in the future. In many cases, the manufacturer is out to solve only one or two of the environmental criteria; and in so doing, often accomplishes more benefits for the environment and application. For example, Air krete, a foamed-in-place insulation, was invented to make insulations more energy conserving and free of toxic chemicals, specifically ureaformaldehyde. Yet, in addition, it is non-combustible, insect resistant, uses little natural resources and is an excellent acoustical material. Xeroflor, a live, plant/flower blanket used as a roofing material instead of sod, was developed to solve maintenance, herbicide use, and water consumption. Yet, it also retains $60 \%$ of the water falling on its surface; therefore, reduced runoff, and it also tempers indoor thermal climates and noise through its added insulation, and its plant-life absorbs air pollution and emits oxygen. Their are a multitude of "green" products entering the market each year, some with better results and credibility than others. The most highly regarded are satisfying all of the environmental criteria. In addition to those mentioned above, lightweight concrete technologies are advancing to offer builders and designers more environmental solutions to construction using concrete, which conventionally produced is not very environmental. ACC, autoclaved cellular concrete, made from cement, water, magnesite, and alumina pioneers new ways of utilizing managed resources for construction. $70 \%$ of its composition is made with either sand or fly ash. The fly ash is obtained from coal-fired electric generating plants, which today, is not used for anything. ACC can be engineered for almost all uses in a building from foundations, to walls, roof, floors, furniture, ornament, etc. It is noncombustible, lightweight, insect-resistant, contains and emits no harmful gases, and is recyclable. It also reduces demands for wood products and finishes. Sustainable wood management is also a source for "green" products. Rather than deplete existing old-growth forests, both temperate and tropical, or encourage mono-species forestry, these newer forestry practices are being spawned throughout the planet. The harvesting or cutting methods are being monitored and certified by independent organizations so that the consumer can be assured of the vendor's claims. Furniture, window and door materials, flooring, fencing, decking, and other wood product uses are being supplied by these sources.

Other "green" products include energy efficient lighting, daylighting technologies, computer management systems for energy and air quality, solar technologies, and water technologies. Water has become a dwindling resource, despite our planet's abundance of water. This depletion 
includes poorer water quality as a result of pollution and reduced water quantity as a result of over-use, deforestation, farming, ranching, and population. "Green" water technologies entering the market include ultra lowflush toilets of 1.5 gallons per flush, and grey and black water treatment systems which clean and then recycle the water back for reuse. These water systems unfold new plumbing techniques, new designs for "green" kitchens where food production, hydroponic gardening, and aquaculture enters the kitchen environment, indoor and outdoor landscapes begin to flourish with plants, birds and increased microbiodiversity.

Before the year 2000, all building and decorating materials will be "green" by market pressure, by choice, or by regulation.

\section{Recycled: Making New Uses for Old Materials}

When we take an existing material or product that has been used for one purpose, disassemble it, shred it, melt it down, and then form it into a new product or combine it with other materials to make a new product for a new use, we have recycled it. This is different from salvaging a material and reusing it the same way, even though this could be considered recycling too. Recycling is a 90 's word; it has become fashionable to demonstrate that a product is recycled, contains recycled content, or is recyclable. And, of course, this is a desirable goal. Throughout history, people with limited resources will always salvage and recycle whenever the opportunity presents itself. Now, too, modern civilizations are finding it necessary to do the same. On first glance, it would appear that anything recycled would be an environmental solution. However, it is not as black and white as this. For example, if we were to review the environmental matrix which identifies a product's full life cycle, we could discover that many renewable and biodegradable resources require more energy to recycle than to break them down into compost or fill. We might even discover that some non-renewable and non-biodegradable products add negative environmental impact by recycling, since energy consumption with fossil fuels used in the recycling process contributes to resource depletion, air and water pollution, and even indoor air hazards. A good example of the complex recycling issue was uncovered during the debate to use paper bags versus plastic bags. At first, the gut reaction was to use paper, sourced from wood, a renewable and biodegradable resource. Then data was accummulated showing that plastic bags required less energy (i.e. less pollution and resource depletion) than paper bags. And finally, the obvious solution was first to "salvage" one 
sturdy bag and reuse it, then recycle plastic bags, if necessary; then finally paper bags. This is an important lesson. First, investigate what the job requires and select a product that will do it with the least environmental impact, when possible and reasonable. If we made more decisions based on this premise we would have less inventory to recycle.

As stated earlier, recycling is an important marketing tool for most manufacturers today, and the public supports it. Too often, however, the product demonstrating recycled content or recyclability has failed to solve many of the environmental criteria. Synthetic plastics, for example, are petroleum-derived and are non-biodegradable. Once we make these plastics they are here to stay, regardless of where we put them. Two of their major environmental drawbacks is that they deplete the planet's fossil fuel reservoirs and they emit hazardous VOC's to indoor air. To recycle synthetic plastics reduces the first, but does not stop the emissions created by the second. The indoor air problems still remain. Also, many recycled products contain less than 50\% recycled content, the remaining $50 \%$ or more is therefore derived from a virgin resource.

Some recycled products benefit society by reducing the demands on conventional products that are either endangered, such as plastic woods or recycled metal studs replacing real woods, or they maximize a product's usefulness for a longer time, such as wool or cotton clothing recycled for use in building insulation. Some recycling efforts create all new products, such as recycling light bulbs to make floor tiles or computer parts to make roofing shingles. We seem to always be creating new markets for new goods for new uses. We have offered the consumer 70 varieties of breakfast cereal, when only 10-20\% of them are actually nutritional at best. We do the same thing in the building industry.

Recycling is vital if we use it prudently. There is little solice in recycling millions and millions of product inventory to make millions and millions more products that do not satisfy the environmental criteria. A wasteful virgin product recycled might only be 10-50\% less wasteful--it is still wasteful.

\section{Conclusion}

The world's resources throughout history have been taken for granted. We now understand that these resources cannot be assumed limitless. As we appear to take 10 steps forward with successive generations through progress in technologies, communications, education, health and recreation, we are also becoming more aware that these are small, baby steps. Our progress has not ended global strife, lifestyles are in 
disarray, cancer is increasing among our young, imbalance of resources is growing, we recreate not for fun or leisure but to escape. Our children today are recognizing this at the same time we, as adults, are. They will, their children will, demand more responsible decisions and directions. Perhaps as the world community celebrates this new century, we will be stewarding our position on the planet for the first time asking the right questions. If we are capable of knowing and uncovering the problems and challenges, then we are capable of solving them. And since humans will always build buildings, this is a critical arena in which to face this challenge and enact a new sensitivity to the world's resources. This arena spans the globe, yet it allows the single homeowner or apartment dweller to make the first step. 


\author{
Green Buildings: \\ DOE's Historical Role and New Directions \\ John P. Millhone \\ Deputy Assistant Secretary \\ Building Technologies \\ U.S. Department of Energy
}

\begin{abstract}
The Department of Energy's (DOE) Office of Building Technologies (OBT) has traditionally played a major role in the development of "green buildings" technologies. OBT's mission is to reduce the amount of fossil-based energy consumed by new and existing buildings, and improved energy efficiency is a critical factor in the green movement. A number of OBT's programs also address other, non-energy facets of green technology, including the development of CFC-free insulation and appliances, indoor air quality research, and the development of standards for water consuming appliances. This paper describes OBT's stategy for enhancing the energy efficiency of the buildings sector, and outlines new directions in the area of green buildings technology resulting from recent congressional legislation and

administration initiatives.
\end{abstract}

\title{
INTRODUCTION
}

As a direct result of concerns arising from petroleum supply disruptions in the early and late $1970^{\prime} \mathrm{s}$, the nation's buildings are now substantially more energy efficient than they were twenty years ago. The U.S. Department of Energy's activities have contributed measurably to this improvement in building energy efficiency through the development and demonstration of advanced technologies, improved building design tools, and the promotion of minimum energy efficiency standards and guidelines for buildings and appliances.

Numerous studies have established that energy consumption within the U.S. buildings sector can be reduced by a substantial additional amount without deleterious impacts on occupant comfort or productivity. For example, a wide array of technically proven building technologies are available that are highly energy efficient, life-cycle cost effective, could reduce energy use by up to 45 percent, but are currently underutilized by the building industry and consumers due to economic and institutional

barriers. In addition, a number of highly advanced energy technologies, in the research stages or under development, have the potential to double the energy performance of today's technologies.

It is the Department's vision that buildings constructed thirty 
years from now will minimize the use of non-renewable energy resources; that occupant needs for comfort and productivity will be met through dynamic building envelopes that selectively collect and release energy between the building and the external environment, and convert solar energy directly to appropriate forms for end-use application including heating, cooling, lighting, and electricity production for appliance operation.

The mission of OBT is to increase building energy efficiency and expand the use of renewable energy resources by supporting research and development of advanced technology and promoting the expanded use of currently available energy efficient technology and practices. Specific goals include improving the efficiency of buildings sector energy use by 30 percent by the year 2010, increasing the use of renewables by 75 percent over current levels by the year 2010, and complete elimination of the use of chlorofluorocarbons in building products by the year 2000 .

\section{BARRIERS TO IMPROVED ENERGY PERFORMANCE}

The Department faces several significant and long-standing barriers, both technical and institutional, in carrying out its mission to improve building energy performance; barriers that inturn define and shape the research, development, and market conditioning and regulation programs that OBT pursues. These barriers include:

Building complexity - A typical building is made up of thousands of individual components and assemblies of subsystems, predominantly site-erected under variable and uncontrollable ambient conditions. As a result, there are numerous sources for unwanted energy losses and gains as these components are assembled, and integrated into a complete building system.

Building Longevity -- When compared to other energy-consuming elements in the U.S. economy, buildings are among the most long-lived. Typically, buildings last an average of fifty years, with some having useful lives of more than double that. A large percentage of the existing building stock therefore reflects design and construction practice from a period in time when energy and the environment was of a lower priority than today. And, decisions now being made with regard to the performance of new buildings will also impact energy use for a long period into the future.

Lack of Integration of Building Technologies -- Building energy use is dependent on a wide variety of interacting features which define the performance of the total building system. "Energy use is determined by decisions about equipment selection and operation, and these decisions are 
made to satisfy a number of constraints." It is important that research encompassing technology design, construction and operation be conducted across a wide range of appropriate technologies to ensure that as broad an array of building technologies as possible reach commercialization, and achieve important benefits quickly.

Highly Diverse Industry - The building industry encompasses literally thousands of different businesses and millions of individual decisionmakers. The resulting fragmentation of the building industry separates developers, designers, builders, utilities, engineers, and occupants from one another as they pursue objectives which are often at crosspurposes. In addition the building industry adopts changes very slowly, which inhibits the adoption of advanced, energy efficient technologies and practices.

Iack of Past support -- During the 1980s, national policy de-emphasized the role of energy efficiency and government funding support for research and deployment activities was minimal. At the same time, because of characteristically low profit margins and pressure for short term results, private industry also cut back on investment in R\&D. Building development efforts are only now recovering from past policies with the Clinton Administration's increasing support for this effort.

Lack of Information and Experience -- Many consumers and building owners are not aware of the range of energy efficient products that are available. Further, because these products are often new in the marketplace, consumers have not experienced their benefits. Efficiency choices are only a small part of the numerous considerations in selecting end-use technologies. The benefits of reducing energy consumption while enhancing comfort or productivity is often seen as uncertain, very small, or too far away in the future. Better information regarding efficiency improvements on cost, maintenance, and performance is needed to improve the expectations for market adoption. This, inturn will improve the perceived risk/reward ratio, which must be more attractive to consumers in order to expand implementation of cost effective new energy saving technologies.

First cost Hurdle -- The adoption of high efficiency equipment is often inhibited by its correspondingly higher first cost. "Over one-third of household and one-quarter of commercial building floor space is rented or leased rather than owner occupied. in these buildings, there is a reduced incentive both to invest in efficient equipment and operate 
equipment efficiently. "2 The new high efficiency opportunities are judged according to the risk of realizing financial returns of investments in efficiency measures through productivity gains or energy savings. The opportunity for efficiency gains is lost when the building designer, or construction contractor installs the least first cost feature or equipment, (usually the least energy efficient), which results in higher consumption and costs for the occupants.

\section{STRATEGY AND PROGRAMS}

The Department's goal is to move the distribution of the nation's energy consuming appliances, equipment, and buildings, as illustrated by the curve in Figure $I$. below, to the right, in the direction of increasing energy efficiency. A combination of three coordinated strategies is carried out in pursuit of this goal.

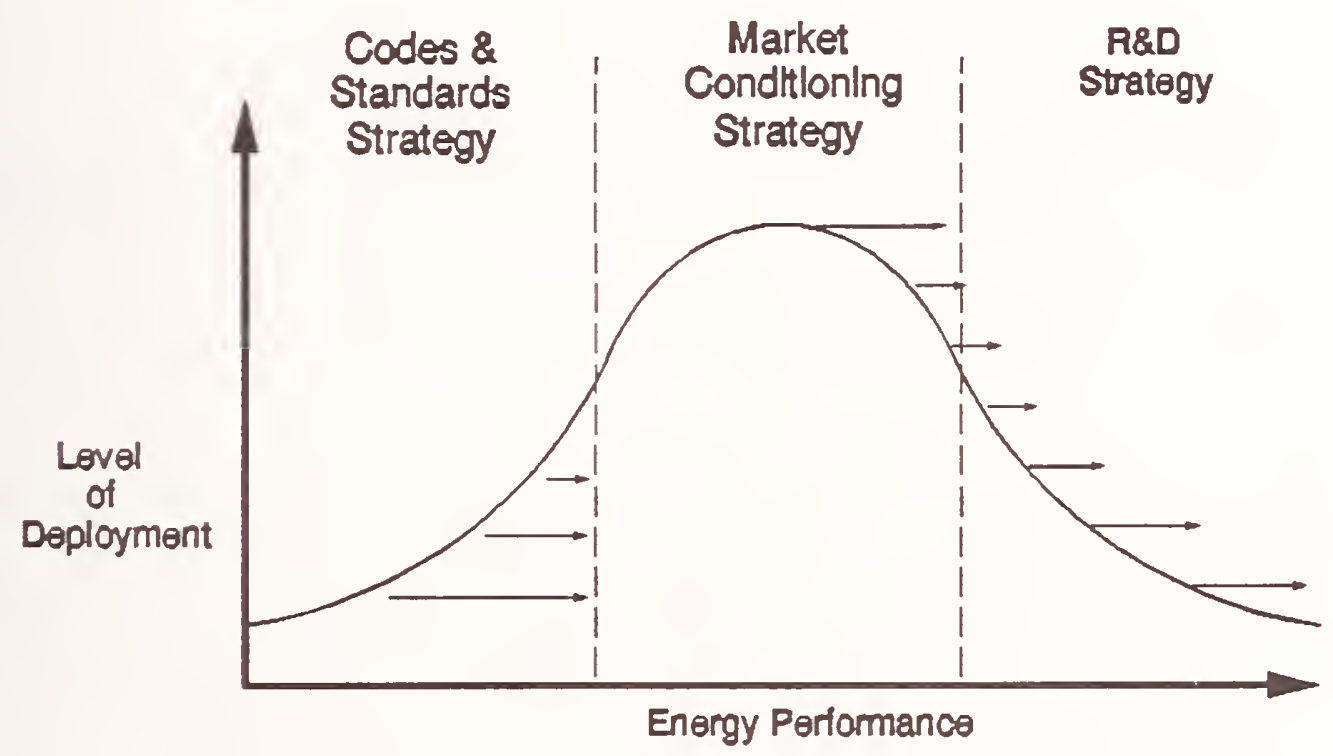

Figure 1. Office of Building Technologles Program Strategy

Ifloid. U.S. Cangress, OTA. 
First, the adoption and implementation of appliance and building codes and standards eliminates energy-wasteful products. The usual statutory guidance is that standards should achieve the maximum energy efficiency that is technologically feasible and economically justified.

second, market conditioning strategies are used to encourage buyers to select products that are more energy efficient than required by the standards. We acheive this by creating metrics, or yardsticks, to measure energy efficiency; by encouraging partnerships with industry and utilities to accelerate the commercialization of new, energy-saving technologies; and by educating consumers and buyers on the benefits of energy value in new products.

Third, we support research that leads to the development of new, energy efficient and solar building appliances, equipment, and whole buildings.

The Department also applies these three strategies to Federal buildings through the Federal Energy Management Program. All new Federal buildings must meet energy efficiency standards. Federal procurement practices are being revised to accelerate the acquisition of energy-efficient products, and Federal buildings and facilities are serving as "test beds" for new technologies.

The Department is pursuing this strategy simultaneously through three separate program management offices: The office of

Buildings Energy Research; The Office of codes and Standards; and The office of Federal Energy Management Programs. The activities of each of these offices is described below.

\section{Office of Buildings Energy Research}

OBT's office of Buildings Energy Research incorporates three primary themes into all of its activities, reflecting the complex nature of building design, construction, ownership, occupancy, and the need to break down the above identified barriers and help to make new technology available. Most importantly, the office looks at buildings from a total systems perspective as well as addressing the building envelope and equipment that is utilized within. The office also responds to the uncertainty inherent in predicting future trends in energy availability, environmental concerns, and national policy by pursuing a broad number of $R \& D$ initiatives representing a range of risk/reward levels. Lastly, it recognizes the substantial level of fragmentation that exists within the buildings sector and the need to reflect consumer decision processes and other non-energy variables in R\&D program design and deployment.

These programs include basic and applied research to prove the feasibility of new, high-risk technologies, and industry cost- 
shared development and demonstration designed to move technologies into the market. Buildings research activities are grouped within three subprograms, summarized as follows:

Building Equipment: Building equipment research addresses the energy performance of heating and cooling systems, refrigeration, lighting, and major appliances. Current activities focus on thermally-activated technologies that utilize natural gas as an alternative to electricity-driven heating and cooling, advanced light sources that are potentially twice as efficient as current fluorescent technology, and new refrigerant mixtures that do not contain ozone-depleting chemicals.

Building Envelope: This subprogram conducts research on the components that comprise a typical building shell: walls, roofs, and foundations; insulating materials; and windows. It also addresses building tightening and ventilation strategies that optimize building energy while maintaining acceptable indoor air quality. Major activities being conducted within this subprogram include research on high Rvalue wall insulation, spectrally selective windows, and dynamic envelope technology capable of responding to changing ambient conditions and building internal requirements for light, ventilation, and heating/cooling.

Building systems: Building systems research integrates all of the various aspects of building design, component construction, and equipment operation into a "whole buildings" approach to energy performance. Activities within this subprogram address industrialized housing processes, computer-based software to support commercial building design/build/operate strategies that optimize life-cycle energy performance, and technologies to effectively retrofit existing buildings.

\section{office of codes and standards}

OBT's office of Codes and standards implements legislatively mandated programs to develop energy conservation standards for buildings and appliances. The Energy Policy and Conservation Act (as amended) prescribes energy conservation standards for twelve major building appliances, and requires the Department to administer an energy conservation program for these appliances consisting of testing, labeling, and mandatory minimum energy efficiency standards.

OBT also carries out a legislatively mandated effort to encourage the implementation, by state and local government, of building energy efficiency codes and standards. In consultation with the building industry, government, and public interest groups, the Department is building on current voluntary codes and standards, state codes and standards, and emerging building research results 
to promote and support the upgrading of state and federal building energy codes. It is also developing programs to train building designers in ways to meet code compliance, and to train building code officials in enforcement.

OBT is also supporting the development of a nationally-recognized method for rating residential energy performance, which would inturn support the acceptance of energy-efficient mortgages. The Home Energy Rating systems (HERS) Council is developing technical guidelines acceptable to the current infrastructure of ratings providers, utilities, and the mortgage banking industry.

\section{Office of Federal Energy Management Programs}

The Federal Energy Management Program (FEMP) implements statutes and Executive Orders that direct the Federal government to use energy efficiently. The goal is a $20 \%$ decrease in energy use in Federal buildings from 1985 to 2000, as measured by energy use per gross square foot of building floor space. (President Clinton subsequently, on March 8, 1994, increased this goal to a $30 \%$ decrease in energy use from 1985 to 2005.)

Program activities being carried out by OBT include: providing guidance to agencies in the development of strategies for financing energy conservation projects and working with utilities on demand-side management projects; training federal facilities managers; providing project design assistance; providing site audits of energy-savings potential; and promoting industry costshared test bed projects at federal facilities.

\section{NEW DIRECTIONS}

As stated earlier, two recent legislative and administration initiatives have altered the direction of Federal energy programs, greatly expanding the Department of Energy's funding and role in promoting energy and resource efficiency and "green buildings." The Energy Policy Act of 1992 and the President's climate Change Action Plan both place substantial emphasis on accelerating the commercialization of energy-efficient and renewable energy technology into the marketplace, in cooperation with industry. They. also ask the Department to pursue research and development and establish standards and regulations in areas outside of the traditional focus of DOE's energy programs. A brief summary of these two initiatives follows

\section{Energy Policy Act of 1992}

The Energy Policy Act (EPACt) contains thirty separate actions designed to improve the energy efficiency and use of renewable energy resources within the buildings sector and reduce levels of greenhouse gas emissions. General target goals established for 
these actions include increasing the energy efficiency of the buildings sector by $30 \%$ by the year 2010, and increasing the percentage of building sector energy derived from renewable resources by 75\% over 1988 levels by the year 2005 .

EPAct places increased emphasis on several market-pull strategies designed to increase the rate of commercialization of advanced, energy efficient building technologies. Cost-shared development and demonstration of new heating and cooling concepts, and small scale cogeneration systems are targeted for expanded activity, as is the development of a "systems" approach to the design, construction and delivery of residential and commercial buildings. EPAct also requires support for a voluntary energy performance rating and labeling system for window products.

EPAct expands the Department's existing appliance and lighting regulatory program to include commercial and industrial equipment, lamps, motors, plumbing products, and commercial office equipment. Initial energy conservation standards, test procedures and labeling requirements are being established for several categories of products and, for the first time, water flow rate standards are being established for certain plumbing products.

In the area of building standards and guidelines, the Department is providing technical assistance to states in the upgrading of building energy codes, and providing financial incentives to states demonstrating exemplary code programs. The department is also developing new energy performance standards for Federal buildings, including improvements to indoor air quality standards.

The Federal Energy Management Program acquires substantial additional responsibility under EPAct. New programs create a Federal energy efficiency fund to provide capital for energy efficiency improvements, provide incentives for utility participation in efficiency improvements for Federal facilities, establish requirements for Federal facility water conservation, and initiate demonstration programs for new technologies. EPAct also expands the Department's role in federal agency training, cash awards to Agency energy managers, energy audits, surveys, and performance contracting activities.

\section{climate change Action plan}

The Administration's Climate Change Action Plan (CCAP), announced in October of 1993, responds to the threat of global warming by promoting nearly 50 new and expanded initiatives to reduce the nation's emmissions of greenhouse gases. Eleven of these new initiatives target residential and commercial buildings, and represent a substantial increase in OBT's scope of activity in 
several areas.

In the residential buildings area the Department is:

-Working with the Environmental Protection Agency to form new "Golden Carrot" programs designed to accelerate the commercialization of advanced, energy efficient appliances through financial "market pull" incentives;

-Developing new energy efficiency standards for 14 categories of heating and cooling equipment and appliances;

-Assisting state governments in upgrading and enforcing their building energy codes and standards;

- Creating residential energy efficiency programs and housing technology centers with the aim of promoting exemplary home building by industry;

-Working with the Department of Housing and Urban

Development and other Federal agencies to promote and expand the availability of home energy rating systems and energyefficient mortgages; and

-Expanding the Federal government's "Cool Communities" program through research and demonstration of technologies and practices that reduce cooling requirements in urban areas.

In the commercial buildings area the Department is:

-Working with the Environmental Protection Agency on two new programs, Energy Star Buildings and Rebuild America, which are designed to provide commercial building designers and developers with the latest information on energy efficient design and equipment selection;

-Establishing a state revolving fund that will provide seed funding for energy management programs targeted to public buildings;

-Expanding industry-cost-shared demonstration of emerging, more energy efficient building technologies as a means of validating their performance, thus reducing barriers their acceptance; and

-Expanding DOE-sponsored energy efficiency and renewable energy information dissemination and training programs. 


\section{Funding}

The Energy Policy Act and the Climate Change Action Plan require substantial additional funding over and above the Department's baseline research and development budget, as illustrated in the table below. As a result of EPAct requirements, FY 1994 Congressional funding for buildings programs increased 57\% over the previous year. The President's FY 1995 Budget, driven by CCAP requirements, requests an additional increase of $115 \%$ above the FY 1994 funding level, primarily to support market-pull action items.

Table 1:

DOE office of Building Technologies Program Funding by Activity

\begin{tabular}{||l|l|l|l||}
\hline & $\begin{array}{l}\text { FY 1993 } \\
\text { (\$ milion) }\end{array}$ & $\begin{array}{l}\text { FY 1994 } \\
\text { (\$ milion) }\end{array}$ & $\begin{array}{l}\text { FY 1995 } \\
\text { (\$ milion) }\end{array}$ \\
\hline Research and Development & 34.8 & 43.5 & 45.5 \\
\hline Codes and Standards & 7.8 & 15.3 & 31.1 \\
\hline Federal Energy Management & 4.6 & 15.7 & 37.1 \\
\hline Market Pull Activities & 4.6 & 1.7 & 57.8 \\
\hline Management \& Planning & 5.3 & 7.9 & 10.3 \\
\hline Capital Equipment & 1.8 & 2.3 & 2.2 \\
\hline \hline Total Buildings Program & 55.1 & 86.4 & 184.0 \\
\hline
\end{tabular}





\section{NIST Technical Publications}

\section{Periodical}

Journal of Research of the National Institute of Standards and Technology-Reports NIST research and development in those disciplines of the physical and engineering sciences in which the Institute is active. These include physics, chemistry, engineering, mathematics, and computer sciences. Papers cover a broad range of subjects, with major emphasis on measurement methodology and the basic technology underlying standardization. Also included from time to time are survey articles on topics closely related to the Institute's technical and scientific programs. Issued six times a year.

\section{Nonperiodicals}

Monographs-Major contributions to the technical literature on various subjects related to the Institute's scientific and technical activities.

Handbooks - Recommended codes of engineering and industrial practice (including safety codes) developed in cooperation with interested industries, professional organizations, and regulatory bodies.

Special Publications - Include proceedings of conferences sponsored by NIST, NIST annual reports, and other special publications appropriate to this grouping such as wall charts, pocket cards, and bibliographies.

Applied Mathematics Series-Mathematical tables, manuals, and studies of special interest to physicists, engineers, chemists, biologists, mathematicians, computer programmers, and others engaged in scientific and technical work.

National Standard Reference Data Series-Provides quantitative data on the physical and chemical properties of materials, compiled from the world's literature and critically evaluated. Developed under a worldwide program coordinated by NIST under the authority of the National Standard Data Act (Public Law 90-396). NOTE: The Journal of Physical and Chemical Reference Data (JPCRD) is published bimonthly for NIST by the American Chemical Society (ACS) and the American Institute of Physics (AIP). Subscriptions, reprints, and supplements are available from ACS, 1155 Sixteenth St., NW, Washington, DC 20056.

Building Science Series-Disseminates technical information developed at the Institute on building materials, components, systems, and whole structures. The series presents research results, test methods, and performance criteria related to the structural and environmental functions and the durability and safety characteristics of building elements and systems.

Technical Notes-Studies or reports which are complete in themselves but restrictive in their treatment of a subject. Analogous to monographs but not so comprehensive in scope or definitive in treatment of the subject area. Often serve as a vehicle for final reports of work performed at NIST under the sponsorship of other government agencies.

Voluntary Product Standards-Developed under procedures published by the Department of Commerce in Part 10, Title 15, of the Code of Federal Regulations. The standards establish nationally recognized requirements for products, and provide all concerned interests with a basis for common understanding of the characteristics of the products. NIST administers this program in support of the efforts of private-sector standardizing organizations.

Consumer Information Series - Practical information, based on NIST research and experience, covering areas of interest to the consumer. Easily understandable language and illustrations provide useful background knowledge for shopping in today's technological marketplace. Order the above NIST publications from: Superintendent of Documents, Government Printing Office, Washington, DC 20402.

Order the following NIST publications - FIPS and NISTIRs-from the National Technical Information Service, Springfield, VA 22161.

Federal Information Processing Standards Publications (FIPS PUB) - Publications in this series collectively constitute the Federal Information Processing Standards Register. The Register serves as the official source of information in the Federal Government regarding standards issued by NIST pursuant to the Federal Property and Administrative Services Act of 1949 as amended, Public Law 89-306 (79 Stat. 1127), and as implemented by Executive Order 11717 (38 FR 12315, dated May 11, 1973) and Part 6 of Title 15 CFR (Code of Federal Regulations).

NIST Interagency Reports (NISTIR)-A special series of interim or final reports on work performed by NIST for outside sponsors (both government and non-government). In general, initial distribution is handled by the sponsor; public distribution is by the National Technical Information Service, Springfield, VA 22161, in paper copy or microfiche form. 
U.S. Department of Commerce

National Institute of Standards and Technology

Gaithersburg, MD 20899

Official Business

Penalty for Private Use $\$ 300$ 